\title{
XIX NATIONAL CONGRESS - VIII INTERNATIONAL SPANISH SOCIETY OF GERODONTOLOGY CIUDAD REAL, SPAIN 16-18 MAY OF 2019
}


XIX NATIONAL CONGRESS - VIII INTERNATIONAL SPANISH SOCIETY OF GERODONTOLOGY CIUDAD REAL, SPAIN 16-18 MAY OF 2019 


\section{ORAL PRESENTATION}


XIX NATIONAL CONGRESS - VIII INTERNATIONAL SPANISH SOCIETY OF GERODONTOLOGY CIUDAD REAL, SPAIN 16-18 MAY OF 2019 


\section{Oral Presentation 1}

\section{TITLE:- STUDY OF THE KNOWLEDGE ABOUT OSTEONECROSIS OF THE JAWS RELATED TO MEDICATIONS IN DENTISTRY STUDENTS}

\author{
Barba Montero C, Gándara Vila P, Rodríguez Zorrilla \\ $S$, Otero Rey E, Seijas Naya F, Blanco Carrión A. \\ Master in Oral Medicine, Oral Surgery and Implantology. Fac- \\ ulty of Medicine and Dentistry. University of Santiago de Com- \\ postela.
}

Objectives: Assess knowledge about the prevention and diagnosis of medication-related osteonecrosis of the jaw (MROJ) in Dentistry students

Material and Methods: A descriptive study was carried out in which 166 students from the Degree of Dentistry of the University of Santiago de Compostela participated during the second semester of the 2018-2019 academic year. All of them were given a questionnaire based on Rosella et al 2017 that included a series of questions about the knowledge of the ONRM and the guidelines to follow for the management of patients consuming these drugs. The results obtained were introduced in a database and analyzed using the SPSS 2.0 system for Windows.

Results: Even though the level of knowledge about ONRM turned out to be proportional to the academic year, a high percentage of students lacked sufficient knowledge for proper diagnosis and management of patients with antiresorptive drugs requiring dental care Conclusions: There is limited knowledge about ONRM in undergraduate students in Dentistry. The situation could be improved with the early inclusion and reinforcement of the ONRM in the undergraduate programs.

\section{Oral Presentation 2}

\section{TITLE:- MAXILLARY SINUS BALLOON LIFTING AND DEFERRED IMPLANTATION OF 50 OSSEO-INTEGRATED IMPLANTS: A PROS- PECTIVE STUDY}

Cano Durán JA, Melero Alarcón C, Chavesta Rivadeneyra P, Blando Ruiz S, Martinez Rodriguez N, López-Quiles J.

Master of Oral Surgery and Implantology, Universidad Complutense de Madrid.

Objectives: The aim of this study was to assess the effectiveness of minimally invasive antral membrane balloon elevation (MIAMBE).

Material and Methods: Twenty-seven patients with severe resorption of the posterior maxilla were treated by balloon catheter-assisted sinus lift procedure with deferred implant placement. Panoramic radiographs and computed tomography scans were obtained prior to surgery and at 6 months after surgery, before implantation. Data collected following surgery included inflammation, pain, bleeding, infection, and haematoma. Pain and inflammation were recorded using a six-point verbal rating scale (VRS). The patients were followed up for an average of 15 months. The initial sinus floor height was measured for each planned implant and compared with the height at 6 months post-surgery.

Results: The average bone height gain was $8.10 \pm 3.45$ $\mathrm{mm}$ (range $0.5-13.95 \mathrm{~mm}$ ). Inflammation on the VRS ranged from 0 to 3 (mean $0.97 \pm 0.85$ ), while pain ranged from 0 to 4 (mean $0.87 \pm 1.19$ ). There was a perforation of the Schneiderian membrane smaller than $2 \mathrm{~mm}$ in one case. In another case, the balloon lift procedure had to be aborted and changed to the conventional Tatum technique due to breakage of the balloon inside the sinus.

Conclusions: The results of this study show the balloon sinus lift technique to be an easy procedure to perform, with apparently low rates of inflammation and pain, and to provide sufficient quantity and quality of bone for the placement of osseointegrated implants.

\section{Oral Presentation 3}

\section{TITLE:- GUIDED TISSUE REGENERATION WITH CUSTOM-MADEOCCLUSIVE TITANIUM BARRIERS}

De Paz Pires V, Alonso Lagartos MI, Tosin F, San Hipólito Marín L, Hernández Montero S.

Máster Universitario en Implantología Oral y Prótesis Implantosoportada. Universidad Alfonso X El Sabio.

Introduction: In recent years, a new alternative of bone regeneration techniques has appeared to match custommade occlusive titanium barriers with individual blood clot, considering that one as the main "biomaterial". Vertical and flat bone regenerations, and even the combination of both of these steps is turning into the new challenge for the latest Dentistry. For many years, new surgical methods have been developed in such a way that some of them, like Khoury technique, would be considered the gold standard in oral surgery, where own bone and growth factors are used. These techniques are although very invasive, so they are not available on a daily basis. According to recent literature, many authors are supporting the importance of these blood clots to regenerate any body-tissue. Also, there are some literature which reports bone and biomaterial graft failures in short and long-term, as well as unlikely management of infections in short and long-term. 
Case Report: The primary goal of this speech is to report a number of clinical trials with different bone defects, which are treated with custom-made occlusive titanium barrier. For that purpose, it's used the whole blood clot with a small amount of pure beta-tricalcium phosphate.

Conclusions: According to the results, this regeneration technique seems to end with great outcomes, and could be considered as alternative for mandibular and maxillary bone atrophy treatment. However, further studies are necessary to consider this technique as gold standard treatment, in both short and long-term.

\section{Oral Presentation 4}

\section{TITLE:- IDENTIFICATION OF CORTICOPHOBIA AMONG ORAL LICHEN PLANUS PATIENTS: A PILOT STUDY}

Fernández González G, Pérez-Sayans García M, Lorenzo Pouso AI, Chamorro Petronacci CM, Somoza Martín JM, Blanco Carrión A.

Máster en Medicina Oral, Cirugía Oral e Implantología. Facultad de Medicina y Odontología. Universidad de Santiago de Compostela.

Objectives: The objective of the present study was to optimize a patient reported outcome measure (PROM) to identify this phenomenon.

Material and Methods: An ad hoc group of qualitative research specialists group adapted the TOPICOP questionnaire to be used as PROM via structural equation modelling (SEM) and internal consistency (IC) analysis. A total of 36 patients with symptomatic OLP treated with TCs took part in a pilot study covering both questionnaires and going through a structured clinical inspectio.

Results: SEM presented an adequate adjustment: RMSA $=0.07$, CFI $=0.94$, and a WRMR $=1.18$, as well as a high IC $(\alpha=0.88)$. A total of 16 patients $(47.1 \%)$ reported having a phobia to TCs consumption. When the Receiver Operating Characteristic (ROC) was performed, a TOPICOP value $\geq 50 \%$ predicted the presence of phobia to CTs with a sensitivity of $93 \%$ and a specificity of $100 \%$.

Conclusions: The use of this adaptation of the TOPICOP scale presented a value as a PROM in patients with OLP. In this vein, TCs phobia can be found in patients with OLP. However, more qualitative and validation studies are required to investigate if this instrument is appropriate for use in this group of patients.

\section{Oral Presentation 5}

\section{TITLE:- STUDY OF HEMATIMETRIC VALUES AND ALVEOLAR LOSS IN THE ELDERLY POPULATION}

Fernández López M, Suárez Quintanilla JA, Otero Rey E, Peñamaría Mallón M, Gamallo Moure A, Blanco Carrión A.

Máster de Patología Médico-Quirúrgica Oral y Odontología Integral. Universidad de Santiago de Compostela.

Objectives: To evaluate the relationship between alveolar loss and hematimetric values in an elderly population in a public dentistry clinical of the Galician health service.

Material and Methods: A study was carried out in a population over 65 years of age who consecutively went to the dentistry office. In all patients, the hematimetric data of the last recorded analysis and alveolar loss were recorded in an orthopantomography. All the data obtained have been processed in the statistical program SPSS statistics 2.4.

Results: We have observed in our study that the alveolar loss of the patients who attend the dentistry consultations of the public system do not present significant differences between the age groups of 40 to 64 and those over 65 years of age. There is a significant relationship between alveolar loss and the number of platelets in patients older than 65 years $(p=0.017)$. On the other hand, there is a relationship between alveolar loss and the number of lymphocytes in the group between 40 and 64 years $(p=0.004)$ that is not seen in the age group over 65 years.

Conclusions: Platelet values are directly related to alveolar loss in patients older than 65 years. The alveolar loss of patients older than 65 years is similar to that of patients between 40 and 64 years of age who attend primary care dentistry clinics.

\section{Oral Presentation 6}

\section{TITLE:-LONG-TERMSUCCESS OF TREATMENT WITH MANDIBULAR OVERDENTURES IN OL- DER EDENTULOUS PATIENTS}

Gil González J, Nuñez Márquez E, Rondón Romero JL, Jiménez Guerra A, Matos Garrido N, Velasco Ortega E. Master of Implant Dentistry. Faculty of Dentistry. University of Seville.

Objectives: Implant dentistry constitute a modality in the prosthodontic treatment of edentulous geriatric patients. This study reports the long-term evaluation of edentulous patients treated with mandibular overdentures by early loading of implants. 
Material and Methods: 45 TSA Defcon $₫$ internal connection and acid-etched surface implants were inserted in 13 edentulous patients for prosthodontic rehabilitation with mandibular overdentures. All implants were inserted non-submerged. Implants were loaded early (6 weeks). Clinical findings were followed at least 15 years.

Results: Clinical results indicate a survival and success rate of implants of $91.2 \%$. Four implants were lost (one implant early by mobility, and after, three implants were lost by peri-implantitis. $76.9 \%$ of patients were treated with overdentures with bar, and the rest of patients (23.1\%) with overdentures retained with balls. $100 \%$ of patients need attachment changes. 6 overdentures with bars and 2 overdenture with balls were removed.

Conclusions: Clinical results of this study indicate that rehabilitation with mandibular overdentures of geriatric patients with implants early loaded can achieve longterm successful outcomes.

\section{Oral Presentation 7}

\section{TITLE:- BURNING MOUTH SYNDROME IN THE ELDERLY}

Juarez Pérez FJ, Uribe Rivera M, Dardel L, Gil Manich V, Martin Gili D, Olmo González B.

Residencia Clínica en Gerontología, pacientes especiales y con compromiso medico Universidad Internacional de Catalunya.

Objectives: To determine which is the most affected population in reference range of age and sex by the BMS as well as symptomatology and treatment.

Material and Methods: It has been made bibliographic review was carried out between 2006 and 2017 using pubmed, scielo database. The key words were: Burning Mouth Syndrome, sex, age and treatment.

Results: The Burning Mouth Syndrome is characterized by burning, stinging or itching generalized in the oral cavity that is called stomatodynia. Its etiology is unknown. In the symptomatology, the buccal burning is located on the edges of the tongue, back of the tongue, lips and palate. Different studies and the bibliographic review indicate that the most affected population is women since in perimenopausal age they suffer or have suffered some time BMS with an age range of 40 to 80 years, unlike the male gender is low. The BMS appear spontaneously and present a variable in the symptoms, some report mild or moderate discomfort other unbearable pain. This bibliographic review reveals the most affected gender and the causes that can trigger it, such as psychological, advanced age and hormonal.

Conclusions: The compilation of this bibliographic research indicates that the BMS predominates in postmenopausal and geriatric women who frequently present anxiety and depression.

\section{Oral Presentation 8}

\section{TITLE:- RELATIONSHIP BETWEEN HEMATI- METRIC VALUES AND EDENTULISM IN A PO- PULATION OF ADVANCED AGE}

López Rodríguez C, Suárez Quintanilla JA, Otero Rey E, Baña Souto S, Gamallo Moure A, Blanco Carrión A. Máster de Patología médico-quirúrgica oral y odontología integral. Universidad de Santiago de Compostela.

Objectives: 1- Evaluation of the hematimetric situation and its relationship with edentulism in an elderly population in a dental practice of the Galician Public Health Service. 2- To evaluate the influence of the epidemiological variables and hematimetric values in this relation.

Material and Methods: A study was carried out in a population over 65 years of age that consecutively went to the dental consultation of the Galician Public Health Service. In all patients, blood parameters and the degree of alveolar loss and edentulism were obtained through a blood analysis and a panoramic radiography. The data obtained were processed in the statistical program SPSS statistics 2.4 .

Results: In this study, edentulism is related to gender in the general population ( $p=0.955)$, as well as in the group between 40 and 64 years $(p=0.737)$ and in the group over $65(p=0.720)$. The relationship of edentulism with hematimetric values in the general population has also been studied, observing significant values in red blood cells $(p=0.036)$, hemoglobin $(p=0.016)$ and hematocrit $(p=0.024)$. No significance was observed in the age groups of between 40 to 64 and over 65 .

Conclusions: In the general population, a relationship between certain hematimetric values and edentulism is observed. This relationship is not found in the population over 65 years of age. More studies are required to determine new evidence about its impact.

\section{Oral Presentation 9}

TITLE:-MEDICATION-RELATED OSTEONECROSIS OF THE JAW ASSOCIATED WITH IMPLANT AND REGENERATIVE TREATMENTS. SYSTEMATIC REVIEW

Luniku R, Granate-Marques A, González Navarro B, Jane Salas E, Estrugo Devesa A, Marí Roig A, López López J.

Master of Medicine, Surgery and Oral Implantology. Faculty of Medicine and Health Sciences - Odontological Hospital University of Barcelona. University of Barcelona. 
Objectives: The aim of this study was to determine if the treatment with biophosphonates and antiangiogenic agents influences in the success of regenerative and/ or implant treatments.

Material and Methods: We realized a review of the literature of the last 5 years in the PubMed database using the following words: "Sinus floor augmentation" OR "Dental Implants" OR "Guided Tissue Regeneration" AND "Osteonecrosis". The articles were selected following the inclusion and exclusion criteria and valuated with STROBE declaration.

Results: The initial search resulted in a total of 27 articles. After exluding those that did not refer to the topic, were duplicated or did not meet the inclusion / exclusion criteria, a full reading of the articles was made evaluating their methodological quality, obtaining six studies with high methodological quality and two with moderate. Conclusions: The literature regarding this topic is scarce, randomized clinical trials would be necessary to establish protocols relative to implant treatment in patients on antiresorptive treatments. The risk of developing an osteonecrosis related with the regeneration / implant placement in patients with benign bone diseases is scarce, but it exists and it should not be underestimated.

\section{Oral Presentation 10}

\section{TITLE:- PSYCHOSOCIAL REPERCUSSION OF THE EDENTULOUS PATIENT}

\section{Marcos Santos A, Arnedo Martínez AM, Arriola Riesta I, De Dios Cano J, Fernández Cáliz F, Barona Dorado C. \\ MsC Oral Surgery and Implantology. Virgen de la Paloma Hos- pital. Madrid.}

Objectives: To develop a holistic vision of the elderly total edentulous patient from the point of view of life quality.

Material and Methods: Systematic search on Pubmed and Scielo databases using the keywords: 'Life quality', 'self-concept', 'edentulous' and "mental health" and an observation period of 10 years, obtaining a total of 20 articles addressing the PICO question: $\mathrm{P}=$ 'Psychosocial repercussion', $\mathrm{I}=$ 'Elderly total edentulous patient', $\mathrm{C}=$ 'Prosthetic need', $\mathrm{O}=$ "Global vision".

Results: Dental loss has a direct impact on the quality of life of people, affecting their diet, psychological state, sexual relations, social interaction and even sleep. Under the WHO health concept of 1948, edentulism without replacement is considered a disability with transcendence in the functional and mental sphere. Smiling is an element of social inclusion. Edentulous people avoid smil- ing, which unconsciously subjects them to a depressive state with consecutive emotions of insecurity and inferiority. The difficulty in diction and feeding (increase of masticatory cycles) and the self-segregation of society predispose them to malnutrition and reduces their life expectancy. Rural-environment dwelling and female gender, often associated to economic constraints, limited access to education and poor availability of treatment remain edentulism risk factors.

Conclusions: Dentistry can be a mental health tool and education the most important agent that prevents tooth loss.

\section{Oral Presentation 11}

\section{TITLE:- ANALYSIS OF ECONOMIC IMPOVE- RISHMENT AND ITS IMPACT ON THE ORAL HEALTH STATUS OF GERONTOLOGY IN THE COMMUNITY OF MADRID}

\author{
Molinero-Mourelle P, Gónzalez Férnandez-Tres- \\ guerres F, Sáez Alcaide LM, Martín Ares M, Cáceres \\ Madroño E, López-Quiles J. \\ Máster en Cirugía Bucal e Implantología, Facultad de Odon- \\ tología, Universidad Complutense de Madrid.
}

Sociocultural changes and the increase in life expectancy in recent decades have contributed to an increase in the retired population in Spain. This population increase requires an economic analysis of prices in dental treatments.

Objectives: The objective of the present study was to investigate the economic impoverishment and its impact on the oral health status of retired patients in the Community of Madrid.

Material and Methods: We analyzed the prices of 8 treatment of 15 dental clinics during 20 years (1998-2018) in the Community of Madrid and they were correlated and compared with the pensions of the retired population in the same period of time.

Results: There has been an increase in prices with the entry of the euro and in the first six years, and a stagnation in the next four and finally a new increase until 2018. The total expenditure of C. Madrid in 2018 was 1,345 million euros, an increase of $7.46 \%$ annually and with an average increase in pensions from 1998 to 2018 ranging from 700 euros to 1250 Euros.

Conclusions: It is necessary for the clinician and for the patient to present a sustainable economic model in order to maintain an acceptable oral health status based on the economic possibilities of the geriatric population. 


\section{Oral Presentation 12}

TITLE:- USE OF THE BIODENTINE AS A MATERIAL OBTURATION BEFORE ABFRACTION IN POPULATION WITH DRY MOUTH. BIBLIOGRAPHIC REVIEW AND IN VITRO CLINICAL TRIAL

\author{
Moradas Estrada M, Alvarez López B, Cabezas \\ Hernández SB, Abounaim S, Villa Vigil MA. \\ University of Oviedo.
}

The dry mouth associated with cognitive deterioration, drug and major pathologies, such as diabetes or tumor processes, generates a change in the salivary $\mathrm{pH}$ and flora and epithelial trophism at the gingival level that generates lesions in the whole oral cavity, putting Check the future restorative and the viability of the tooth and consequent rehabilitation option. $t$

Objectives: To clarify this question, the following objectives were set: 1 . Check the result at 3,6 months and 2 years of the use of biodentine as a resin-free restorative material at the cervical level. 2. Compare the results of the biodentine with glass ionomer and composite resin. 3. Determine if the biodentine in combination with composite resin and glass ionomer gives better clinical and symptomatic results.:

Material and Methods: A descriptive literature review of the published evidence indexed in 3 impact journals in the last 3 years was carried out. After applying the inclusion and exclusion criteria, and the keywords 'orla behavior'; 'Biodentine'; 'Silicate cement', 'xerostomy pathology', were 126 articles used (meta-analysis, systematic review and clinical cases). In addition, an in vitro clinical trial was carried out with 25 teeth, undergoing filtration examination and bacterial invasion, at 15 days, 3 months and 6 months (canine with abfraction, 5 filled with resin, 5 filled with ionomer, 5 filled with biodentine ., 5 filled with biodentine + ionomer, 5 filled with biodentine + resin). The data were subjected to statistical analysis system ANOVA of a highway.Methods:

Results: With the obvious limitations of this study we can conclude: 1 . The use of biodentine offered better results in all the cases and cases studied, in the medium and long term. 2. The biodentine and glass ionomer mixture showed greater statistical significance in the review and trials. 3. The cost, handling and aesthetics were the negative aspects cited by all the authors.

Conclusions: The use of active material represents a new way that will allow us to offer more conservative, safe and durable treatment in risk patients, such as dry mouth.

\section{Oral Presentation 13}

\section{TITLE:- IMPLANT TREATMENT OF GERIA- TRIC PATIENTS BY TRANSCRESTAL MAXI- LLARY SINUS ELEVATION}

Nasser Nasser K, Jiménez Guerra A, Gil González J, Rondón Romero JL, Monsalve Guil L, Velasco Ortega E. Master of Implant Dentistry. Faculty of Dentistry. University of Seville.

Objectives: The aim of this study was to report the outcome of treatment with maxillary dental implants inserted by transcrestal sinus elevation.

Material and Methods: 23 patients (12 males and 11 females) with maxillary tooth loss were treated with 31 IPX ${ }^{\circledR}$ Galimplant internal connection and sandblasted and acid-etched surface implants inserted by transcrestal sinus elevation for rehabilitation of posterior maxilla. Implants were loaded after a healing free-loading period of 6 months.

Results: Clinical results indicate a survival and success rate of implants of $100 \%$. The mean elevation height was $7 \mathrm{~mm}$ (range: $4-10 \mathrm{~mm}$ ). $74,1 \%$ of implants were inserted in molar and $25,9 \%$ in premolar localization. Bone substitutes were used in $56,6 \%$ of implants. After a mean functioning period of 49.4 months (range: 36-64 months), no late complications were reported. $51.6 \%$ of implants were restored with fixed bridges and $48,4 \%$ with single crowns.

Conclusions: This study indicate that treatment with dental implants inserted in maxilla by transcrestal sinus elevation constitute a successful implant treatment.

\section{Oral Presentation 14}

\section{TITLE:- IMMEDIATE FIXED TOTALLY REHA- BILITATION BY INSERTED IMPLANTS WITH GUIDED SURGERY IN GERIATRIC EDENTU- LOUS MANDIBULAR PATIENTS}

\section{Ordóñez Sousa B, Jiménez Guerra A, Matos Garrido $N$, España López A, Ortiz García I, Velasco Ortega E. Master of Implant Dentistry. Faculty of Dentistry. University of Seville.}

Objectives: The aim of this study was to present clinical results of treatment with implants inserted by the technique of guided surgery and immediate loading in geriatric edentulous mandibular patients.

Material and Methods: Patients were diagnosed by cone beam tomography and treated with 8-10 Galimplant ( implants for rehabilitation by the technique of guided 
surgery and immediate loading. Immediately after surgery a full provisional immediate restoration was placed. At 6 months, the final restoration was performed. The clinical follow-up period was at least 7 years of functional loading.

Results: 28 patients were treated with 241 implants. The results indicate a success rate of $98.4 \%$. Four implants were lost during the healing period with the provisional prosthesis. After a mean functioning period of 84.4 months from the final restoration, there was no late complications.

Conclusions: This study indicates that treatment with dental implants by guided surgery and immediate loading in the maxilla is a high success rate therapeutic alternative in geriatric patients.

\section{Oral Presentation 15}

\section{TITLE:- RELATIONSHIP BETWEEN ROOT CARIES AND THE PRESENCE OF CANDIDA ALBICANS IN THE REMOVABLE PROTESIS OF OLDER PERSONS}

Ortolá Siscar JC, Fernandez Pastor M, Ortolá Piera C. Stomatology Department. University of Valencia.

The presence of root caries in the abutment teeth of removable partial dentures leads us to study the possible linkage of yeasts of the biofilm with the development of this type of lesions.

Objectives: The purpose of this study is to relate the condition of being a carrier of removable prostheses with the appearance of lesions of asymptomatic and slowly evolving root caries in patients over 65 years of age.

Material and Methods: A sample of 42 patients, 24 with root caries (cases) and 18 without root caries (controls). The average age is 74.14 years. The presence of Candida Spp. in saliva, the biofilm of the prosthesis, biofilm of the faceted tooth and in a sample of the faceted tissue. The samples are sown in culture plates whose medium, sabouraud dextrose agar, allows a selective fungal growth. Results: Regarding the sample of the biofilm of the prosthesis, it is observed that there is a statistically significant relationship ( $p 0.018)$ between the patients with root caries and the presence of yeast in the part of the prosthesis closest to the tooth.

Conclusions: Patients with root caries have higher levels of yeast in the biofilm of the prosthesis. Yeast presence was detected in $67 \%$ of the cultures of the faceted tissue. Therefore, although more studies are needed, we suspect that Candida Albicans may have some role in the development of certain types of root caries in the elderly.

\section{Oral Presentation 16}

\section{TITLE:- PREVALENCE OF COMPLICATIONS IN IMPLANT-SUPPORTED HYBRID PROSTHESES. A 10 YEARS RETROSPECTIVE STUDY}

\author{
Ortuondo Becerra C, Quiñones Perez G, López Suárez \\ C, Tobar Arribas C, Suárez García MJ. \\ Máster en Prótesis Bucofacial y Oclusión de la Universidad \\ Complutense de Madrid.
}

Objectives: As a consequence of the increase in the life expectancy of the western population, there has been an increase in the number of edentulous patients who attend the dental consultations. With the appearance of implants, the therapeutic range for dental replacement has expanded enormously. However, it has become a great challenge to plan this type of rehabilitation to the patient due to the different patterns of bone resorption, as well as different density of bone available in the area to be treated; factors that have a direct relationship with the success of the treatment. The placement of hybrid prostheses is a clear option when it comes to replacing teeth and support tissues. The objective of this work is to analyze the biological and mechanical complications of hybrid prostheses on implants through a retrospective analysis and review of the literature.

Material and Methods: Thirty patients were selected through the database of the Complutense University of Madrid treated with hybrid prostheses placed in the Master of Prosthesis and Occlusion between January 2008 and December 2018 and their complications were analyzed. Multiple variables were distinguished such as the number of implants, upper or lower arch, presence of distal cantilever, among others. An electronic literature search was also carried out in the databases "Pubmed", "Cochrane" and "Medline". Different keywords were used and the search was reduced to clinical studies and articles published between 2000 and 2018. Relevant studies were selected according to the inclusion and exclusion criteria.

Results: Among the prostheses reviewed at 10 years, complications were found in 16 of them. They highlighted the fracture of the teeth, fracture of the structure, loosening and fracture of the screws, periimplantitis and mucositis among others. In the review carried out, a total of 187 articles were initially found, of which 21 were selected for analysis after the filtering process. All of them mentioned the complications of hybrid prostheses, with complications similar to those found in the retrospective study.

Conclusions: The treatment of choice in patients with moderate bone resorption is rehabilitation using implantsupported hybrid prostheses since they replace teeth and soft tissue. However, they present several complications 
in the short and long term. These are both; biological and biomechanical. The most prevalent complication is the fracture or wear of the resin teeth.

\section{Oral Presentation 17}

\section{TITLE:- RELATIONSHIP BETWEEN METABO- LIC CONTROL AND THE PERIAPICAL STATE IN A DIABETIC POPULATION}

Pérez Losada F de L, Segura Egea JJ, López López J, Jané Salas E, Estrugo Davesa A.

Faculty of Medicine and Health Sciences, University of BarceIona. URF Dentistry. Oral Medicine Unit.

The aim of this study is to analyze the possible relationship between the metabolic control of type 2 diabetic patients evaluated by the HbAlc level and the prevalence of PA.

Material and Methods: Cross-sectional observational study, with a sample of 216 patients. Two groups were established according to their metabolic control: group A: $(\mathrm{HbAlc}<6.5 \%)$ and group B: $(\mathrm{HbAlc} \geq 6.5 \%)$. The periapical state was assessed by the periapical index score (PAI).

Results: 47 patients were included in group A (21.7\%) and $169(78.2 \%)$ in group B. We found 96 patients (44.4\%) with at least 1 tooth endodontically; with a higher percentage in group B, 80 patients $(83,3 \%)$ while in group A, only $16(16,6 \%)$. were obtained. We found at least 1 endodontized tooth with PA in the total sample in 27 patients $(21,4 \%)$, obtaining in group B 22 patients $(82,5 \%)$ and in group A 5 patients $(18,5 \%)$, although there is no statistically significant difference both groups [odds ratio: $1.25,95 \%$ CI $0.45-3.52, p=0.66]$. Regarding teeth with periapical pathology (PA), we obtained a total of 113 patients (52.3\%) with at least 1 tooth with PA, the prevalence of PA was higher in group B with 91 patients $(80,5 \%)$ compared to group A, with 22 patients $(19,5 \%)$, [odds ratio $=1.33 ; 95 \%$ CI 0.69-2.53; $p=0.39$ ].

Conclusions: Diabetic patients poorly controlled have a worse periapical state with a greater number of periapical lesions RL.

\section{Oral Presentation 18}

\section{TITLE:- MULTICENTRIC RETROSPECTIVE STU- DY BASED ON 97 ORAL LIPOMA CASES}

Ponte Calvo F, Pérez Sayáns M, Oliveira Alves MG, La Fuente Irene, Aguirre Urízar JM, Blanco Carrión A. Máster de Medicina Oral, Cirugía Oral e Implantología. Universidad de Santiago de Compostela.
Objectives: The objective of this study is to identify the main clinicopathological characteristics of this tumour in a case series of oral lipomas (OL) in a population from Spain and Brazil.

Material and Methods: A multicentre retrospective observational study was conducted in collaboration with the Oral Pathology Unit of the State University Universidade Estadual Paulista Filho de Mesquita (UNESP) in Brazil, and the Oral Medicine and Pathology Units of the University of Santiago de Compostela (USC) and the University of the Basque Country (UPV/EHU) in Spain. Results: This multicentre series consists of a total of 97 of OL cases, 31 of which correspond to Spain, and 66 to Brazil with an overall prevalence of $0.33 \%$. The average age of the patients is 56.44 years old, with a range of 10-92. Buccal mucosa was the most frequent location (42.3\%). Cases from Spain coexisted with other lesions in a significant number of cases, $12.9 \%$, Vs Brazil, $1.5 \%$. According to the progression time, Brazil has an average of 60.35 months compared to 5.41 months in Spain. Average size is $12.55 \mathrm{~mm}$, ranging from 2 to $75 \mathrm{~mm}$.

Conclusions: Correct differential diagnosis of the clinical lesion is key, followed by a good histopathological study, to achieve the final diagnosis.

\section{Oral Presentation 19}

\section{TITLE:- EVALUATION CRITERIA FOR THE CLINICAL IMPROVEMENT OF LICHEN PLA- NUS AFTER TREATMENT}

Riveiro Pousada A, Suárez Quintanilla JA, Otero Rey E, Baña Souto S, Peñamaría Mallón M, Blanco Carrión $A$.

Máster en Medicina Oral, Cirugía Oral e Implantología. Facultad de Medicina y Odontología. Universidad de Santiago de Compostela.

Objectives: Evaluation of therapeutic efficacy in the treatment of oral lichen planus and its relationship with the quality of life of patients through quality of life tests and clinical quantitative means.

Material and Methods: Evaluation of 20 patients diagnosed clinically and histologically with oral lichen planus who presented symptomatic lesions. Before and after treatment, the lesions are evaluated using the R.E.U. and the OHIP-14 questionnaire is completed to assess the perception of quality of life.

Results: After one month of treatment, $100 \%$ of patients are pain-free. With the system R.E.U. of evaluation of the lesions we observed a significant improvement, from 16.1 points to $5.225(p=0.011)$. Also in the average score of OHIP-14 we found a significant improvement, from 17.95 points before treatment to 15.11 after treatment $(p<0.001)$. 
The relationship between the improvement in lesions and quality of life is directly proportional, although after treatment not statistically significant ( $p=0.244)$.

Conclusions: (1) Triamcinolone acetonide in $0.5 \%$ aqueous solution reduces lesions and reduces symptomatology. (2) Through the R.E.U. we observed an improvement in the clinical type, size and extension of the lesions. (3) We observed an improvement in the quality of life after treatment. (4) There is a relationship between improvement in lesion and quality of life after treatment, although it is not statistically significant.

\section{Oral Presentation 20}

\section{TITLE:- STUDY OF THE RELATIONSHIP BETWEEN BIOCHEMICAL VALUES AND AL- VEOLAR LOSS IN AN ELDERLY POPULATION}

Rodríguez Vega C, Suárez Quintanilla JA, Otero Rey E, Rivas Mundiña B, Peñamaría Mallón M, Blanco Carrión A.

Master's Degree in Medical-Surgical Pathology and Integral Dentistry. University of Santiago de Compostela.

Objectives: Study the relationship between biochemical values and alveolar bone loss.

Material and Methods: A study was carried out in a population over 65 years old who consecutively attended the Odontology office of the Galician Public Health Service.

All of them were asked for a blood test and a panoramic radiograph to assess the amount of alveolar loss and edentulism. The data has been processed in SPSS statistics 2.4 program.

Results: There are no significant differences between age groups (40-64 and $>65)$ and alveolar loss $(p=0,518)$. The patients of the both age groups had differences in the values of urea $(p<0,001)$, uric acid $(p=0,0046)$, GTP $(p=0,010)$ and cholesterol $(p=0,037)$. However, we did not find any significant difference between the alveolar loss and the biochemical parameters between the two age groups.

Conclusions: The alveolar loss of patients between 40 and 64 years who attend primary care public consultations is very high with respect to the general population. There are biochemical differences between both age groups, with increased values of urea and uric acid for those over 65 and increased values of GPT and cholesterol in the group between 40-64.

\section{Oral Presentation 21}

\section{TITLE:-STUDY OF PLATELET LEVEL IN RE- LATION TO ALVEOLAR BONE LOSS IN AN EL- DERLY POPULATION}

\begin{abstract}
Talbaoui A, Suárez Quintanilla JA, Otero Rey E, Rivas Mundiña B, Gamallo Moure A, Blanco Carrión A. Master's Degree in Oral Medical-Surgical Pathology and Integral Dentistry. University of Santiago de Compostela.
\end{abstract}

Objectives: The objective of this study is to examine the relationship of the platelet level with alveolar bone loss, the number of teeth as well as the different blood parameters.

Material and Methods: A study was carried out in a population over 65 years old, considering a control group between 40 and 64 years old $(n=238)$ who have come consecutively to the public consultation of Dentistry of the Galician Health Service.

In all patients, a blood test and a panoramic radiography have been performed to evaluate the degree of alveolar bone loss and edentulism. The data obtained have been processed in the statistical programme SPSS Statistics 2.4.

Results: The level of platelets was related with sex in the group between 40 and 64 years old as in the group older than 65 years old $(p=0,015)$. In addition, there is a statistically significant relationship between the level of platelets and alveolar bone loss in the population over than 65 years old $(p=0,025)$. Finally, in this same group, this haemathymetric parameter was directly related to monocytes $(\mathrm{r}=0,227, p=0,007)$, basophils $(\mathrm{r}=0,262$, $p=0,002)$, leukocytes $(\mathrm{r}=0,246, p=0,003)$ and lymphocytes $(\mathrm{r}=0,248, p=0,003)$ and indirectly with uric acid $(\mathrm{r}=$ $-0,216, p=0,024)$, urea $(\mathrm{r}=-0,274, p=0,003)$ and bilirubin $(\mathrm{r}=-0,298, p=0,007)$.

Conclusions: Based on the present study, the platelet count is related to alveolar bone loss in the elderly population and is associated with different hematimetric and biochemical parameters. More studies are needed to obtain new evidence on its impact.

\section{Oral Presentation 22}

\section{TITLE:- RELATIONSHIP BETWEEN BIOCHE- MICAL VALUES AND EDENTULISM IN POPU- LATION OF ADVANCED AGE}

Valentinov Iliev I, Suárez Quintanilla JA, Otero Rey E, Rivas Mundiña B, Baña Souto S, Blanco Carrión A. Máster de patología medico-quirúrgica oral y odntología integral. Santiago de Compostela University. 
Objectives: To evaluate the biochemical values and their relationship to edentulism of an advanced age population of a dental consultation.

To evaluate the influence of epidemiological variables and biochemical values in this relation.

Material and Methods: This study is made in a population over 65 , who went consequently to dental revision of a Galician Public Health Service. The blood parameters, the degree of alveolar loss and edentulism have been obtained through a blood analysis and a panoramic radiography. The data obtained has been processed with the statistical program SPSS 2.4.

Results: In this study, edentulism has been related to gender in the general population $(p=0.955)$, as well as in the group between 40 and 64 years $(p<0.001)$ and in the group over 65 years $(p<0.014)$. In addition, the relationship of edentulism with biochemical values in the general population was studied, with significant results observed in glucose $(p=0.003)$, glycosylated haemoglobin ( $p=$ $0.013)$ and TSH $(p=0.025)$, with no significant values in the group of patients over 65 years.

Conclusions: In the general population a relationship between certain biochemical values and edentulism is observed. This relationship is not found in the population over 65 years of age. More studies are required to determine new evidence about its impact.

\section{Oral Presentation 23}

TITLE:- CLINICAL AND PATHOLOGICAL CORRELATION. CHARACTERISTICS OF ORAL LICHEN PLANUS. A RETROSPECTIVE OBSERVATIONAL STUDY

Vera Echevarria A, Pérez-Sayans García M, Boñar Alvarez P, Otero Rey E, Gándara Vila P, Blanco Carrión A. Master in Oral Medicine, Oral Surgery and Implantology. Faculty of Medicine and Dentistry. University of Santiago de Compostela.

Objectives: The aim of this study is to determine the correlation of histopathological characteristics with clinical aspects and OPL variants.

Material and Methods: A retrospective study of a group of 59 adult patients with confirmed clinical and histopathological diagnosis of OPL from the Oral Pathology Unit of the University of Santiago de Compostela. Age, sex, location of lesions, clinical type, toxic habits and concomitant treatments were evaluated. Histopathologically, the epithelial response, the presence of ulceration, the degree of injury and distribution of the interface, the intensity and the composition of the inflammatory infiltrate were analyzed.
Results: As a result we observed that patients treated with several systemic drugs had more atrophic / erosive forms of OPL. Plasma cells were found more frequently in the cases that showed a deep inflammatory affectation of the subepithelial connective tissue than in those in which the inflammation was only located superficially. Its presence was also associated with epithelial erosion-ulceration.

Conclusions: Patients treated with several drugs had more atrophic / erosive forms of LPO and were frequently associated with a deep specific inflammatory pattern based on plasma cells. Our results could suggest that the intake of medications by some patients could confer an aggravating character complementary to the disease, alone or together with other unidentified factors. More studies should be done to confirm this trend and to evaluate if this characteristic can influence the evolution of the lesions.

\section{Oral Presentation 24}

\section{TITLE:- PLACEMENT OF DENTAL IMPLANTS IN ATROPHIC JAW WITH THE TECHNICAL SPLIT CREST}

Arnedo Martínez AM, Barbi Actis J, Rubio Alonso LJ, Ruiz Sáenz PL, Martínez Rodríguez N, MartínezGonzález JM.

Hospital Virgen de la Paloma de Madrid. Master in Mouth Surgery and Implantology.

Introduction: Nowadays, the prosthetic rehabilitation on implants is a treatment highly demanded in the clinic. Nevertheless, there are cases where they find bony maxillary atrophies in vertical or horizontal sense. There exist different surgical alternatives that allow to realize the treatment in situations in that there is a bony insufficient width, since they can be; onlay grafts, bony holding a permit regeneration, alveolar osteogenic distraction, narrow implants, technology SBBT (Split Block Bone Technique), the use of dilators or expanders, as well as the technical Split Crest.

Case Report: 67-year-old female patient, who came to the Service of Mouth Surgery and Implantology of the Hospital Virgen de la Paloma in Madrid for a jaw rehabilitation. During the intraoral exploration it was observed partial edentulism with jaw horizontal atrophy in the third and fourth quadrant. A TC was requested and after the informed assent we proceeded to the boarding by a crestal incision lightly platinized, crestal osteotomy, separation with bony expanders with his later bony regeneration and finishing with the placement of four implants. Conclusions: Technical Split Crest is a good option to be able to rehabilitate big horizontal atrophies in the maxillary ones in geriatric patients. 


\section{Oral Presentation 25}

\section{TITLE:- MEDICATION-RELATED OSTEONE- CROSIS OF THE JAW}

Baca González L, Palacio Ochoa A, Cadenas Vacas G, Izquierdo Orts R, Sainz Brihuega L, López-Quiles Martínez $J$.

Master in Oral Surgery and Implants. Facultad de Odontología. Universidad Complutense de Madrid.

Introduction: The aim of this case is to report the treatment of a medication-related osteonecrosis of the jaw as well as to review current literature on this issue.

Case Report:: 48-years-old female suffering breast cancer and bone metastasis. She received intravenous biphosphonates treatment (zolendronic acid) for 2 years until 2015. Currently, she is being treated with chemotherapy including a monoclonal antibody (bevacizumab). She is referred by her dentist because "I had a tooth extraction 8 months ago and I have a sharp sore that is painful when I touch it". Two bone expositions $1 \mathrm{~mm}$ each are observed at the lingual aspect of absent 3.6. The anterior one presents light suppuration. They are slightly painful at palpation. There are not lymphadenopathies. A radiolucency without sclerotic margin area is observed on the crestal aspect of the alveolar ridge. A curettage was undertaken under local anaesthesia and without raising a flap. Then sharp edges smoothed with a round bur. A CGF clot and double membrane where positioned over the defect to promote soft tissue healing. Antibiotic prophylaxis was administered (amoxicilin/clavulánic acid $875 \mathrm{mg} / 125 \mathrm{mg} / 8 \mathrm{~h} / 2$ previous days and after treatment up to a complete week, auxina $\mathrm{A}+\mathrm{E} 5000 \mathrm{UI} / 10 \mathrm{mg} / 24 \mathrm{~h} / 7$ days and usual analgesic/antiinflammatory treatment. Suture was removed a week after. Conclusions: Platelet concentrates enhance soft tissue healing and constitute a therapeutic option for medication-related osteonecrosis of the jaw.

\section{Oral Presentation 26}

\section{TITLE:- BONE FLORID DYSPLASIA. ABOUT A CLINICAL CASE}

Barbi Actis J, Gala Penagos E, Rubio Alonso LJ, Ruiz Sáenz PL, Naval Gías L, Martínez-González JM. Master of Oral Surgery and Implantology Virgen de la Paloma Hospital, Madrid.

Introduction: Florid osseous dysplasia (FIOD) is a benign, usually asymptomatic, idiopathic anomaly that presents histologically as a fibrous connective tissue stroma with the presence of collagen that contains pro- liferation of cement foci and various osteoid and bone mineralized materials present in at least two quadrants. The reason for this communication is to present a clinical case diagnosed with FlOD, together with its results and clinical management. Florid osseous dysplasia (FlOD), a term proposed as "florid cemento-osseous dysplasia" for the first time by Waldron CA in 1985, has been coined in numerous ways over the years.According to the WHO, it is included in osseous dysplasias (OD). FlOD is a benign, usually asymptomatic, idiopathic anomaly that presents histologically as a fibrous connective tissue stroma with the presence of collagen that contains proliferation of cement foci and various osteoid and bone mineralized materials present in at least two quadrants. The etiology is unknown and has a higher prevalence in the black race, followed by the Asian and Caucasian, and in women between 30 and 50 years. The differential diagnosis includes other odontogenic tumors, chronic osteomyelitis, cementoblastoma, osteoblastoma, Paget's disease or malignant mandibular neoplasms.The reason for this communication is to present a clinical case diagnosed with FlOD, together with its results and clinical management. Clinical Case: Female, 65 years old, of black race, with no medical history of interest goes to the Oral and Maxillofacial Surgery department for inflammatory episodes at mandibular level, bilaterally with suppuration by intraoral fistulas. After the failure of the conservative approach, we proceeded to the surgical approach through general anesthesia, consisting of ostectomy of the dysplastic areas. At 6 months, the patient was rehabilitated by implantoprosthetic treatment with a hybrid prosthesis. The current evolution of two years shows the consolidation of bone regeneration as well as the osseointegration of the implants.

Conclusions: The clinical case presented shows the viability of the rehabilitation treatment through implants or regenerative treatments in patients with DOFl even after a surgical approach to the pathology.

\section{Oral Presentation 27}

\section{TITLE:- DIGITAL FLOW AS WORKING TOOL IN GERIATRIC PATIENTS}

Carrion Martín M, Albánchez González MI, Serrano Torrecilla M, Alonso Fuente M, Cortés- Bretón Brinkmann J, Suárez García MJ.

Master of buccofacial prosthodontics and occlusion. Complutense University Madrid.

Introduction: To present and demostrate how digital flow can help us in order to obtain satisfactory functional and esthetic results in geriatric patients both in tooh or implant supported rehabilitations. 
Case Report: We present two clinical cases report of geriatric patients who seek treatment at the Department of Buccofacial Prosthetics and Occlusion at the Complutense University of Madrid (Spain).

Both patients demand an improvement of their functional and esthetic oral health. After intraoral exploration and pertinent clinical complementary tests we concluded that both patients were suitable to be treated with a jointly tooth and implant supported rehabilitation.

A digital work flow was performed based on previously made provisionals. Both clinical cases were digitally scanned with Scanner TRIOS 3 Shape.

A correct fit between the restorations and the teeth and implants have been observed in both rehabilitations with an additional correct function and esthetic. Besides digital impressions reduces the number of appointments improving consequently patients perception of comfort.

Conclusions: Digital work flow offers particular advantages for the patient compared with conventional impression techniques such as communication with the laboratory and reduction of working time in dental praxis. Besides digital impressions present an alternative to eliminate procedural distortions by improving the fit between the restoration and the implants/teeth.

\section{Oral Presentation 28}

\section{TITLE:- SUBMANDIBULAR SIALOLITHIASIS. CASE REPORT}

Coello de la Cruz. L, Espiga Pacheco J, Franco Carro B, Santos Marino J, Martínez Rodríguez N, Barona Dorado $C$.

Hospital Virgen de la Paloma. Máster en Cirugía Bucal e Implantología.

Introduction: Salivary gland lesions represent a diverse group, in which there are benign and malignant pathologies that can be difficult to distinguish. Sialolithiasis is one of the most common non-neoplastic pathologies. Obstruction of the salivary duct secondary to the calculus formation is a frequent alteration of the submandibular gland that usually manifests as episodes of pain accompanied by inflammation during meals.

Case Report: A 70-year-old female patient with hypertension came to the oral surgery and implantology service of the Virgen de la Paloma Hospital, due to episodes of pain and inflammation associated with meals. The intraoral examination showed a mass in the line of the Wharton duct on the right side of $0.8 \times 2.5 \mathrm{~cm}$ in diameter, which was hard to palpate, all accompanied by poor hygiene. The lesion was extirpated intraorally under local anesthesia. After a follow-up of two years, recurrence has not been observed.
Conclusions: There are anatomical and salivary factors related to the development of sialolithiasis. More studies are required to standardize the diagnosis and treatment of this pathology.

\section{Oral Presentation 29}

\section{TITLE:- A CASE OF NECROTIZING SIALOME- TAPLASIA}

Chavesta Rivadeneyra P, Pérez González F, Cano Durán J, Sánchez-Labrador L, Sainz Brihuega L, Cáceres Madroño E.

Master on Oral Surgery and Implantology - Complutense University, Madrid.

Introduction: Necrotizing sialometaplasia is a rare selflimiting, inflammatory, benign disease that normally affects minor salivary glands. The pathogenesis is unknown but is believed to be due to ischemia of vasculature supplying the salivary gland lobules. Nevertheless, it can sometimes resemble malignant diseases, such as mucoepidermoid carcinoma, which can lead to diagnostic errors.

Case Report: 48-year-old woman, no significant previous medical or surgical records. Smoker (5 cigars a day). The patient came to the Oral Surgery and Implantology Department presenting with an asymptomatic, slightly elevated lesion on the hard and soft palate, detected during a routine check-up, so development time is unknown. The patient does not recall any trauma in the area. Intraoral examination revealed a single, circumscribed, raised lesion, with an ulcerous aspect, of about $1 \mathrm{~cm}$ diameter. No nodes were found on palpation. It was advised to perform an escisional biopsy; histological report revealed, features compatible with a necrotizing sialometaplasia diagnosis. The lesion disappeared spontaneously weeks after the biopsy.

Conclusions: Necrotizing sialometaplasia is a self-limiting disorder of the minor salivary glands. It normally affects the hard palate. Its clinical characteristics are similar to those of some malignant glandular disorders, which can lead to unnecessary treatments. For this reason, it is advised that both clinicians and pathologists know the nature of this disease to avoid misdiagnosis. 


\section{Oral Presentation 30}

\section{TITLE:- THE PEMPHIGUS IN GERIATRIC PA- TIENT. 2 CLINICAL CASES}

Gala Penagos E, Martínez Puga M, Rubio Alonso LJ, Ruiz Sáenz PL, Naval Gías L, Martínez-González JM. Máster de Cirugía Bucal e Implantología Hospital Virgen de la Paloma, Madrid.

Introduction: Pemphigus is a rare and potentially serious autoimmune and intraepithelial disease. There are 6 forms of pemphigus: vulgar, vegetative, immunoglobulin A, foliaceous, erythematous and paraneoplastic. This type of injury can occur between 50 and 65 years old. In most cases, the initial manifestation occurs in the oral cavity as multiple ulcerations preceded by blisters that rupture and then spread to other mucous membranes, skin and sometimes to the esophageal area.

Clinical Case: Two clinical cases of pemphigus vulgaris are presented: Woman, 65 years old, with chronic gastritis and dyslipidemias without known drug allergies, who reported diffuse painful lesions in the oral cavity for approximately 1 month. Woman, 67 years old, without known drug allergies, who reported lesions at the base of the tongue increasing in size in 10 days, making it difficult to eat and reducing appetite. She was treated by her Dentist with sodium diclofenac $50 \mathrm{mg}$ for pain and with acetonide. $0.1 \%$ triamcinolone in orabase without improvement. Biopsies were performed in both patients and histopathology confirmed the presence of pemphigus vulgaris in the jugal mucosa. From the anatomopathological study they were treated with corticoids.

Conclusion: It is important to highlight the value of histopathological diagnosis as well as early treatment of these patients, which is why patients who are treated with a rapid response to treatment have a better prognosis and a better evolution.

\section{Oral Presentation 31}

\section{TITLE:- COMPLICATIONS DERIVED FROM TREAT-MENT AND SURGERY AFTER MALIG- NIFICATION OF ORAL LICHEN PLANUS INTO ORAL SQUAMOUS CELLS CARCINOMA}

\section{Galera Molero F, López Jornet P.}

Área de Medicina Oral. Hospital Universitario Morales Meseguer. Facultad de Medicina y Odontología Universidad de Murcia.

Introduction: Malignization of OLP is the major complication of the disease. The treatment of OSCC may require surgical techniques for tumor resection and intra- operative reconstructions, which some possible sequelae. In addition, complications derived from systemic, immune or pharmacological changes are also important.

Case Report: Female non-smoking patient. 65 years. HTA, hypothyroidism. No alergics. Diagnosed OLP clinically and histopathologically in 2004, according to Van der Meij criteria and follow-up by otolaryngologist. We evaluated and biopsy lesion in the left alveolar ridge, describing the report Squamous mucosa with moderate-severe dysplasia-ISC. Maxillofacial treatment with cervical emptying and segmental mandibulectomy. Reconstruction with an osteocutaneous flap of the left micro-vascularized fibula and a regulated tracheotomy. Diagnosis of OSCC righ mandibule (T2 N0 M0) and left (T1 N0 M0). Hospital discharge. Four months later, reoperation of granuloma in tracheostoma. Continues controls and treatment of LPO with corticoid against outbreaks. Evaluation by demand of rehabilitation with implants 6 months after the intervention. On examination, a granulomatous raised lesion appears on the vestibular border of the graft and white plaque on the floor of the mouth. Conclusions: After primary complications of the maxillofacial intervention, such as hemorrhage, infection, thrombosis, pain or loss of sensitivity, we can find aesthetic or functional sequelae, or recurrent relapses the concept of field cancerization. Also, in patients with active OLP, treatment with corticosteroids can hinder the correct healing of the graft. Finally, restoring oral function by implants surgery, appears as one of the main concerns of patients.

\section{Oral Presentation 32}

\section{TITLE:- MANDIBULAR OSTEONECROSIS DUE TO DENOSUMAB. ABOUT A CASE}

\section{González Valls G, González Navarro B, Jané Salas E, López López J. \\ Master of Medicine, Surgery and Oral Implantology, University of Barcelona // Master of Medicine, Surgery and Oral Implan- tology. Faculty of Medicine and Health Sciences - Odontologi- cal Hospital University of Barcelona. University of Barcelona.}

Introduction: Many medications can produce side effects in the oral cavity. Denosumab, a human monoclonal antibody, has shown the emergence of side effects such as osteonecrosis. It is of great importance that professional knows both the effects of this drug and the procedure to follow.

Case Report: 65-year-old woman, without known allergies and medical history of breast cancer in 2010 and relapse in 2013 with metastases in the pleura, liver and bones. She had been treated with Denosumab for 5 years 
at doses of $120 \mathrm{mg}$ intramuscularly once a month. She had interrupted the treatment 8 months ago since she began to report discomfort in the oral cavity. She went to the HOUB, submitted by his primary care center for the extraction of the 1.7 and 3.8.

Orthopantomography shows an image in the 3rd quadrant of possible infectious process associated with sclerotic bone with radiolucent margin, compatible with osteonecrosis by Denosumab. Thanks to the radiological tests it is known that the affected bone portion is of large dimensions, from the area of 3.7 to the Spix spine. However, is considered necessary to be biopsied to confirm our diagnosis of presumption and thus rule out a malignant process. Pathological anatomy confirms that it is an osteonecrosis due to Denosumab. The patient is referred to the maxillofacial service of Bellvitge Hospital to continue with the treatment.

Conclusions: It is important to know the radiological characteristics of the lesions, perform a good anamnesis and help of radiological tests for an optimal planning and case study.

\section{Oral Presentation 33}

TITLE:- OSTEOMYELITIS OF THE JAW WITH PATHOLOGICAL FRACTURE AS A POST-EXTRACTION COMPLICATION OF A RETAINED CORD FOLLOWING EXTRACTION OF AN IMPACTED WISDOM TOOTH. A CASE REPORT

Graterol Duran, González Navarro B, Arranz Obispo C, Jané Salas E, López López J. Master of Medicine, Surgery and Implantology. Faculty of Medicine and Health Sciences - Odontological Hospital University of Barcelona. University of Barcelona.

Introduction: Osteomyelitis is a rare complication in oral surgery. Due to osteomyelitis, the bone weakens and may cause mandibular fractures. This is an infrequent complication that a review of the diagnosis and management of osteomyelitis should be performed in patients with mandibular fracture.

Case Report: A 60-year-old man who attends the Master of Medicine, Surgery and Oral Implantology at the University of Barcelona for 4.8 extractions and with advanced generalized periodontal disease. At 2 weeks the patient reported intense pain in the area and trismus, without clinical or radiological evidence of infection. After a month and a half of the extraction, the patient goes to the emergency room, to the Maxillofacial Surgery service of the University Hospital of Bellvitge, with severe pain in the fourth quadrant. The intraoral scarring appeared to be correct, with slight suppuration at pressure. The orthopantomography showed a line of fracture at the level of the right mandibular angle not displaced (which was not evident in the previous radiological control), with areas of rarefaction of the bone. It is decided, therefore, to intervene the patient to perform a reduction and mandibular osteosynthesis, in addition to a broadspectrum antibiotic treatment by intravenous route.

Conclusions: The complications of mandibular third molar extraction can arise in a low percentage of cases, so it would be convenient to make a correct clinical and radiological diagnosis.

\section{Oral Presentation 34}

\section{TITLE:- PERI-IMPLANTITIS TREATMENT OF THE PATIENT WITH PARKINSON'S. REGAR- DING A CLINICAL CASE}

Martínez Puga M, Ruiz de Carlos C, Rubio Alonso LJ, Ruiz Sáenz PL, Martínez Rodríguez N, MartínezGonzález JM.

Hospital Virgen de la Paloma de Madrid.

Introduction: Peri-implantitis is an inflammatory process of the tissues that surround the implant and presents progressive bone loss. The aim of the treatment is to achieve the elimination of the bacterial infection, the reduction of the depth of the periodontal pocket and the bleeding in the probing, as well as to stop bone loss.

Case Report: A 67-year-old female patient with Parkinson's disease attended the Oral Surgery and Implantology service of the Virgen de la Paloma Hospital in Madrid. The patient, who presented a fixed prosthesis on six implants in jaw, attended due to the presence of recurrent periimplantitis. A thorough intraoral exploration was performed in which a generalized inflammation and a large amount of calculus were observed around the implants. As a complementary test, a panoramic radiography was performed, observing a large peri-implant bone loss, so it was planned to perform a resective surgery combined with a surface treatment of the implants. Initially, the treatment of choice for the surface was implantoplasty.

Initially, the treatment of choice for the surface was implantoplasty, but due to the continuous tremors of the patient, it was impossible to polish the coils. As a consequence, the surface was polished with the use of titanium curettes and the subsequent bicarbonate blasting to increase cleaning.

Conclusions: It is important to keep in mind that patients with alterations in movement present more difficulties in any dental treatment 


\section{Oral Presentation 35}

TITLE:- PROTOCOL FOR THE APPLICATION OF HIGH CONCENTRATION FLUORIDES IN THE PREVENTION OF ROOT CARIES: A PURPOSE OF TWO CLINICAL CASES OF 22 YEARS OF EVOLUTION

Ortolá Piera C, Ortolá Siscar JC, Almerich Torres T. Stomatology Department. University of Valencia.

We show the results obtained on arrestment of incipient root caries lesions and her prevention based on the application of a Sodium Fluoride 5\% varnish $(22,500 \mathrm{ppm})$ Duraphat $\mathrm{R}$ in patients considered at high risk of caries, after a follow-up period of 22 years.

Introduction: There are very few long-term clinical studies on the benefit of fluorides in the prevention and evolution of incipient lesions of root caries in elderly patients. The establishment of preventive protocols is necessary because they are losing the ability to maintain good oral hygiene. It is in these phases of life where the role of professionals to establish and control these prevention protocols becomes more important.

Case Report: We present the results obtained from the application of a protocol for the prevention and arrest of incipient lesions of root caries, by applying a 5\% Sodium Fluoride varnish $(22,500 \mathrm{ppm})$ in 2 patients considered to be at high caries risk, after of a follow-up period of 22 years.

Conclusions: Following the presentation of clinical cases we can conclude that the application of fluoride varnish Duraphat R can stop the progression of incipient root caries lesions and the appearance of new lesions.

\section{Oral Presentation 36}

TITLE:- OCLUSSIVE BARRIES: A REGENERATION ALTERNATIVE CASE REPORT

Pérez González F, Chavesta Rivadeneyra P, SánchezLabrador Martínez de Morenín L, Cano Durán J, San Hipólito Marín L, Martín Ares M.

Oral Surgery and Implants Degree. University Complutense of Madrid.

Oclussive: Barries could be a useful alternative in maxilary and mandible atrophic cases.

Introduction: It exists different treatment options when bone atrophic is presented: guided bone regeneration, split crest, bone block graft, basal implants, and oclussive barriers appears to be a recent alternative with bone deficiency. Case Report: 58-years old woman, posterior bilateral edentulous with rbone egeneration failure history. A preoperative CBCT is done in order to print a CAD-CAM oclussive barrier for third cuadrant. Oclussive barrier is fixed with titanium screw and filling with particulated autologous bone and platelet Platelet-Rich Plasma (PRP). Follow-up at 5th day, 2nd and 10th week. Five month after surgery, a control CBCT is done and a histomorphometric analisys is done of the regenerated zone. Data suggest that soft tissue and hemorragic material predominated in the sample.

Conclusions: Results in our oclussive barrier case are not satisfactory, but exist literature that support the technique. More studies are neccesary to understand oclussive barrier behaviour.

\section{Oral Presentation 37}

\section{TITLE:- POSSIBLE TREATMENTS OF THE EPULIS FISSURATUM. A CASE REPORT}

Román Quesada N, González Navarro B, López López J. Master of Medicine, Surgery and Oral Implantology. University of Barcelona.

Introduction: A poorly fitted prosthesis can lead to several pathologies like epulis fissuratum, found over the soft tissues along the borders of a denture. It is a fibrous hyperplastic tissue with pseudotumor growth, which requires surgical excision with appropriate prosthetic reconstruction to avoid recurrences. Excision with a surgical scalpel does not require the necessary hemostasis. $\mathrm{CO}_{2}$ laser presents the needed requirements, however, there are other surgical options that also do, such as electro-scalpel, diode laser, etc.

Case Report: A 68-year-old man attended the Odontological Hospital of the University of Barcelona, with a history of hypertension and diabetes mellitus type II, unable to place his full upper prosthesis adjusted for a year and a half. The clinical examination reveals a massive growth of vestibular oral mucosa, with $1 \mathrm{~cm}$ wide folds occupying the entire anterior area of the maxilla. We use the surgical scalpel technique in combination with the electrical scalpel in the areas of greatest bleeding. Subsequently, we sutured a gauze on both sides of the excision to prevent losing vestibular depth. The hyperplastic tissue surgical excision was done following the prosthesis as a guide for the healing of soft tissues.

Conclusions: The electrical scalpel is able to is able to cut, coagulate and desiccate tissues. The $\mathrm{CO}_{2}$ laser is a good option for the removal of fibrous hyperplasia due to multiple intra- and postoperative advantages. However, it should not be viewed as the sole treatment option. The combination as both, surgical and electrical scalpel affords good results. 


\section{Oral Presentation 38}

\section{TITLE:- IMMEDIATE LOADING WITH HYBRID PROS-THESIS ON 4 IMPLANTS FOR TREATMENT OF TOTAL MANDIBULAR EDEN- TULISM. CONCERNING A CLINICAL CASE}

Ruiz de Carlos C, Coello de la Cruz L, Franco Carro B, Santos Marino J, Martínez Rodriguez N, Barona Dorado $C$.

Hospital Virgen de la Paloma in Madrid. Master in Oral Surgery and Implantology.

Introduction: In the last few years, from the point of view of functional load, protocols have been developed that proclaim the early and/or immediate loading of the implants in order to obtain a shorter recovery time and thus favour the psychological well-being of the patients.

Case Report: A 77-year-old male patient went to the Oral Surgery and Implantology Service of the Virgen de la Paloma Hospital in Madrid, showing mandibular edentulism and preserving the upper front sector with a partial posterior prosthesis, with the aim of being rehabilitated at a lower level. The patient had a medical history of type II diabetes under treatment with Metformin. After signing the informed consent and under local anesthesia, 4 mandibular implants were placed in the interforaminal space. Immediately, functional loading was performed by placing a hybrid prosthesis $24 \mathrm{~h}$ after surgery. One week after the surgery and an uncomplicated postoperative period, the suture was removed. There was a favorable annual follow-up.

Conclusions: Immediate loading with hybrid prosthesis on 4 implants in the treatment of the edentulous mandible is a therapeutic option with a high rate of success, so it is a treatment to be considered for total mandibular rehabilitations in geriatric patients.

\section{Oral Presentation 39}

\section{TITLE:- ORAL LEUKOPLAKIA ASSOCIATED WITH TOBACCO, IN RELATION TO A CASE}

Torrejón Moya A, González Navarro B, Rodríguez de Rivera E, Estrugo-Devesa A, Jané-Salas E, LópezLópez $J$.

Master of Medicine, Surgery and Oral Implantology. Faculty of Medicine and Health Sciences - Odontological Hospital University of Barcelona. University of Barcelona.

Introduction: Oral leukoplakia is a potentially malignant lesion common in the oral mucosa. Predominantly white that does not detach from scraping and that cannot be characterized like any other lesion. Classically we talk about idiopathic and associated with tobacco leukoplakia.

Case Report: Male 63 year old patient, with tobacco use (20cig / day) and intake of 5UBE/day.

$\mathrm{He}$ comes in for evaluation of indurated lesion in the floor of the mouth, compatible with leukoplakia. He has a family history of liver cancer of the father, brain tumor, cancer of the larynx, leukemia and oral cancer of the brothers. During oral examination, we observed leucoedema in the buccal mucosa, leukoplakic lesions in the left retro-commissal area, and white lesions in the floor of the mouth. The area of the caruncle the lesion was more warty. In the extraoral examination no adenopathies were palpated. We agreed with the patient to stop the smoking habit and assess the lesions later. After 21 days the patient comes with regression of the lesions of the floor of the mouth, a very discreetly whitish, residual, non-infiltrated area in the right part of the tongue and leukoedema in the left buccal mucosa. After 2 months the patient continues without smoking and during oral examination we observed leukoplakic lesions at the level of the occlusal line in both buccal mucosa, which coincide with acute cusps of the molars and leucoedema in the mucous membranes. We polish sharp cusps and perform inferior vacumm.

Conclusions: Based on the case previously discussed, we can conclude that in this case there is a relationship between oral leukoplakia and tobacco use.

\section{Oral Presentation 40}

\section{TITLE:-ANTICOAGULATED PATIENT IN GE- RODONTOLOGY: CURRENT STATUS}

Merchán Morales S, Ruiz Sáenz PL, Trejo González $S$, Vintanel Moreno CB, Leco Berrocal I, MartínezGonzález, JM.

Máster de Cirugía Oral e Implantología. Hospital Virgen de la Paloma.

Objectives: Revision of the dental treatment protocols in anticoagulated patients and update regarding the new direct-acting anticoagulants (ACODs or NACOs) of last generation.

Material and Methods: A search was made in the PubMed database of articles referring to dental management of anticoagulated patients and the ACODs o NACOs. The search interval was between 2014 and 2019.

Results: We found 28 articles that met the inclusion criteria: two reviews, one consensus document and 37 clinical trials in humans. The ACODs or NACOs (Apixaban, Edoxaban, Rivaroxaban and Dabigatran) are a valid al- 
ternative to dicumarinic vitamin $\mathrm{K}$ antagonists.

Conclusions: The risk of hemorrhage should be stratified (high, medium or low). It is necessary to follow some presurgical, surgical and post-surgical guidelines and evaluate if the surgery is simple, complex or complicated. The risk of thromboembolism is much greater than that of bleeding and complications from thromboembolism are more serious than from bleeding. If the INR is stable, it is enough to monitor it until 72 horas before surgery. If it is unstable, it will be 24 hours before. If it is greater than 4 , we will refer to the hematologist for adjustment. Bleeding is much greater in a patient with double antiagregation (ASA + Clopidogrel).

\section{Oral Presentation 41}

\section{TITLE:- BIPHOSPHONATES VS MONOCLONAL ANTIBODIES, WHAT UNITES THEM AND SEPA- RATES THEM}

Baltasar Corral MV, Rodríguez Martín A, Gómez Mañas P, Frutos Saucedo R, Rodríguez Molinero J, López Sánchez $A$.

Experto en Medicina Oral. Universidad Rey Juan Carlos.

The use of bisphosphonates is considered a widely used therapy for the treatment of patients with osteoporosis, as well as those suffering from bone metastases derived from cancer. Currently, new antiresorptive drugs that inhibit osteoclasts (monoclonal antibodies such as denosumab) have been introduced. The appearance of bone lesions associated with this type of drugs has modified the nomenclature of the same, suggesting the term Osteonecrosis of the jaws associated to medicaments (OJAM). Objectives: To compare the differences between bisphosphonates and denosumab in order to establish prevention strategies for the development of OJAM.

Material and Methods: A literature review of scientific articles consulted in the data bases TESEO, IME; PUBMED; MEDLINE and COCHRANE LIBRARY, published in the last 10 years, is carried out. Key words consulted: Bisphosphonates, osteoporosis, denosumab, osteonecrosis of the jaws.

Results: Although both bisphosphonates and denosumab inhibit the formation of osteoclasts, their mechanism of action and half-life are totally different, which may be helpful to know the best way to act in case of performing risky dental treatments and prevent the appearance of OJAM.

Conclusions: Despite the development of new drugs such as denosumab, the possible appearance of OJAM has not been avoided. Despite this, the pharmacological characteristics of them make the management of complications more favorable.

\section{Oral Presentation 42}

\section{TITLE:- THE "ALL-ON-4" CONCEPT. QUALITY OF LIFE IN EDENTULISM OLD-AGE PATIENTS}

Blanco Ruiz S, Sanchez-Labrador L, Pérez González F,
Melero Alarcón C, Rubio Alonso LJ, Meniz, García C.
Master degree in oral surgery. Complutense University Madrid.

A 20 per cent of the population is older than 65 years old and it is expected that it speed-up to a $30 \%$ in a near future, owing to life expectancy is increasing. The advances in implantology and the concept of all on-4 allow to solve the maxillary atrophy linked to the elderly patient who suffer from edentulism and establish a fixed prostodontic solution unseating other removable prosthetic solutions and restoring comfort and masticatory capacity at low cost.

Objectives: This bibliographic review aims to evaluate the success rate of "all-on-4" and compares it with the different therapeutic alternatives

Material and Methods: A search of scientific literature has been carried out in Pubmed, Embase, Cochrane

Results: The "all-on-4" technique shows success rates of $98 \%$ at 5 years. In addition, it allows the patient to return the masticatory capacity prior to tooth loss and a better quality of life compared to the different alternative treatments to the "all-on-4" technique by means of removable appliances. Conclusions: The concept of "all-on-4" is a valid option for the treatment of maxillary atrophy in elderly patients because it shows success rates comparable to conventional implantology without having to performance guided bone surgeries. Moreover, it let the patient save time and money.

\section{Oral Presentation 43}

\section{TITLE:- ORAL MANIFESTATIONS AND DEN- TAL MANAGEMENT OF GIANT CELL AR-TE- RITIS}

Cadenas Vacas G, de la Rosa García A, Izquierdo Orts R, Cascos Sánchez R, Rubio Alonso LJ, Martín Ares M. Máster en Cirugía Bucal e Implantología. Universidad Complutense de Madrid.

Objectives: The aim of the present study is to know the different oral manifestations of giant cell arteritis, as well as the medical and surgical management of these patients. Material and Methods: A literature search was performed in PubMed, The Cochrane Library, EBSCO and EMBASE databases with the following keywords: "giant cell arteritis", "temporal arteritis", "oral symptoms", 
“oral manifestations", "orofacial manifestations", “dental management", "corticosteroids".

Results: Giant cell arteritis can affect the oral cavity producing odontogenic pain, tongue necrosis, lip necrosis, jaw claudication, hypoesthesia of the chin, facial swelling and trismus. For the dental treatment it is necessary to consult with the endocrinologist to assess the need for steroid supplementation. In dental treatments that do not involve surgery or in minor surgeries steroid supplementation will not be necessary taking the usual dose two hours before the intervention. It will be necessary to perform steroid supplementation in major surgeries and treatments lasting more than one hour. Short morning appointments are recommended, evaluating the medication with benzodiazepines or nitrous oxide to reduce intraoperative stress. Odontological treatment should not be performed in patients with uncontrolled adrenal insufficiency.

Conclusions: The knowledge of the oral manifestations of giant cell arteritis can help in the diagnosis of this disease. An adequate dental management will allow to avoid complications such as the development of an adrenal crisis.

\section{Oral Presentation 44}

\section{TITLE:- TREATMENT WITH BOTULINUM TOXIN TYPE A FOR SIALORRHEA IN THE ELDERLY PATIENT WITH SPECIAL NEEDS}

Cárcamo España VS, Martín Gili D, Olmo González B, Gil Manich V, Ribera Uribe JM.

Gerodontology and Medically Compromised Patients Department. Universitat Internacional de Catalunya. Barcelona.

Objectives: Sialorrhea is a disabling complication of the elderly, that affects their quality of life and social interaction. The objective of this review is to describe the efficacy and toxicity of botulinum toxin type A as a treatment for sialorrhea in the elderly patients with special needs.

Material and Methods: A bibliographic review and analysis was carried out in Pubmed and EBSCO databases between 2000 and 2018. The keywords used were: "sialorrhea", "botulinum toxin", "botulinum toxin type A" and "disabled people".

Results: 18 studies were included. The dose administered was heterogeneous, from $7,5 \mathrm{U}$ to $200 \mathrm{U}$. In $50 \%$ of the studies, only the parotid gland was injected, and the duration of the effect was from 4 to 24 days. The most prevalent disease in the published cases was Parkinson's with $48,2 \%$. In all the studies, decrease of salivary flow was reported, where $50 \%$ of the studies verified, referred adverse effects, the most prevalent being the dysphagia, xerostomia and pain at the puncture site.

Conclusions: The bibliography consulted would deter- minate that the use of botulinum toxin to treat the sialorrhea turns out to be effective, safe and is able to improve the quality of life, since the patients didn't present major adverse effects. It's convenient to perform new tests to improve the prognosis in those patients who maintained the frequency of drooling despite the decrease in severity after the injection of the toxin.

\section{Oral Presentation 45}

\section{TITLE:- INFLUENCE OF STATINS ON OSSEO- INTEGRATION: LITERATURE REVIEW}

Cascos Sánchez R, Baca González L, Palacio García Ochoa A, De la Rosa García A, Meniz García CM, Saiz Carrasco $S$.

Título propio "Cirugía Bucal e Implantología". Facultad de Odontología. Universidad Complutense de Madrid.

Objectives: The objective of this literature review was to analyze the effects of statins on the osseointegration of dental implants.

Material and Methods: An electronic literature search for in vitro, animal model studies and clinical trials was conducted using Pubmed and Scopus databases for articles in English. Articles published between January 2004 and January 2019 were selected. Letters to the editor, case reports, case series and commentaries were excluded. The integrated search was made with the following key terms: osseointegration, statins, hyperlipidemia, simvastatin and dental implants.

Results: Ten studies were included. All studies were experimental, eight performed in animal models and two in cell culture. The follow-up duration range between four days and twelve weeks. Results from all studies showed that statin administration enhanced new bone formation around implants.

Conclusions: In vitro and animal model studies suggest a positive effect of statins on increasing osteogenesis and osseointegration around dental implants.

\section{Oral Presentation 45B}

\section{TITLE:- DIABETES AND PERIODONTITIS IN THE ELDERLY}

Suarez M, Durán J, Martín C, Somacarrera ML. Department of Dentistry. Faculty of Health Sciences. Universidad Europea de Madrid.

Diabetes is a set of metabolic diseases, characterized by hyperglycemia that can be caused by a defect in the se- 
cretion of insulin, a defect in the use of insulin or a mixed problem.

Objectives: In this literature review that we are going to carry out, we intend to know the current periodontal state of elderly diabetic patients, their treatment needs and the most common complications in the dental office.

Material and Methods: A literature review is performed by searching the PubMed/MEDLINE and Cochrane databases for the last 10 years, using the keywords diabetes, periodontitis, periodontal disease, elderly patient.

Results: There are many studies on the relationship between diabetes and periodontal situation. Patients over 65 years are a risk group due to both age and poorly controlled or undiagnosed endocrine pathology. The prevalence of periodontal pathology in elderly diabetic patients is very high. The severity of periodontitis is aggravated in poorly controlled diabetic patients. A bad periodontal situation also influences poor blood glucose control.

Conclusions: The bidirectional relationship between both processes is established in the different studies reviewed. Good control of diabetes improves the periodontal situation and good periodontal control will improve the endocrine situation of these patients.

\section{Oral Presentation 46}

\section{TITLE:- THE STATINS AS A COADYUVANT TREATMENT IN BONE REGENERATION AND PERIODONTAL DISEASE}

Cruz Carrera J, Enríquez Garcés DA, Arriola Riesta I, De Dios Cano J, Fernández Cáliz F, Buesa Bárez JM. Master en Cirugía Bucal e Implantología. Hospital Virgen de la Paloma. Madrid.

Objectives: Evaluate how statin treatment works in bone metabolism and periodontal disease in the elderly.

Material and Methods: A literature review was made in Medline database using the keywords "statins", "periodontal disease" and "bone regeneration", following these inclusion criteria: - Articles written in English and Spanish - Publications between 2013 and 2018 - Studies related to the oral cavity

Results: 137 articles were found, of which 98 were discarded for not meeting the inclusion criteria, selecting a total of 39 .

Conclusions: The statins or HMG-CoA reductase inhibitors are lipid-lowering drugs. They are used because they block the enzyme needed for cholesterol synthesis. They can produce an inhibition of bone resorption and bone formation. The studies analyzed suggest that the use of statins is effective in the treatment of periodontal disease and bone regeneration. Due to the limited number of pub- lications on human trials and their short duration, more studies and more follow-up would be necessary

\section{Oral Presentation 47}

\section{TITLE:- NON-INVASIVE METHODS FOR THE DIAGNOSIS OF ORAL CANCER AND PRECAN- CER. BIBLIOGRAPHICAL REVIEW}

\section{Egido Moreno S, Estrugo Devesa A, González Navarro B, Roselló Llabrés X, Jané Salas E, López López J. Master of Medicine, Surgery and Oral Implantology. Faculty of Medicine and Health Sciences - Odontological Hospital Univer- sity of Barcelona. University of Barcelona.}

Objectives: Achieve a bibliographical review of the less invasive methods that present a high sensibility and specificity for the early detection of oral cancer and precancer. Material and Methods: A bibliographical review of the last 5 years was undertaken in the Medline/Pubmed database about the early diagnosis of oral cancer and precancer, where there was mention of the use of methods such as: vital dies, chelators, quimiofluorescence, autofluorescence and cytological studies.

Results: Despite the many different methods for the diagnosis of oral cancer, the biopsy still is the most efficient procedure. The use of these techniques has its value in programs of screening in susceptible populations.

Conclusions: The biopsy still is up to date the best method for the early diagnosis of cancerous and precancerous lesions in any stage. The use of non-invasive methods can provide with a sensation of a false security. These noninvasive methods must attain a complementary status for diagnosis, and in the case of a positive result they will demand us to undertake more invasive tests.

\section{Oral Presentation 48}

TITLE:- TRANSDENTAL IMPLANTS AS AN ALTERNATIVE TO THE SURGICAL TREATMENT OF IMPACTED TEETH. A LITERATURE REVIEW

Enríquez Garcés DA, Marcos Santos A, Arriola Riesta I, De Dios Cano J, Fernández Cáliz F, Barona Dorado C. Master in Oral Surgery and Implantology. Virgen de la Paloma Hospital. Madrid.

Objectives: Present the current evidence about "transdental" implants as an alternative to the surgical treatment of impacted teeth.

Material and Methods: A literature review was per- 
formed using the databases Medline and Cochrane and the terms: "dental implants", "impacted teeth". Articles chosen were related with the placement of implants in contact with impacted teeth and published since 2012 in English or Spanish languages.

Results: Articles founded include one article with favorable results that contains 10 case reports of implants placed invading the radicular or coronal portion of impacted canines, those cases where followed up from 1 to 8 years. There was also literature of implants placed in contact with residual roots in order to avoid their extraction; and articles studying the relation between the dental tissues, distinct from bone, and the implant.

Conclusions: Transdental implants are nowadays an unconventional treatment with low evidence. They are a less invasive alternative than the usual treatment of these kind of patients where the extraction of the impacted teeth is performed followed by the bone regeneration of the resulting defect. More trials are needed in order to stablish this treatment as a valid alternative.

\section{Oral Presentation 49}

\section{TITLE:- ARE MINI IMPLANTS A GOOD ALTERNATIVE TOCONVENTIONAL IMPLANTS IN CASES OF LARGE BONE RESORPTION? BIBLIOGRAPHIC REVIEW}

\section{Espiga Pacheco J, Rodriguez Crespo P, Franco Car- ro B, Santos Marino J, Martínez Rodríguez N, Buesa Bárez JM. \\ Virgen de la Paloma Hospital.}

Objectives: To evaluate the survival rate and complications associated with mini implants as an alternative to conventional implants in patients with bone atrophy.

Material and Methods: A bibliographic literature review was carried out between 2015 and 2019 in the Cochrane and Pubmed databases with the following keywords: "Narrow dental implant", "Crestal bone loss", "Mini-Implant" and " Overdenture.

Results: The percentage of survival of mini-implants of diameter 3.3 and $3.4 \mathrm{~mm}$ at 3 years is $97.8 \%$ with resorbations of the marginal ridge of $0.5 \mathrm{~mm}$ on average. However, those narrower mini implants, diameters of 3 and $3.25 \mathrm{~mm}$ ) had a statistically lower survival rate of $94.7 \%$. The main associated complications are peri-implantitis and prosthetic problems.

Conclusions: The simplicity of the technique required for the placement of the mini implants, dispensing with the need to open a flap, together with the high survival rates published in the literature, make the mini implants an alternative especially indicated for geriatric patients.

\section{Oral Presentation 50}

\section{TITLE:- LICHEN PLANUS ORAL AND CARDIO- VASCULAR DISEASES}

\section{García Pérez A, González Navarro B, Polis Yanes C, Estrugo Devesa A, Jané Salas E, López López J. Máster de Medicina, Cirugía e Implantología Oral. Facultad de Medicina y Ciencias de la Salud - Hospital Odontológico de Bell- vitge. Universidad de Barcelona.}

Objectives: Oral lichen planus is an inflammatory mucocutaneous disease that affects $1-4 \%$ of the population. It has recently been associated with a higher incidence of cardiovascular diseases. Since it is believed that exist a dependence between the chronic inflammation and the appearance of risk factors in cardiovascular diseases, the aim of this review is to study wether it exists or not a relationship between the oral lichen planus and cardiovascular diseases.

Material and Methods: A search in PubMed is made with the terms "cardiovascular diseases" and "lichen planus oral". The search criterias are focused in english and spanish research articles, dismissing the articles not based in humans.

Results: Having done the research, a total of 32 articles are obtained. After reviewing the articles, 15 were rejected because the subjects are not related with this review. The review is focused in 17 articles in total. As it has been demonstrated, oral lichen planus and cardiovascular diseases have a high inflammatory component, elevating the systemic reaction of inflammation. The relationship between the oral lichen planus and cardiovascular diseases rely on various factors such as the state of the oral mucosa or the type of cardiovascular diseases of the patients.

Conclusions: It seems that exist a relationship between the oral lichen planus and the cardiovascular diseases. Therefore it is a subject that should be investigated in order to know better the type of vincle that exist between them.

\section{Oral Presentation 51}

TITLE:- OSTEONECROSIS OF THE JAWS NOT RELATED TO BISPHOSPHONATES. BIBLIOGRAPHIC REVIEW

Iglesias Rodeiro E, Cruz Carrera J, Arriola Riesta I, De Dios Cano J, Fernández Cáliz F, Buesa Bárez JM. Master in Oral Surgery and Implantology. Hospital Virgen de la Paloma. Madrid. 
Objectives: To study the drugs most recently related to the appearance of Osteonecrosis of the jaws (ONJ) as an adverse effect and the most current protocols for the management of patients under treatment with them.

Material and Methods: A bibliographic review of scientific articles has been carried out by means of manual search, consulting the MedLine and The Cochrane Library Plus databases, without restriction of date, in the Spanish, English, Chinese and German languages. No restrictions have been made regarding the type of study. Results: The electronic search identified a total of 40 scientific articles, whose results have allowed to determine that there are drugs beyond the group of bisphosphonates, such as Denosumab and Sunitinib, with multiple therapeutic utilities in the treatment of osteoporosis and various tumor lesions, which can generate the appearance of ONJ as an adverse effect. The protocol for the management of patients under treatment with this type of medication will depend on the type of medication administered and the period of time it is administered, as well as the presence or absence of lesions associated with ONJ in any of its stages.

Conclusions: Treatment with drugs such as monoclonal antibodies and inhibitors of the enzyme tyrosine kinase, either alone or in combination with bisphosphonates, has shown the appearance of ONJ as an adverse effect.

\section{Oral Presentation 52}

\section{TITLE:- TEACHING ORAL HYGIENE IN THE ELDERLY PATIENT WITH COGNITIVE IM- PAIRMENT}

Larrosa Henríquez N. Gil Manich V. Ribera Uribe M. Martín Gili D. Olmo González B.

Área Gerodontología, Pacientes Especiales y con Compromiso

Médico. Universitat Internacional de Catalunya. Barcelona.

Objectives: To determine oral hygiene techniques and guidelines for elderly patients, caregivers and family members of patients. Define the best way to proceed according to the degree of cognitive impairment and collaboration.

Material and Methods: A bibliographic review was made in the PubMed database with the MeshTerms: "Cognitive Dysfunction", "Oral hygiene", "Dentistry".

Results: The evidence indicates that training patients, relatives, and caregivers in oral hygiene increases the quality of the care provided to this type of patients. The techniques described for routine brushing, the use of antimicrobial and fluorinated agents, verbal and nonverbal communication and handling techniques, the use of separators or utensils that interrupt reflex acts such as biting, are useful in patients with low degrees of collaboration. Both the patient and the family members should be instructed in oral hygiene and, in the case of fully dependent patients, we must make the family member or caregiver responsible for oral care.

Conclusions: The rational use of the different techniques described together with adequate management of the patient facilitates care in oral hygiene and therefore is an important measure of prevention of the usual problems that usually present patients with cognitive impairment such as gingivitis, periodontitis, edentulism, root caries, etc. The person responsible for oral care and hygiene in totally dependent elderly patients will be the caregiver or relative who takes charge.

\section{Oral Presentation 53}

\section{TITLE:- DOWN SYNDROME; INCREASE IN LIFE EXPECTANCY, PREMATURE AGING AND IMPLICATIONS IN DENTAL TREATMENT}

\section{López Castaño F, Martín Gili D, Palanques Girbau M, Gil Manich V, Olmo González B, Ribera Uribe JM. Residencia Clínica de Gerodontología, Pacientes Especiales y con Compromiso Médico. Universitat Internacional de Catalunya.}

Objectives: Description of changes in elderly Down Syndrome patients and the implications in dental treatment. Material and Methods: Bibliographic review in Pubmed from 1998 to 2018. The key words used were: Down syndrome, mental retardation, general anaesthesia, dental treatment, intellectual disabilities, cognitive impairment and adult.

Results: Despite most scientific literature focuses in patients under 40 years old, life expectancy of Down Syndrome patients have increased considerably in the last decades and it is nowadays 60 years old. After this increase in their life expectancy, a premature aging has been observed in Down Syndrome patients, with cognitive-behavioural changes and a higher prevalence of systemic pathologies that appear around 20 years earlier than in the general population. All these changes, as well as the bucal pathology inherent in the Down Syndrome, make considerably more difficult to carry out dental treatment in a conventional way and general anaesthesia may be required.

Conclusions: Down Syndrome patients are well studied as paediatric patients but not so well as adults. This population is medically compromised and with fast cognitive worsening. It demands new therapeutical approaches as its life expectancy has increased. All these changes, that can condition the dental treatment plan, are a new challenge for the dental professionals. 


\section{Oral Presentation 54}

\section{TITLE:- MANAGEMENT OPTIONS FOR LOW- DOSE METHO TREXATE-INDUCED ORAL ULCERS: A SYSTEMATIC REVIEW}

\begin{abstract}
Menéndez Valdés CB, Chamorro Petornacci CM, Otero Rey E, Gándara Vila P, García García A, Blanco Carrión $A$.

Oral Medicine, Oral Surgery and Implantology Unit. Faculty of Medicine and Dentistry, University of Santiago de Compostela.
\end{abstract}

Objectives: Review and analyse the information from articles related to oral ulcers produced by low-dose MTX and to record the clinical management performed and the MTX dose given to the patient.

Material and Methods: An initial search was carried out in the aforementioned databases with the terms 'methotrexate AND oral OR ulcer'. The search was carried out using both medical subject heading (MeSH) terms and a free search between January 2003 and January 2018. Of the results obtained, two indepen $\neg$ dent researchers analysed abstracts that met the search criteria. Next, both researchers read the complete article and determined whether it met the following inclusion criteria. A third investigator acted as a mediator in cases of dispute. Agreement was calculated using Cohen's kappa coefficient, with a $\mathrm{k}$ value of 0.82 . The Preferred Reporting Items for Systematic Reviews and Meta- Analyses (PRISMA) guide for systematic reviews was used.

Results: The initial search resulted in a total of 66 articles, of which 30 were selected to assess their inclusion in this study. Finally, 16 met the inclusion criteria.

Conclusions: Evidence on the management of oral ulcers in the oral cavity produced by MTX at low doses is scarce due to the heterogeneity of data. Therefore, it seems that this management is relegated to the perception of the clinician rather than to a specific pro $\neg$ tocol of action. Studies with a longer follow-up duration and larger sample size are needed.

\section{Oral Presentation 55}

\section{TITLE:- PAROTID SIALOLITHIASIS. A CLINI- CAL CASE}

Trejo González S, Merchán Morales S, Ruiz Sáenz PL, González Regueiro I, Martínez Rodríguez N, MartínezGonzález JM.

Facultad de Odontología. Universidad Complutense de Madrid.

Introduction: Sialolithiasis is a pathology of the salivary glands characterized by the formation of stones or sialo- liths, which cause a mechanical obstruction of the gland or his duct. The development is slow and asymptomatic, usually taking periods of pain and inflammation. It represents $60 \%$ of non-neoplastic pathologies, most of which are found in submandibular gland.

Case Report: A 70-year-old woman with acute inflammation and pain in the left face region. She suffers celiac disease, hypothyroidism and hypercholesterolemia, all of them controlled. She reports that she was diagnosed with sialolithiasis 5 years ago, presenting periods of exacerbation to date. The patient was treated by several specialists in two hospitals in Madrid, in which she was treated to lithotripsy and S. Sjögren was discarded. When we performed the examination, inflammation was absent. The jugal mucosa adjacent to the Stenon duct presents a slight reddening. In the initial palpation, we did not find calculus in the surrounding left parotid gland area. In the requested A.C.T., radiological anomalies were not found, nor in the requests for study of the 3D image, was shown a proximal calculus in Stenon duct. We recommend BuscapinaoR 3t/ daily, and drinking 2-3L/daily of low mineralization water. Two months later, she presented a new colic with suppuration and distal palpation of the sialolith, so we prescribed Amoxicillin $750 \mathrm{mg}$ plus the previous treatment.

Conclusions: The diagnosis by $3 \mathrm{D}$ image turned out to be enlightening. The treatment with antispasmodic drugs and abundant hydration seems to favor the expulsion of the sialolith.

\section{Oral Presentation 56}

\section{TITLE:- ELEVATION OF DEEP MARGIN (DME) VS CORONARY LENGTHENING (LC). REVIEW OF THE LITERATURE}

\author{
Net Samon C, Gil Manich V, Olmo González B, Martín \\ Gili D, Ribera Uribe JM. \\ Residencia Clínica de Gerodontología, Pacientes Especiales y \\ con Compromiso Médico.Universitat Internacional de Catalu- \\ nya. Barcelona.
}

Objectives: The objective of this review is to determine whether the use of both techniques would allow us to maintain more teeth in old age and describe in which case the technique of deep margin elevation and crown lengthening would be indicated.

Material and Methods: A bibliographic search was carried out in the Pubmed database between 1998 and 2018. The following keywords were used: "Deep margin elevation", "proximal box elevation", "clinical crown lengthening", "biological width" and "Dental restoration".

Results: Currently the restoration of endodontics is a challenge for the dentist not only because of the exces- 
sive loss of dental tissue but also due to the invasion of the biological width. According to the literature, we can find 7 most common scenarios in which to perform management of the margin of the cavity, assessing the need for the elevation of the deep margin or lengthening of the crown. Maintaining the proper biological width is a complication in this type of restoration, in the case of not being able to maintain the correct biological width, the treatment of choice will be crown lengthening.

Conclusions: More studies should be done to achieve a level of evidence in this field. We can conclude that both techniques will allow us to keep more teeth in the oral cavity when we reach old age. The type of technique used will depend on the amount of remaining tooth structure. Whenever we can use a matrix that allows us to raise the wall increasing the margin, we can use a deep margin elevation, when we have an invasion of connective tissue or bone crest, we will use a crown lengthening.

\section{Oral Presentation 57}

\section{TITLE:-PULPOTOMY IN PERMANENT EL- DERLY TOOTH}

Orellana Mendoza KM, Olmo González B, Gil Manich V, Martin Gili D, Ribera Uribe M.

Universitat Internacional de Catalunya. Barcelona Gerodontology and Medically Compromised Patients Department.

Objectives: Description of the pulpotomy treatment with different dressings in permanent elderly teeth with irreversible pulpitis. Establishment of clinical and radiographic results with NEC (Novel Endodontic Cement), CEM (Calcium Enriched Mixture), MTA (Mineral Trioxide Aggregate), Biodentine and Calcium Hydroxide.

Material and Methods: A bibliographical review was carried out on literature available in PubMed from 2007 to 2018. The key words searched were: pulpotomy, pulpitis, mineral trioxide aggregate, calcium enriched mixture and calcium hydroxide.

Results: NEC (Novel Endodontic Cement), is biocompatible, it promotes the natural processes of reparative dentine formation, it is hydrophilic, it is a good sealant and it reduces working time. MTA (Mineral Trioxide Aggregate), is a good sealant, it is biocompatible and it stimulates pulp cells. CEM (Calcium Enriched Mixture), is able to form hydroxyapatite and dentine-like tissue, it is non toxic, it has antibacterial properties similar to Calcium Hydroxide and greater than (MTA), it reduces working time and it is biocompatible. BIODENTINE is biocompatible, it replaces dentine, it can repair perforations, it has a fast setting time and it is easy to use. CALCIUM HYDROXIDE is bactericide and it promotes dentine remineralisation.
Conclusions: Pulpotomy is a treatment option in permanent elderly teeth with irreversible pulpitis

\section{Oral Presentation 58}

\section{TITLE:- GINGIVAL METASTASIS MIMICKING A BENIGN EXOPHYTIC LESION AS THE FIRST MANIFESTATION OF OCCULT ADENO- CARCINOMA OF THE LUNG. CASE REPORT AND SYSTEMATIC REVIEW}

Piñeiro Donís S, Gándara Vila P, Suárez Peñaranda JM, Pérez-Sayáns García M, García García A, Blanco Carrión $A$.

Oral Medicine, Oral Surgery and Implantology Unit, Faculty of Medicine and Odontology, University of Santiago de Compostela, Santiago de Compostela, Spain.

Objectives: To update the diagnosis and management of oral metastasis being the first clinical manifestation of the tumor and review all the cases published to date, providing a new original clinical case with very specific histopathological characteristics.

Material and Methods: We systematically reviewed the literature in order to find all the cases of primary lung tumors that appeared with a gingival metastasis as the first manifestation.

Results: The search process involved a total of 438 articles, of which 424 were excluded because they were not articles based on cases of primary lung tumors that appeared with a gingival metastasis as the first manifestation. After reading the latter, 13 met (one of them with two different cases) the inclusion criteria.

Conclusions: We present a lung adenocarcinoma that first manifested as a metastasis in the gum, simulating a benign lesion. The unusually high growth rate should conduct to have other diagnostic possibilities, and histopathological confirmation is essential.

\section{Oral Presentation 59}

\section{TITLE:-RELATIONSHIP BETWEEN PERIO- DONTITIS AND ALZHEIMER DISEASE}

\section{Rodríguez Crespo P, Iglesias Rodeiro E, Franco Carro B, Santos Marino J, Fernández Cáliz F, Buesa Bárez JM. Hospital Virgen de la Paloma.}

Objectives: Study the relationship between periodontal disease and Alzheimer in the elderly.

Material and Methods: A search of articles was carried out in PubMed / MEDLINE bibliographic database and 
manually in scientific journals through the internet. Articles of less than or equal to 5 years were selected in English and Spanish.

Results: 24 articles were included, of which twelve correspond to systematic reviews, ten to research works and two to meta-analytic studies.

Conclusions: Periodontitis shows a higher prevalence in patients with Alzheimer's disease than in healthy patients, in the same way that there seems to be an association between the presence of periodontal disease and an increased risk of Alzheimer.

\section{Oral Presentation 60}

\section{TITLE:- PREVENTION AND TREATMENT OF ACTINIC CHEILITIS}

Rossit M, Prió Torres L, Molina Garcia C, Ruisánchez del Sol A, Donadios Sánchez, R, Ribera Uribe JM.

Universidad Internacional de Catalunya.

Objectives: Describe and compare different prevention and treatment options for Actinic Cheilitis (AC) with a specific focus on the geriatric population, in which the pathology presents a higher prevalence.

Material and Methods: A search was conducted through Medline (search string: "Actinic"[tiab] AND "Cheilitis/drug therapy"[Mesh] OR "Cheilitis/prevention and control"[Mesh] OR “Cheilitis/rehabilitation"[Mesh] OR "Cheilitis/surgery"[Mesh] OR "Cheilitis/thera-py"[Mesh]) and Cochrane Library (describer: "Cheili-tis"[mh:noexp]) as primary databases. Abstracts (published after 2008) were screened for suitability, and full-text articles were obtained for those complying the inclusion and exclusion criteria.

Results: Applying the search parameters, 113 articles were retrieved, 35 of these were eligible. In the studies various surgical techniques are proposed as therapeutic interventions (vermilionectomy): cold scalpel, laser ( $\mathrm{CO}_{2}$, Er:YAG, Thulium), cryosurgery, electrodesiccation with curettage and dermabrasion. Non-surgical alternatives are: photodynamic therapy (PDT), 5-fluorouracil, imiquimod 5\%, diclofenac 3\%, trichloroacetic acid (TCA), ingenol mebutate, topical retinoids, topical corticosteroids, follow-up with intense local photoprotection. Conclusions: Significant differences were undetectable supporting the efficacy of the different therapies to treat $\mathrm{AC}$, though each one has its own advantages and disadvantages. Traditional vermilionectomy is considered the treatment of choice of AC because only scalpel intervention allows the histopathological examination of all the tissue extirpated. Non-surgical therapies on the other hand are less invasive and have fewer secondary effects than surgical therapies. It is fundamental to conduct a detailed analysis of every specific case to decide the most effective treatment. Prevention is the most effective measure toward UV light damage.

\section{Oral Presentation 61}

\section{TITLE:-IMPLICATIONS OF DEPRESSION IN THE STATE OF ORAL HEALTH}

Ruiz Sáenz PL, Merchán Morales S, González Regueiro I, Trejo González, S, Vintanel Moreno CB, MartínezGonzález JM.

Hospital Virgen de la Paloma. Master de Cirugía bucal e Implantología. Madrid.

Objectives: Evaluate the effect of depression on the perception of oral health and quality of life, in a group of older adults, who are institutionalized or not, comparing different studies

Material and Methods: Bibliographic review comparing various methods to measure depression and assess its influence on the quality of life and oral care of these patients. We value different variables and sociodemographic contexts.

Results: These subjects have a negative perception of their oral and general health that leads to a worsening of their quality of life. Those who are outside nursing homes have a more positive perception of their quality of life and oral health than those who live in them, being in all cases more negative for those who have depression. Conclusions: The global aging of the population and the natural phenomena that accompany it make the elderly a high-risk group to suffer from depression. In our environment, the results show a higher frequency than expected, so it is necessary to take actions to reduce its presentation as much as possible, act on the risk factors that can be modified and inform our medical community about the findings of this study. Therefore, that surveillance is increased and risks avoided in these people.

\section{Oral Presentation 62}

\section{TITLE:- SOCKET-SHIELD. CLINICAL PROTO- COL AND CURRENT EVIDENCE}

Sáez Alcaide LM, Molinero Mourelle P, FernándezGonzález-Tresguerres F, San Hipólito Marín L, Rubio Alonso L, Hernández Oliveira $M$.

Oral Surgery and Implant Dentistry Program. Faculty of Dentistry. Complutense University of Madrid. 
Objectives: The objective is to update the current clinical protocol of the Socket-Shield technique and evaluate the scientific evidence that supports this technique.

Material and Methods: A bibliographic search was carried out in electronic databases to analyze the current evidence available on the Socket-Shield technique.

Results: This technique has demonstrated the preservation of the alveolar bone by maintaining the bundle-bone, being an alternative to other alveolar preservation techniques. However, a high rate of associated complications has been described so further studies are needed.

Conclusions: Socket-shield is today an experimental technique with promising results but with limited scientific evidence.

\section{Oral Presentation 63}

\section{TITLE:- SINUS LIFT AUGMENTATION WITHOUT GRAFT}

Sánchez-Labrador L, Blanco Ruiz S, Melero Alarcón C, Chavesta Rivadeneyra P, Saiz Carrasco S, Madrigal Martínez-Pereda $C$.

Oral Surgery and Implants Degree UCM.

Sinus lift augmentation with bone graft can be considered an unpredictable technique, with a resorption rate of 49,5\% after 6 months of healing. Therefore, sinus lift augmentation without graft was described, as an alternative with minimal surgical trauma, infection risk and complications related with the grafting material.

Objectives: To explain advantages and mean bone gain with this technique.

Material and Methods: Collect database from Pubmed with this keywords: "minimally invasive sinus augmentation", "sinus lift without graft", "sinus lift".

Results: Mean bone gain obtained varies among 1.5-6.5 $\mathrm{mm}$, and survival rate of dental implants is similar to other techniques, having less general complications.

Conclusions: Sinus lift augmentation without graft is a predictable technique when a correct case planification is done.

\section{Oral Presentation 64}

\section{TITLE:- NITROUS OXIDE TOXICITY}

Torrubia Espuch I, Gil Manich V, Olmo González B, Martín Gili D, Ribera Uribe M.

Área Gerodontología, pacientes especiales y con compromiso médico. Universitat Internacional de Catalunya. Barcelona.
Objectives: Undertake a bibliographic review to determine if the use of nitrous oxide in dental practice entails some type of risk for the patient.

Material and Methods: An electronic search was performed in the Medline-Pubmed database and in the digital library of the Universitat Internacional de Catalunya (UIC), articles published between 2008 and 2018 were chosen. The following keywords were used: Nitrous Oxide, nitrous oxide and dentistry, nitroux oxide and toxicit Results: Nitrous oxide presents toxicity at hematological and neurological level. At the hematological level, cases have been reported in which it has been seen that it can lead to a deficit of vitamin B12, triggering a pernicious anemia. At the neurological level, it could have detrimental effects on NDMA receptor antagonists, enzyme inhibition and cerebrovascular alterations. However, despite the toxicity of $\mathrm{N} 2 \mathrm{O}$, it has been reported in the literature that the therapeutic range has a large margin of safety and appears as a safe sedative agent.

Conclusions: Nitrous oxide sedation used in therapeutic ranges has a large safety margin and does not entail adverse effects for the patient's health.

\section{Oral Presentation 65}

\section{TITLE:- DOWN SYNDROME IN THE PATIENT OLDERTHAN55YEARS:MEDICALCONDITIONS AND IMPLICATIONS IN DENTISTRY}

\section{Vener Ni, Campioli E, Martin C, Somacarrera ML.}

Departamento de Odontología. Facultad de Ciencias de la Salud. Universidad Europea de Madrid.

Introduction: In recent years, the life expectancy of people with Down Syndrome (DS) has increased considerably. It is therefore not surprising that the need for dental care by older patients with DS should experience growth in the future. In the elderly patient affected by this condition a whole series of specific 'problems' converge, some of them independent of age and others specifically linked to aging.

Objectives: To describe the pathological conditions associated with aging in people with DS with special attention to oral implications, identify their consequences at the level of dental care and provide data on the prevalence of adults over 50 with DS in Spain.

Material and Methods: The bibliographical research was carried out through a search in PubMed, as well as in documentation centers specialized in development anomalies.

Results: In Spain, $13.5 \%$ of the population with DS is over 50 years old and the bibliography suggests that, under the special conditions that characterize their con- 
dition at any age (congenital heart disease, sensory alterations, hypothyroidism, obstructive apnea), add others explicitly linked to aging, such as a strong propensity to develop early dementia and a progressive decrease of $\operatorname{Ig} \mathrm{A}$ immunoglobulins in saliva.

Conclusions: The elderly patient with DS is particularly vulnerable and prone to the development of infections of the oral cavity. In addition, due to the risk factors associated with their condition and the early development of dementias, their treatment requires special measures that allow the patient to be treated effectively and maintain the best possible levels of health. 
XIX NATIONAL CONGRESS - VIII INTERNATIONAL SPANISH SOCIETY OF GERODONTOLOGY CIUDAD REAL, SPAIN 16-18 MAY OF 2019 
XIX CONGRESO NACIONAL - VIII INTERNACIONAL SEGER CIUDAD REAL 16-18 MAYO DE 2019

\section{POSTERS}


XIX NATIONAL CONGRESS - VIII INTERNATIONAL SPANISH SOCIETY OF GERODONTOLOGY CIUDAD REAL, SPAIN 16-18 MAY OF 2019 


\section{- Poster 1}

TITLE:- DESCRIPTIVE STUDY ABOUT ORAL PATHOLOGY IN PATIENTS WITH CARDIOVASCULAR DISEASE

González Navarro B, Pintó Sala X, Rodríguez Sánchez MA, Jané Salas E, López López J.

Oral Medicine, Oral Surgery and Implantology Master. Medicine Faculty - Odontologic Hospital of Bellvitge. University of Barcelona. Vascular Risk Unity, Internal Medicine Department, Universitary Hospital of Bellvitge-IDIBELL.

Introduction: Cardiovascular disease is the leading cause of death in developed countries. The relationship between inflammatory pathologies and cardiovascular diseases has been studied. Dental and periodontal pathologies are inflmmatory chronic systemic diseases that can contribute in the development an aggravation of cardiovascular diseases. This posible association is not entirely clear, because these pathologies share many risk factors. Our objective is to study the relationship between oral and dental pathology with atherothrombotic cardiovascular diseases and also to study if the oral and / or dental pathology could condition the cardiovascular status of the patient.

Material and Methods: A total of 99 patients with atherothombotic cardiovascular disease were collected and compared with 50 patients in the control group. Both groups underwent a complete oral examination, an orthopantomography an a blood test with unconventional cardiovacular parameters.

Results: Patients with cardiovascular disease have worse oral health status than patients in the control group. They also present a greater severtity of periodontal disease and a greater number an severity or chronic apical periodontitis. Conclusions: These data suggest that patients with cardiovascular disease have worse oral health status tan individuals free of this disease. Given that both atherosclerosis and oral pathology have an inflammatory base, it is necessary to perform longitudinal and prospective studies that prove the relationship between these two pathologies.

\section{- Poster 2}

TITLE:- SURGICAL TREATMENT COMBINING IMPLANTOPLASTY, ANTIBIOTIC DESINFECTION AND REGENERACTION OF PERI-IMPLANT BONE DEFECTS. ONE COHORT PROSPECTIVE OBSERVATIONAL STUDY

González Regueiro I, Vintanel Moreno CB, Martínez Rodríguez N, Ruiz Sáenz PL, Barona Dorado C, Martínez-González JM.

Oral Surgery and Implantology Master. Virgen de la Paloma Hospital, Madrid.
Objectives: To evaluate the efficacy of a combined resective and regenerative treatment, with antibiotic disinfection with piperacillin/tazobactam $100 / 12,5 \mathrm{mg}$, on soft and hard tissues over a 12 months follow-up period.

Material and Methods: Observational prospective onecohort study.The study was authorized by the Ethics Committee of the San Carlos University Clinical Hospital of Madrid. Patients underwent surgical treatment: bone defect curettage and implantoplasty, bone regeneration and disinfection employing piperacillin/tazobactam 100/12,5mg 7 days prior to the intervention and intraoperative. Probing depth, bleeding or suppuration on probing and radiological bone level were analysed during a 12 month follow-up. Besides, treatment results were evaluated regarding the influence of the peri-implant defect configuration.

Results: 43 patients were included: 28 women and 15 men, with an average age of $60,19 \pm 9,26$ years. Probing depth was reduced $3.22 \pm 2.04 \mathrm{~mm}$ on average, bleeding on probing was reduced from a $100 \%$ of the cases to a $14 \%$, and suppuration fully disappeared. Statistically significant differences were found attending bone defect refill according to bone defect configuration $(p=0,001)$.

Conclusions: The approach proposed provides favourable results, although more studies with larger sample sizes are needed to achieve greater statistical power for the subgroups analysis.

\section{- Poster 3}

\section{TITLE:-SATISFACTION OF THE GERIATRIC PATIENT REHABILITATED WITH IMPLANTS: MULTICENTRIC STUDY}

Iglesias Velázquez O, Herbas Tellez AW, Shan Bai E, Martín Carrillo C, Martín Morales JF, Leco Berrocal I. Faculty of Dentistry. Complutense University of Madrid.

Objectives: To know the needs and complications of the geriatric patient with implant-supported prosthesis and to assess the perception of improvement in life quality and satisfaction of these patients.

Material and Methods: A survey was carried out consisting on 11 items for patients with implant-supported prosthesis, in which the motivation before treatment, time since the placement of the prosthesis, complications and its time of solution, were evaluated, as well as the perception of the patient about the improvement in life quality and satisfaction with the treatment.

Results: The patients who participated in the survey were older than 65 years, the number of men being higher than women. More than half of the sample implants were 
placed on the recommendation of a professional and they were carriers of the prosthesis for more than 5 years, with few complications that were mostly resolved early. $62 \%$ of the sample reported that their quality of life improved a lot after the placement of the implants and $75 \%$ would recommend the treatment.

Conclusions: This study shows that patients with implant- supported prosthesis are highly satisfied with the treatment and consider that it has meant an improvement in their quality of life, although it is true that these treatments are not exempt of complications.

\section{- Poster 4}

\section{TITLE:-SELF PERCEPTION OF THE QUALITY OF ORAL LIFE IN GERIATRIC PATIENTS OF THE UNIVERSITY CLINIC OF THE UCM}

Martín Carrillo C, Campo Fernández L, Herbas Tellez AW, Velasco del Rio A, Leco Berrocal I, Martín Morales $\mathrm{JF}$.

Faculty of Dentistry. Complutense University of Madrid.

Objectives: To know the self-perception of the oral health in elderly patients who go to the university clinic of the Complutense University of Madrid.

Material and Methods: Epidemiological transverse study carried out by completing the GOHAI Survey (Geriatric Oral Health Assessment Index) and oral exploration according to OMS's approaches.

Results: All those surveyed and explored who come to the clinic are over 65 years old, being $53 \%$ of adult males, this group present a high perception of their oral quality life (51 points in the GOHAI Survey) compared to women who are less satisfied with only 41,3 points obtained in the Survey. The DMFT index of the explored patients is high, especially in the case of women who reach a value of 23,2 in contrast with their male partners with a value of 15,2 . When we disaggregate the DMFT index in its components we see that women have fewer active caries and more teeth absent by caries.

Conclusions: Elderly people trust in the dental services of the university clinic of the UCM. Men have a high degree of oral satisfaction in their quality of life. Our elders reach a high DMFT index.

\section{- Poster 5}

TITLE:- NEUROSENSORY COMPLICATIONS AFTER REPOSITION OF INFERIOR ALVEOLAR NERVE TECHNIQUE: A SYSTEMATIC REVIEW

\author{
Palacio García-Ochoa Á, Cascos Sánchez, Baca \\ González L, Cadenas Vacas G, Hernández M, Madrigal \\ Martínez-Pereda $\boldsymbol{C}$. \\ Master of Oral Surgery and Implantology. University Com- \\ plutense of Madrid.
}

Objectives: The aim of this review is to analyze the possible neurosensory complications that may occur when the inferior alveolar nerve reposition technique is done.

Material and Methods: Research of human beings studies using Pubmed and Scopus data bases with following key words: "dental", "nerve", "lateralization" and "transposition". After abstracts reading, 9 articles were selected for the systematic review.

Results: A total of 9 articles were included according to the inclusion criteria: 1 of transposition, 4 of lateralization, and 4 about both techniques, including retrospective and prospective studies, systematic reviews and doctoral tesis. All the results are individually collected in tables. Conclusions: IAN lateralization technique seems to be a more physiological procedure than transposition, being both of them useful techniques for the implant placement in edentulous atrophic mandibles, with predictable clinical and radiographic results after 5 years of prosthetic loading.

\section{- Poster 6}

\section{TITLE:- A STUDY OF THE NECESITIES AND REASONS FOR TOOTH LOSS OF THE GERA- TRIC POPULATION TREATED AT THE COM- PLUTENSE UNIVERSITY DENTAL CLINIC}

Velasco del Rio A, Shan Bai E, Campo Fernández L, Iglesias Velázquez O, Martín Morales JF, Leco Berrocal I. Faculty of Dentistry. Complutense University of Madrid.

Objectives: To analyze the needs for dental extraction of the geriatric population at the Complutense Dental Clinic, to describe the epidemiological aspects of tooth loss as well as to determine its cause and the prosthetic rehabilitation treatment chosen by the patients.

Material and Methods: An observational, cross-sectional and prospective study was conducted on patients over 65 years of age who atended the Complutense Dental Clinic and require dental extractions, analyzing the epidemiological data as well as the causes and the subsequent re- 
habilitation treatment chosen by the patients. All the data was then processed through a descriptive statistic.

Results: The results obtained show a higher number of extractions on women, slightly higher on the upper maxilla, with the molars and premolars being the most extracted teeth. Dental caries followed by periodontal disease are determined as the main causes of tooth loss, and as for the rehabilitation treatment chosen by patients to replace dental loss, removable dentures, either partial or complete, followed by implant-supported rehabilitation. Conclusions: This study shows that the dental loss on geriatric patients in the studied population is mainly determined by caries and that patients select removable dentures and implants as a rehabilitation treatment.

\section{- Poster 7}

\section{TITLE:- INFLUENCE ON PATIENT SATISFAC- TION AFTER THE ADMINISTRATION OF ORA- VERSE® IN IMPLANT TREATMENTS}

Vintanel Moreno CB, Leco Berrocal I, González Regueiro I, Merchán Morales S, Sanz Sánchez A, Martínez-González JM.

Máster en Cirugía Bucal e Implantología. Hospital Virgen de la Paloma. Madrid.

Objectives: Evaluate whether the use of OraVerse ${ }^{\circledR}$, after the placement of dental implants at mandibular level supposes a greater satisfaction for the patient, without increasing the pain and analgesic consumption after the intervention, anomalous alterations of the vital signs, or the appearance of adverse effects.

Material and Methods: Fifty patients requiring dental implant placement at mandibular level were included, assigned into 2 different groups. All of them were informed in advance of the benefits of the product, as well as the possible adverse effects. Constant measurements were made in both groups prior to the beginning of the intervention and 10 minutes after the intervention completion. To all patients were given a satisfaction survey, and to the control group were given another small questionnaire related to their experience with the product.

Results: It were statistical differences in relation to the numbness in lip and tongue, and in relation to pain and analgesic consumption.

Conclusions: The use of OraVerse ${ }^{\circledR}$ after the placement of dental implants implies an increase in patient satisfaction due to the early reversal of the anesthetic effect, not increasing the analgesic consumption or post-intervention pain compared to the Control Group, as well as without involving hemodynamic alterations or higher adverse effects. A high percentage of patients would request it in future treatments and would recommend it to friends and family.

\section{- Poster 8}

\section{TITLE:-THE IMPORTANCE OF THE CONTROL OF PREMALIGNANT LESIONS: ABOUT A CASE}

Apalimova A, Seguer Parera I, Mishra S, Arranz Obispo C, Estrugo Devesa A, López López J. Máster Medicina, Cirugía e Implantología Oral de la Universitat de Barcelona.

Introduction: Oral Squamous Cell Carcinoma (OSCC) is the most common malignant epithelial neoplasm affecting the oral cavity. It is more frequent in men over 50 years of age and in patients with toxic habits like smoking and consumption of alcohol. OSCC is usually located on the tongue, the soft palate or the floor of the mouth.

Case Report: A 79-year-old woman with no history of allergies and diagnosed with arterial hypertension, polycythemia vera, COPD, peptic ulcer, hyperuremia, insomnia and depression visited the Dental Hospital, University of Barcelona in 2013 with a chronic ulcer in the left retromolar triangle. During the intraoral exploration an erythroleucoplasic ulcer of 2-3 cm of diameter with indurated borders was observed, with no associated adenopathies or pain. After discarding a traumatic component, an incisional biopsy of the lesion was performed. The histopathological study result was: "Non infiltrating severe epithelial dysplasia". An excisional biopsy with safety margins was performed and the patient was regularly followed-up every 6 months. In February 2019 an ulcerated and bleeding lesion measuring $2 \mathrm{~cm}$ in diameter and indurated borders was observed. An incisional biopsy was performed and after histopathological study it was diagnosed to be: "Infiltrating squamous cell carcinoma". The patient was referred to the department of Maxillofacial Surgery of the University Hospital of Bellvitge for treatment and follow-up.

Conclusions: A periodic control of potentially malignant lesions is essential for an early diagnosis and conservative treatment to our patients.

\section{- Poster 9}

\section{TITLE:- ATYPICAL LESION OF ORAL LICHEN PLANUS. ABOUT A CASE}

Apoita Sanz M, Chimenos Küstner E, González Navarro B, Estrugo Devesa A, Jané Salas E, López López J. Master of Medicine, Surgery and Oral Implantology, University of Barcelona, Faculty of Medicine and Health Sciences Odontological Hospital University of Barcelona. University of Barcelona. 
Introduction: In the oral cavity, a large amount of entities can be found as white lesions. To achieve an accurate diagnosis, the clinical history as well as the anamnesis will be essential. Oral lichen planus and leukoplakia should be taken into account as differential diagnosis due to its malignancy potential, therefore it is important to obtain an adequate definitive diagnosis.

Case Report: 73 year old woman came to the HOUB complaining about pain, tongue stinging and oral dryness, these symptoms started 5 years ago. Her medical history includes ischemic heart disease, hypercholesterolemia, DM II, hyperchromic anemia, AMI and polyarthrosis. The examination revealed white lesions on the lingual dorsum and buccal mucosa was slightly over elevated, as well as an ulceration in the lower left molar area and a depapilated and extremely xerostotic tongue. She was treated with antifungals without positive results. We treated the lesions with triamcinolone acetonide $0,1 \%$ in aqueous solution 3 times per day during 3 weeks. We performed an incisional biopsy of the lingual dorsum and left buccal mucosa, which gave a diagnosis of chronic transition mucositis with hyperkeratosis compatible with different mucous processes, including lichen planus.

Conclusions: It is difficult to reach a clear diagnosis when we are facing atypical lesions of OLP, for this reason we recommend not to give up in the study of this entity and provide as much data as possible. It is also highly valuable to discern between the different presentations of the OLP.

\section{- Poster 10}

\section{TITLE:- MULTIDISCIPLINARY TREATMENT IN A PARTIALLY EDENTULOUS ADULT PA- TIENT}

\section{Baña Souto S, Fernández López M, Rivas Mundiña B, Suárez Quintanilla J, Blanco Carrión A. Master's Degree in Oral Medical-Surgical Pathology and Inte- gral Dentistry. University of Santiago de Compostela.}

Introduction: Patients with multiple absences often have vertical dimension loss. To assess the patient's occlusal rehabilitation, the ideal vertical dimension must be recovered.

Case Report: We present a 66-year-old man with loss of vertical dimension, multiple dental absences in the four quadrants, deep overbite and mild horizontal bone loss in the maxilla. The patient demands an implant-supported fixed prosthesis. The vertical dimension is recovered with provisionals before the rehabilitation with implants to achieve occlusal and joint balance, recover prosthetic space and conservative sanitation of the remaining teeth is performed.
Conclusions: 1.-In patients with loss of vertical dimension, this must be recovered before rehabilitation with the final prosthesis. 2.- The use of fixed provisional resin facilitates the recovery of vertical dimension, being able to be adjusted in appointments and achieving a satisfactory aesthetics for the patient

\section{- Poster 11}

\section{TITLE:- DIFFERENTIAL DIAGNOSIS OF DES- QUAMATIVE GINGIVITIS AND TREATMENT COMPLICATIONS IN AN ELDERLY WOMAN}

\section{Bazal Bonelli S, Ballesteros Martín MC, Fernández García P, Solana Ferrer CM, Hernández Vallejo G, López-Pintor Muñoz RM. \\ Degree in Oral Medicine, Complutense University of Madrid.}

Introduction: Mucosal pemphigoid is a vesiculo-ulcerative disease of the oral cavity whose etiological origin appears to be autoimmune. It is caused by subepithelial blisters that usually appear in the gum, causing pain and bleeding.

Clinical Case: 89 year old woman who attends the University Specialist in Oral Medicine due to pain and gum bleeding. The patient is hypothyroid, is medicated by depression and also has skin and genital lesions. On examination, vestibular and palatine desquamative gingivitis of the anterosuperior gum, vestibular of the anteroinferior sector and ulcerous lesions in the lower edentulous ridge is observed. Differential diagnosis was performed with oral lichen planus, pemphigus vulgaris and mucosal pemphigoid. Histological results were compatible with mucosal pemphigoid. The patient underwent a tartrectomy and was treated with $0.05 \%$ triamcinolone acetonide for 3 weeks. Subsequently, she was treated with $0.05 \%$ clobetasol propionate for 3 weeks because she was reluctant to use systemic corticosteroids. Finally, with oral prednisone $10 \mathrm{mg}$ for 3 weeks. There were no significant improvements, so the patient was included by her dermatologist in a study group for the use of biological agents. Conclusions: It is necessary to study the medical history and antecedents of the patients in order to arrive at a correct diagnosis. Elderly patients may have different systemic diseases that may complicate treatment. On many occasions we must also adapt the treatments to the wishes of the patients. 


\section{- Poster 12}

\section{TITLE:-THERAPEUTIC MANAGEMENT OF THE KERATOCYSTIC ODONTOGENIC TUMOR. A CASE REPORT}

Burgos Montes M, Cabezas Mojón J, Jimeno Rodríguez B, Oliván Molina S, Fernández Domínguez M. Máster en Cirugía Bucal e Implantología: Universidad San Pablo CEU. Madrid.

Introduction: The keratocyst or keratocystic odontogenic tumor (KCOT) is an odontogenic cyst derived from the remnants of the dental lamina. Morphologically similar to other cysts, but with histological characteristics that differentiate it. It has a great destructive and extensive potential, it expands the cortical plaques surrounding mucosa and soft tissues. Its high rate of recurrence (25\%-60\%) causing discrepancies in the choice of treatment. Its highest incidence occurs between the 2nd and 3rd decade of life. It normally affects area of the lower third molar and the mandibular angle. Treatment options: marsupialization, enucleation, adjuvant measures and bone resection. The resection of the cyst linked to the excision of the overlying mucosal tissue and the treatment of the bone bed by surgical curettage seems to have the best results. Nowadays the treatment of choice is a more conservative therapeutic measures as long as the size and location allow it.

Clinical Case: A case of a male patient, 78-year-old, was reported. On clinical examination, buccal insufflation was observed through vestibule in the edentulous space of 24 , without tooth mobility and normal vitality tests in the adjacent teeth. In the orthopantomography, a radiolucent lesion was seen from 22-26 with involvement of the chest and the CT confirmed the lesion with features of a keratocyst odontogenic tumor with the possibility of differential diagnosis of central giant cell granuloma. Surgical treatment was performed with excision of the cyst and extraction of 23 and 25, confirming pathological anatomy the compatibility of keratocystic tumor without signs of malignancy.

Conclusions: The results were satisfactory and without clinical signs of recurrence so far.

\section{- Poster 13}

\section{TITLE:- TREATMENT WITH EMDOGAIN IN ELDERLY PATIENTS. ABOUT A CASE}

Diab A, Cabezas Mojón J, Oponowicz L, Oliván Molina $\boldsymbol{S}$, Fernández Domínguez $M$.

Máster en Cirugía Bucal e Implantología. Universidad San Pablo CEU. Madrid.
Abstract: Thanks to the discovery of the technique of regeneration with Emdogain $\AA$, it has been possible to obtain excellent results in the treatments of bone regeneration, and of subgingival tissues. In this clinical case we have discovered the benefits of this technique.

Introduction: Emdogain ${ }^{\circledR}$ is a compound of proteins that derive from the enamel matrix, induces the true regeneration of the insertion apparatus. Its main indication is the treatment of bony defects, bone regeneration and decreased depth of probing.

Case Report: Woman of 70 years, presents a fixed tooth supported prosthesis. In the clinical exploration we can observe $12 \mathrm{~mm}$ bags and radiographically we can see bone loss at the level of the teeth: 3.1, 3.2, 4.1, 4.2. Therefore, we decided to perform a periodontal treatment consisting of a wide open-pit flap. We have used Perioset and curettes to remove periodontal pouches and correct bone imperfections. The bone graft has been positioned in the receptor bed in addition to the Emdogain ${ }^{\circledR}$. The tooth supported sutures have been used to approximate the two buccal and lingual sides of the soft tissues and have an optimal seal.

Conclusions: Regeneration with Emdogain ${ }^{\circledR}$ and bone grafts has a good success rate, but it is essential to carry out a continuous follow-up.

\section{- Poster 14}

\section{TITLE:- GUIDED BONE REGENERATION USING CROSS-LINK MEMBRANES IN ALVEOLAR PRE- SERVATION. ON THE BASIS OF A CASE}

Diab N, Cabezas mojon J, Lorenzo Carballal AC, Oliván Molina S, Álvarez Berenguer JA, Fernández Domínguez $M$.

Master in Oral Surgery and implantology. San Pablo CEU University of Madrid.

Guided bone regeneration is nowadays the treatment of choice to preserve and correct bone defects. When associated with slow-resorption collagen membranes such as the "Cross link", we guarantee the bone separation of epithelial insertions, the preservation of the alveolar clot or, the bone graft, giving it time for a full osteointegration. Clinical Case: The patient is 65 years old. The exploration presents a mobility degree of three in mesial part of 2.4 , absence of the the bone support by mesial and the absence of 2.3. We did not find any inflammation and/or drainage. The patient wants to be rehabilitated with implants. After using an infiltrating anesthesia, we proceed to the extraction of the 2.4 and scrape the Alveolus. We raise minimally the vestibular and palatal gingival flips, and placed some particulate bone (xenograft) hydrated 
by condensing it and we placed The membrane "Crosslink", covering the totality of the defect and separating the bone from the epithelial insertions. We approximate the flaps with cross stitches, we give the analgesic treatment, antibiotic, anti inflammatory and the indications post operative.

Conclusions: The ROG using xenograft and Cross-link membrane allowed the total and uniform closure of the post-extraction defect and the stability of the alveolar regeneration.

\section{- Poster 15}

\section{TITLE:- USE OF TOPICAL CORTICOSTEROIDS IN ORAL MEDICINE. CASE REPORT}

Fernández García P, Hernández Ruiz de Azcárate F, Solana Ferrer CM, Bazal Bonelli S, Hernández Vallejo G, López Pintor Muñoz RM.

Título Especialista Universitario en Medicina Oral, Universidad Complutense de Madrid.

Introduction: Topical corticosteroids are the first line of treatment for oral mucocutaneous diseases. Although this medication is considered safe, it can sometimes cause side effects in elderly people.

Case Report: A 58-year-old woman with a clinical and histological diagnosis of liquen planus, came to Oral Medicine postgraduate from the Complutense University of Madrid in May 2018, due to the presence of longterm, symptomatic erosive-atrophic lesions distributed throughout the oral mucosa. The patient was treated with 0,05 clobetasol propionate rinse for three weeks, starting with 3 takes/day. When the treatment was finished, as she wasn't feeling better, she started again the three daily takes. Because of the recurrent presence of active lesions, it was decided to administrate clobetasol propionate $0,05 \% 3$ takes/day again, and review in two weeks. The evolution was not the expected as the patient suffered several remissions. Due to this, she continued with the treatment until September 2018. At that time, the patient's dermatologist changed the medical treatment to triamcinolone acetonide $0.1 \%$ in orabase and prednisone $5 \mathrm{mg} /$ day. It was in that appointment when we noticed that the patient was presenting full moon face, central obesity and lower extremities hematomas, so we decided to ask for an evaluation with her doctor.

Conclusions: We should take into account that patients treated with corticosteroids can develop a iatrogenic Cushing's syndrome. Due to this it is very important to carry out periodic evaluations, in order to avoid those side effects and to check out that the medical guidelines are being correctly fulfilled.

\section{- Poster 16}

\section{TITLE:- HEMANGIOMA. CLÍNICAL CASE}

Frexes Argemí R, Aceves Argemí R, Arranz Obispo C, Chimenos Küstner E, Jané Salas E, López López J. Master of Medicine, Surgery and Oral Implantology. Faculty of Medicine and Health Sciences (Dentistry). University Odontological Hospital (University of Barcelona).

Introduction: Most of the hemangiomas are congenital malformations and they are observed usually in the newborn babies or in the first years of life, but when hemangiomas appear in more advanced ages, they shoud be called real neoplasias with benign course, caused by the proliferation of small blood vessels.

This pathology is more frequent in women and its most habitual location is in the lips, the jugal mucous, tongue and palate.

Clinical Case: A 84-year-old male patient with medical history of Diabetes Mellitus type II, arterial hypertension, hypercholesterolemia, hypothyroidism and colon cancer in 2007, which was treated with surgery and chemotherapy. The patient is currently in treatment with Metformin, Bisoprolol, Atorvastatin and Levothyroxine sodium.

In oral examination we observed a nodular lesion, sessile and violaceous. It is soft to the touch and paling with digital pressure, located in the right jugal mucosa near the lower lip and several years of evolution. The patient refers deglutition and phonatory alterations.

In the clinical differential diagnosis it is included: cavernous hemangioma, lymphangioma, pyogenic granuloma, Kaposi's sarcoma and nevus flammeus.

An excisional biopsy by cold scapel was performed, and the sample was sent to the pathologist for histopathological study. The results of pathological anatomy show: vascular proliferation without atypia.

Conclusions: Through medical and clinical examination, a good diagnosis of presumption can be made, as well as, evaluating the extension and planning the treatment, although a histopathological study is necessary to confirm the diagnosis and rule out other types of vascular lesions.

\section{- Poster 17}

\section{TITLE:- THE IMPORTANCE OF DIAGNOSTIC IMAGING IN THE DENTAL OFFICE IN RELA- TION TO A CLINICAL CASE}

Gamallo Moure AB, Rodríguez Vega C, Rivas Mundiña B, Otero Rey E, Suárez Quintanilla J, Blanco Carrión A. Master's Degree in Oral Medical-Surgical Pathology and Integral Dentistry. University of Santiago de Compostela. 
Introduction: In cases of non localized irradiated pain it is difficult to determine the origin. Currently, the diagnosis in dentistry is made after an exhaustive clinical exploration, complemented with imaging techniques, the main ones being conventional radiology and more and more the computed tomography (CT). CT allows 3-D reconstructions of both bone and soft tissues, obtaining more information than with conventional radiography.

Case Report: It is a 66-year-old woman who had severe pain referred to ear and throat. The pain was increasing in the last 48 hours. To the clinical exploration, endodontia is observed in tooth 4.7. We made a periapical radiograph, in which we still didn't know the origin of the pain, so a panoramic radiograph was done, observing a radiolucent periapical image at level 4.7 , not very clear but appreciable. For all this, we decided to do a localized CT of the area, where it is clearly observed the presence of apical infection in 4.7. The treatment plan was the reendodontia of 4.7. with subsequent reconstruction with composite.

Conclusions: We should always start with the physical examination, followed by vitality and percussion tests. Request a panoramic radiograph and do periapical radiography with positioner. Radiological tests are one of the most important diagnostic methods in dentistry. CT provides more information than conventional X-rays in complex cases, allowing a more precise treatment planning.

\section{- Poster 18}

\section{TITLE:- DIGITAL FLOW IN THE ORAL REHA- BILITATION OF ONCOLOGICAL PATIENTS}

García Añorve S, Castañeda Vega P, Omaña Cepeda C, Estrugo Devesa A. López López J, Jané Salas E. Master of Dentistry in Oncology and Immunocompromised Patients. Faculty of Medicine and Health Sciences, Bellvitge Campus, University of Barcelona.

Introduction: Odontology treatments in cancer patients are usually complex, however, the clinical conditions caused by the side effects of oncological treatments (chemotherapy, radiotherapy and surgery), make oral rehabilitation a significant challenge. It is important to use and implement all the possible tools to simplify the rehabilitation treatments, and at the same time not reduce the quality of them. The current literature positions the digital flow as a promising ally in oral rehabilitation, and that is why we set out to present its application in oncological patients treated in the master's degree in oncology and immunocompromised patients at the University of Barcelona.
Clinical Cases: We present a series of patients who share oncological records, who were rehabilitated using the digital flow (intraoral 3 shape scanner) as the main tool for obtaining information.

Conclusions: The digital flow rehabilitation allowed to reduce clinical time, an important aspect in cancer patients. The limitation of the oral opening appears as the main counter indication for this rehabilitative technique.

\section{- Poster 19}

\section{TITLE:- TREFOIL CONCEPT: NEW POSSIBILI- TIES FOR MANDIBULAR REHABILITATION IN ELDERLY PATIENTS}

García Montoya V, Mudarra Fraguas B, Sanchez Caballo JA, López Sacristán H, Domínguez Viguera J, del Canto Pingarrón $M$.

Affiliation: Master's degree in Oral Surgery, Implantology and Periodontics. University of Leon. Spain.

Introduction: With the aging of the population increases the percentage of people who have total absence of teeth. To solve these situations, new techniques and work protocols are emerging to reduce chair time, economic costs and improve the experience of elderly patients. The placement of three implants to support a fixed implantsupported prosthesis was introduced by Branemark with the Novum model. In 2017, the Trefoil concpet was created by Nobel Biocare (Zurich, Switzerland). Differentiating itself from its predecessor in the placement of a prefabricated bar that has a mechanism of pins that compensate for the inclination of the implants. The development of this system facilitates prosthetic rectification of surgical inaccuracies in the placement of the implants. This mechanism allows the immediate placement of a definitive hybrid prosthesis in edentulous jaws comparable to a rod manufactured with individualized CAD / CAM. Case Report: The sequence of selection and planning of a case will be carried out among the patients of the solidarity clinic where the Master of surgery, implantology and periodontics it develops, which is adapted to the requirements of the Trefoil technique, and will subsequently be operated in our center.

Conclusions: The use of fixed implant-supported prostheses has an extra cost for a large group of patients. With this system is intended to get the option that is affordable for a larger population group. The fact that this system presents a prefabricated bar implies the need to make a correct selection of patients for the reception of the treatment. 


\section{- Poster 20}

\section{TITLE:- THE RELATIONSHIP BETWEEN OHIP- 14 (ORAL HEALTH IMPACT PROFILE) AND EQ- 5D (GENERAL HEALTH STATE) IN AN ELDERLY POPULATION IN REGION OF MURCIA (SPAIN)}

\author{
García Moya J, Torralba García D, Guerrero Gironés \\ J, Pecci Lloret M, Martínez López F, Ruiz Roca JA. \\ Gerodontología. Departamento de Dermatología, Estoma- \\ tología, Radiología y Medicina Física. Facultad de Medicina. \\ Universidad de Murcia.
}

Objectives: To evaluate the oral-health-related quality of life (OHRQoL) in a group of murcian older patients and establish relationship with overall health status.

Material and Methods: Cross-sectional study, which analysed baseline data from patients aged over 65 years, from two nursing homes, to take part in this study. All patients completed the Oral Health Impact Profile (OHIP14) and EuroQol-5D (EQ-5D) questionnaires. Data from the Quality of Life questionnaires were analysed to check possible differences between healthy and frail elders and were assess the associations between OHRQoL and general health.

Results: The patient sample consisted of $60(41,67 \%)$ male and $84(58,33 \%)$ female participants, with a mean (SD) age of 75,4 (6.4). Frail patients reported a higher mean OHIP-14 score compared to non-frail patients ( $p$ $<0.05$ ). Pearson's correlation analysis showed a negative association between OHIP-14 and EQ-5D scores. Regression analysis showed that among frail individuals, better general health corresponded to poorer OHRQoL. In the non-frail cohort, better general health was related to better OHRQoL, but these results were not statistically significant $(p>0,05)$.

Conclusions: General health was not significantly associated with the way that these murcian patients perceive their oral health within this patient group. However, factors such as objective oral health, patient's expectations and denture wear, may play a role in this association.

\section{- Poster 21}

\section{TITLE:- ATYPICAL LOCATION OF A LOBULAR CAPILLARY ANGIOMA. CASE REPORT}

Gimeno López D, Olivera Oliva A, Estrugo Devesa A, Jané Salas E, Marí Roig A, López López J.

Master of Medicine, Surgery and Oral Implantology. Faculty of Medicine and Health Sciences - Odontological Hospital University of Barcelona. University of Barcelona.
Introduction: Lobular capillary angioma is the most common connective tissue tumor where there is a development of fibrovascular tissue with endothelial proliferation. It is defined as a reactive lesion. It is also known as pyogenic granuloma.

It is more frequent in women than in men (2: 1). It can appear in any anatomical location of the oral cavity; the most frequent location is the interdental papilla in up to $70 \%$ of cases. Clinically it appears as a reddish, bluish or purple, soft, sessile or pedunculated tumor, its size can vary from a few millimeters to several centimeters.

Case Report: A 71-year-old male attending the Master of Medicine, Surgery and Oral Implantology at the University of Barcelona due to a lesion on the floor of the mouth, hyperplastic at the level of $32-33$ of $12 \times 10 \times 3 \mathrm{~mm}$, of 4 months of evolution and firm, non-painful consistency. not bleeding and does not interfere with swallowing.

In the periapical radiographs, slight bone involvement of the alveolar ridge was observed, so that in the beginning the diagnosis of presumption was peripheral giant cell tumor. An excisional biopsy was performed, and the histopathological diagnosis indicated the presence of a lobular capillary angioma; the floor of the mouth being an infrequent location.

Conclusions: The anatomopathological diagnosis is essential to make the definitive diagnosis of this type of lesions, especially when they appear in atypical locations rarely described in the literature.

\section{- Poster 22}

\section{TITLE:- USE OF PEDICLED BUCCAL FAT PAD FOR CLOSURE OF OROANTRAL COMMUNICA- TIONS. A CASE REPORT}

González Fernández-Tresguerres F, Sáez Alcaide LM, Molinero Mourelle P, Buesa Bárez JM, Sáiz Carrasco $S$, Meniz García $C$.

Máster en Cirugía Bucal e Implantología. Universidad Complutense de Madrid.

Introduction: The term oroantral communication (OAC) refers to a pathological perforation of the maxillary sinus that establishes a communication with the oral cavity as a consequence of the loss of soft tissues (buccal and sinus mucosa) and hard tissues (teeth and maxillary bone). OAC is a complication of tooth extraction that facilitates microbial contamination from the oral cavity into the maxillary sinus. The Bichat's fat pad was first mentioned as an anatomical element by Heister in 1732, and described by Bichat in 1802; this highly vascularized adipose tissue is very useful for the closure of OAC, due to its capacity for metaplasia. 
Case Report: A 60-year-old man, with no relevant medical history, who attended the Master of Oral Surgery and Implantology of the UCM, referred by his dentist for the extraction of the retained upper wisdom teeth. The 28 presents a big cystic lesion in direct relation with the maxillary sinus. It was decided to perform the extraction of 28 and 27 teeth, cystectomy, maxillary sinus lavage with liquid metronidazole and saline, and, finally, closure of the CBS with a pedicled buccal fat pad and a platelet concentrate (PRGF) associated with a coronally advanced flap.

Conclusions: The use of the pedicled buccal fat pad combined with the PRGF was safe and effective for the treatment of a large OAC, showing a complete epithelialization 15 days after surgery.

\section{- Poster 23}

\section{TITLE:- BENIGN FIBRO-OSSEOU LESION: CASE REPORT}

Jaillita Quispe W, Schiavone Mussano R, Estrugo Devesa A,Chimenos Küstner E, Jané Salas E, López López J.

Master of Oral Medicine. Faculty of Medicine and Health Sciences (Dentistry) - University of Barcelona.

Introduction: Fibro-osseous lesions are disorders that affect the medullary portion of the bones, which normal bone is replaced by fibrous connective tissue and calcified cementum tissue of the avascular type, radiographically it can have radiolucent, mixed and radiopaque appearance with radiolucent halo.

Case Report: It is an elderly, 60 years old, as a medical history of hypertension, hypercholesterolemia and anxiety, currently taking Fluoxetine and Lorazepam. The reason for the consultation was to perform extraction of tooth 48 due to a pericoronaritis. We requested an orthopantomography for an initial evaluation, where we observed that the 48 was partially retained, dental calculus on the distal face of tooth 47 , which could cause an exacerbation of symptoms. In addition, when analyzing the orthopantomography, a radiopaque area with a radiolucent, rounded, approximately $1 \mathrm{~cm}$ diameter, asymptomatic, located in the periapical region of tooth 46 was observed as a casual finding. The conduct was to perform the extraction of 48 , for this we requested a cone beam computed tomography for better evaluation and surgical planning. In this examination the periápice of 46 was also evaluated, where we confirmed that it was a mixed lesion compatible with periapical cemento-osseous dysplasia. Patient is in annual controls to monitor this lesion clinically and radiographically.
Conclusions: Fibro-osseous lesions are relatively frequent and can be found as casual findings in older adults. It is important to identify them and make a differential diagnosis in order to establish the treatment plan

\section{- Poster 24}

\section{TITLE:- FULL-ARCH REHABILITATION USING PHOTOGRAMMETRY IMPRESSION TECHNI- QUE WITH TITANIUM- ZIRCONIUM SILICATE}

Izquierdo Orts R, Cadenas Vacas G, De la Rosa García A, Palacio García-Ochoa A, Buesa Bárez JM, Martínez Rodríguez $N$.

Máster en Cirugía Bucal e Implantología. Universidad Complutense de Madrid.

Introduction: In conventional digital impression techniques, as the number of implants to be included in the impression increases, precision decreases, since the individual measurement error for each of them is cumulative. Such problems are reduced with photogrammetry because the discrepancies have been reported to be $5 \mathrm{~mm}$ to $5.6 \mathrm{~mm}$

Case Report: A totally edentulous 76-year old man comes to the Dentistry Faculty of UCM seeking for a full-arch rehabilitation. After planning the case, it was decided to place 6 submerged implants (Astra EV) in the mandible and make a superior conventional complete prosthesis.

After 3 months, a digital photogrammetry impression was made using the Pic Dental system, through CAD/CAM base on a milled titanium structure with zirconium silicate.

Lack of passivity was found. However, this complication was finally solved.

Conclusions: The manufacture of prostheses by CAD / CAM has great precision but it is not free of complications. The combination of digital and conventional impressions techniques allows to obtain great results. - Zirconium silicate offers a high aesthetic and reduces the wear of acrylic teeth as it is a material with high flexibility.

\section{- Poster 25}

TITLE:- AESTHETIC AND FUNCTIONAL REHABILITATION OF ANTERIOR TEETH. A CASE REPORT

Otero Rey E, Talbaoui A, Rivas Mundiña B, Gamallo Moure AB, Suárez Quintanilla J, Blanco Carrión A. Master's Degree in Oral Medical-Surgical Pathology and Integral Dentistry. University of Santiago de Compostela. 
Introduction: Currently, the demand of the geriatric patient has increased in dental treatments not only at the functional level but also the aesthetic requirement. In those cases where direct or indirect restorations are indicated, the professional should know the restorative materials that are at his disposal valuing their combination for a complete rehabilitation. On the one hand, the use of fully ceramic systems for the restoration of teeth in the anterior sector allows the combination of aesthetic and functional properties being a flexible material, resistant and above all, we can achieve a natural tooth tone. On the other hand, the direct restoration with composite resins proposes a conservative technique, fast, with good polishing capacity, hardness and resistance to wear.

Case Report: We present the case of a 71 year old male patient who attended the Master's Degree in Oral Medical-Surgical Pathology and Integral Dentistry of the USC due to aesthetic inconformity. At the clinical examination, metal-ceramic crowns are observed at the level of 1.1 and 2.1 presenting, as well, incisal wear and multiple interdental spaces at the level of the lower incisors. A waxing was carried out to decide the treatment plan, rehabilitation of upper central incisors with lithium disilicate crowns (e.max) and direct restoration of the anterior-inferior sector with composite resin stratification technique of the Amaris system (VOCO).

Conclusions: 1 . The availability of varied techniques and materials increases treatment alternatives to meet the aesthetic needs and expectations of the patient. 2. It is important to emphasize the importance of the management of the different techniques in all their steps in addition to the communication with the dental technician to achieve aesthetic, conservative and long term durability results.

\section{- Poster 26}

TITLE:- EVALUATION OF TREATMENT OPTIONS FOR TEETH WITH LITTLE REMAINING STRUCTURE. CONSERVATIVE, SURGICAL OR COMBINED TREATMENT? ABOUT A CASE

\author{
Peñamaría Mallón M, Riveiro Pousada A, Rivas \\ Mundiña B, Otero Rey E, Súarez Quintanilla J, Blanco \\ Carrión A. \\ Master's Degree in Oral Medical-Surgical Pathology and Inte- \\ gral Dentistry. University of Santiago de Compostela.
}

Introduction: Geriatric patients should be analyzed assessing the complete clinical history, occlusion and aesthetic commitment to decide between conservative, surgical or combined treatment in the anterior teeth. The endodontic retreatment and the reconstruction with fiberglass post allow us to preserve teeth with little remain- ing structure. In the anterior sector, this option means shorter treatment time, being useful in medically compromised patients with limitations when performing surgical treatments, it allows the placement of fixed provisional prosthesis throughout the treatment and presents a more predictable aesthetic than other non-conservative treatments. In cases in which the stumps do not have the necessary ferrule, we must perform a surgical coronary lengthening to ease rehabilitation with fixed prosthesis.

Case Report: 73-year-old male who attended the Master's Degree in oral-surgical surgical pathology and integral dentistry, for presenting two fractured upper incisors, both with previous endodontic treatment. No medical history of interest.

Conclusions: A vacuum splint with composite veneers was used to solve the initial aesthetic compromise provisionally. The endodontic retreatment of 1.1 and 1.2 was performed, and reconstruction with fiberglass post. Final rehabilitation with metal-ceramic crowns.

\section{- Poster 27}

\section{TITLE:- CONSERVATIVE TREATMENT OF IN- TERNAL ROOT RESORPTION: A CASE REPORT}

Rivas Mundiña B, López Rodríguez C, Otero Rey E, Peñamaría Mallón M, Suárez Quintanilla J, Blanco Carrión A.

Máster en Patología Médico-Quirúrgico y Odontología Integral de la Universidad de Santiago de Compostela.

Introduction: Internal root resorption is a type of tooth resorption whose etiopathogenic mechanism is unknown, there are authors who claim that it is produced by the pulpal reaction originated after a trauma, originating the original resorption through the inflammatory response

Case Report: Female patient of 65 who presented an internal radicular reabsorption reported at level 1.1, diagnosed by a casual finding during a tartrectomy in the Master's Degree in "Patología Médico-Quirúrgica y Odontología Integral" of the USC. Surgical and conservative treatment options were evaluated. Finally, because there is suppuration through the gingival pocket, it is decided to do a root canal treatment because of its more immediate and conservative nature. The surgical treatment is ruled out initially, due to the fact that the infection would oblige us to carry out a deferred treatment and complicates the possibility of carrying a provisional one, without dispensing with this option in the future.

Conclusions: The conduct must be located with DG16, this will prevent us from occupying it during the reconstruction. The treatment was performed with Bioden- 
tine ${ }^{\circledR}$ due to the absence of bone around the lesion, so we could not place MTA. We put a fiberglass post to reinforce the remaining tooth structure. We must perform an annual control in which there is no suppuration.

\section{- Poster 28}

\section{TITLE:- ONLAY BONE BLOCK GRAFT: A CASE REPORT}

Rodríguez Martín A, Baltasar Corral MV, Gómez Mañas P, Frutos Saucedo R, Miguelañez Medrán BC, López Sánchez A.

Expert in Oral Medicine. Universidad Rey Juan Carlos.

Introduction: Currently, clinicians find some difficult situations when they try to place implants, such as vertical or horizontal bone atrophy of the maxilla. Fortunately, numerous treatment alternatives have been developed in order to solve this problem. It is highly demonstrated that autologous bone is the Gold Standard and it's essential for appropriate bone regeneration.

Case Report: We present the case of a 67 -year old woman without known diseases, who came to our clinic to place an implant in position 1.2. As an additional test, an orthopantomography and a CBCT were performed and they showed a poor horizontal bone availability. Therefore, the surgery could not take place until we performed a previous guided bone regeneration. The first surgical intervention aimed to obtain a palatal connective tissue graft, to improve the periodontal biotype. The second intervention consisted of obtaining two discs of blocks bone grafts, that were taken from the chin, and were placed in the receiving area fixed with osteosynthesis screws, and covering them with a membrane. After a waiting period of 4 months, the implant was placed, and an immediate provisional was loaded to replace the aesthetic function. Conclusions: We can conclude that after performing the surgical techniques previously defined, the results obtained in terms of predictability were optimal, there was no bone graft reabsorption, not exposure, achieving functional and aesthetic rehabilitation of the patient.

\section{- Poster 29}

\section{TITLE:- CONSERVATIVE AND SURGICAL TREATMENT OF LARGE CYST}

Suárez Quintanilla J, Valentinov I, Rivas Mundiña B, Baña Souto S, Otero Rey E, Blanco Carrión A. Master's Degree in Oral Medical-Surgical Pathology and Integral Dentistry. University of Santiago de Compostela.
Introduction: Periapical cysts can be differed in true cysts, with a totally independent light, and cysts in the pouch, which are open to the root canal (granuloma 50\% and cysts paradentarios $35 \%$ ).

The lesion manifests with a radiolucent priapical image. It can be a granuloma or a cyst. It is a well-accepted fact that a granuloma heals after endodontic treatment.

In certain studies, such as that of Nair (2016), it was shown that $50 \%$ of the lesions were epithelialized, but only $15 \%$ were true periapical cysts.

Patients with multiple absences often have vertical dimension loss. To assess the patient's occlusal rehabilitation, the ideal vertical dimension must be recovered.

Case Report: Patient of 65 years, who goes to the master's degree in medical-surgical oral and comprehensive dentistry of the USC for review. When performing a panoramic radiograph with a radiolucent pericapical lesion at level 4.4, 4.5 and 4.6. An endodontic treatment of 4.4, 4.5 and 4.6 is started. After 6 months, radiological control was performed and we verified that the lesion had not changed in size, so we performed a surgical treatment (cystectomy and apcicectomy of 4.5).

Conclusions: 1- If we doubt about the origin of the cyst we can begin with a conservative treatment and do a reevaluation after 6 months.

2- If no improvement is observed in the lession, a surgical treatment should be done.

\section{- Poster 30}

\section{TITLE:- MASTICATORY EFFICIENCY, PSY- CHOMETRIC ANALYSIS AND DEGREE OF SA- TISFACTION OF THE ELDERLY PATIENT WITH OVERDENTURES ON TWO SHORT IMPLANTS OF 5 MM}

Torralba García D, García Moya J, Guerrero Gironés J, Pecci Lloret M, Martínez López F, Ruiz Roca JA. Gerodontología. Departamento de Dermatología, Estomatología, Radiología y Medicina Física. Facultad de Medicina. Universidad de Murcia.

Objetives: To evaluate psychometric parameters (patient satisfaction and masticatory ability) and masticatory efficiency in elderly people before and after oral rehabilitation by overdenture with two short implants $(5 \mathrm{~mm})$.

Material and Methods: This study included elderly individuals who wore clinically unsatisfactory complete dentures. Subjects first received new maxillary and mandibular conventional complete dentures. After 2 months, subjective and objective variables were measured by applying a visual analog scale to rate patient satisfaction with stability, comfort, ability to chew, ability to speak, 
ease of cleaning, esthetics, and general satisfaction of their new complete dentures. Masticatory ability was assessed by asking participants to rate on a VAS their ability to chew foods with different roughness and consistencies. After evaluations were completed, each participant received two short implants, which was placed in the symphysis region. Subjects used the overdentures for 2 months, and then all variables were reevaluated.

Results: The elderly showed greater stability satisfaction with their overdentures compared to their conventional full dentures. Satisfaction with the aesthetics did not differ between both types of prostheses, although the masticatory efficiency $(p<0.0001)$, obtaining in general lines a satisfaction in all the evaluated parameters, less in the economic impact.

Conclusions: Two short implants overdentures changed the patient perceptions, improving their satisfaction with stability, but decreasing satisfaction with esthetics. Despite that, masticatory efficiency of elderly people with decreased residual bone height was greatly improved two short implants overdenture use.

\section{- Poster 31}

\section{TITLE:- MAXILLOMANDIBULAR RADIOLU- CENT LESIONS. A SYSTEMATIC REVIEW}

\author{
Almarza Beristain P, Del Campo Orellana C, Prada \\ Vales MJ, Barrilero Martín C. Alobera Gracia MA, del \\ Canto Pingarrón $M$. \\ Master's degree in Oral Surgery, Implantology and Periodon- \\ tics. University of Leon. Spain.
}

Objectives: To analyze the most frequent radiolucent lesions in the jaws, knowing their radiographic characteristics in orther to do a correct diagnosis and treatment.

Material and Methods: A literature search was carried out between January 2013 and january 2019 to identify all scientific publications on the topic of radiolucent lesions of the jaws. We searched the main scientific databases: Pubmed, Cochrane, Ebsco.

Key words: radiolucent lesions, oral cavity cyst, oral cavity tumors, differencial diagnosis cyst, paronamyc radiography, CBCT.

Results: The most important and frequent lesions that present as radiolucencies on conventional radiography of the jaws has an inflammatory origin, the most of them asociated to non-vital teeth. Tumoral and cyst lesions, like odontogenic cyst and ameloblastoma, has some important imagin characteristics. Common radiography is just a complement of clinical examen and biopsy if necessary.
Conclusions: The most of radiolucencies lesions are benign, neoplastic origin can be distinguished according to: multiple or solitary, poor or good marginal definition (wide or narrow zone of transition), relationship with the crown or root of teeth, buccolingual expansion, displacement of teeth and other structures.

\section{- Poster 32}

\section{TITLE:- THE TREATMENT WITH OVERDEN- TURES IN GERIATRIC PATIENTS WITH ATRO- PHIC EDENTULOUS MAXILLA}

Balawi Balawi O, Pérez Errazuriz S, Matos Garrido N, Rondón Romero JL, Monsalve Guil L, Velasco Ortega E. Master of Implant Dentistry. Faculty of Dentistry. University of Seville.

Introduction: The prosthetic treatment in edentulous patients with huge atrophic maxilla is a common procedure in our dental practice. It is necessary an individual treatment planning that restoring the chewing function and aesthetic profile, and improve the quality of life of the patient. Clinical Case: 72-year old male without medical conditions, with deficient oral hygiene, completely edentulous in upper arch, carries a complete prothesis. In the lower jaw carries acrylic partial removable prothesis. The patient comes to our dental practice to improve the prothesis in upper jaw. In order to rehabilitate the upper jaw it is recommended the placement of 4 dental implants splinted by means of a milled bar with 3 anchorage points Locator type, to support an overdenture. The procedure will be carried out with the conventional protocol of loading implants and in two surgical phases in order to put a provisional acrylic prothesis while the osseointegration is achieved.

Conclusions: Overdenture by four implants can be an alternative of success treatment in maxillary edentulous geriatric patients achieving a functional and aesthetic rehabilitation.

\section{- Poster 33}

\section{TITLE:- CORRELATION BETWEEN ORAL AND GENITAL LICHEN PLANUS. SYSTEMATIC RE- VIEW}

Bobadilla Rico JH, Cassol Spanemberg J, PérezHerráez A, Estrugo Devesa A, Rodríguez-de-RiveraCampillo ME, López-López J.

Master of Oral Medicine. Faculty of Medicine and Health Sciences (Dentistry). 
Lichen Planus (LP) can affect simultaneously to different parts of the body, as oral cavity, genital mucosa, skin, scalp and nails, among others. In a common way, genital involvement is prevalent but tends to be misdiagnosed, a multidisciplinary team is required. The objective was to perform a systematic review to evaluate the correlation between oral and vaginal lichen planus. A literature review was performed by searching articles of the last 14 years in Pubmed/Medline using specific key-words. The orogenital LP is not common (3.7-9.3\% of patients with LP) condition and has been documented in the literature as a series of cases or cases. Some cases of oral-genital LP are presented as "vulvovaginal-gingival syndrome", it is a rare triad of erosive or desquamative vulvitis and vaginitis and desquamative gingivitis. In all patients with suspected oral and genital LP, we must confirm the clinical diagnosis by histopathological analysis. The pharmacological treatment is topical corticosteroids. In some cases, it can be administered systemic corticosteroids or immunosuppressive drugs.

Conclusion: The oral cavity is the main location of lichen planus and in many cases the first or the only form of presentation. Patients with oral lichen planus must be monitored and referred to the corresponding specialists to rule out involvement of other mucous membranes, such as the genital. The variation between studies and different results, difficult for us to know the correlation between oral and genital LP, as there may be different factors responsible for the development of the disease and its anatomical distribution.

\section{- Poster 34}

TITLE:- EFFICACY AND PATIENT SATISFACTION WITH IMPLANT-SUPPORTED PROSTHESES IN COMPARISON WITH CONVENTIONAL COMPLETE DENTURES IN ELDERLY PATIENTS

Botellé del Hierro R, Parra García S, Mena Collado P, Matos Garrido N, Jiménez Guerra A, Nuñez Márquez E. Master of Implant Dentistry. Faculty of Dentistry. University of Seville.

Objectives: To establish a comparison between treatment with conventional complete dentures and implantretained overdentures in elderly patients by conducting a literature review.

Material and Methods: A paper review has been carried out in the database Pubmed and Medline between the years 2009 and 2019.

Results: Among the 60 articles found in the initial search, 20 met the inclusion criteria. Most of the articles stated superiority of the mandibular implant-retained overdenture therapy over the conventional complete denture regarding patient satisfaction and quality of life.

Conclusions: Patients with implant treatment presents higher satisfaction and improvement of quality of life. In addition, the implant-treated patients gave significantly higher ratings on comfort, stability, and masticatory function.

\section{- Poster 35}

\section{TITLE:- DENTAL AUTOTRANSPLANTATION}

Collado Casasola J, Álvarez Figaredo I, Gamero Sánchez G, de Elio Oliveros J, Alobera Gracia MA, del Canto Pingarrón M.

Master's degree in Oral Surgery, Implantology and Periodontics. University of Leon. Spain.

Introduction: The autotransplantion of theet technique is a surgical treatment which replaces a dental gap using a tooth of the same person but located in a different area.

Objectives: The aim of this review is to analyse the survival rate of the autotransplanted tooth, the difficulties and complications of the treatment and the use of techniques that improve the prognosis of the treatment. Material and Methods: We did a detailed search in Pubmed, using key words such as "autotransplantion of theet", "tooth transplant". We also search reports of well known researchers in this field such us Ole Schwartz or Jens O. Andersen.

Results: We included 12 researches. Survival rate vary from $75,3 \%$ up to $96,7 \%$. Complication rate regarding excessive mobility was detected in $3,6 \%$ of the tooth transplant, the anquilosis post treatment between 2,9\% and $12 \%$ and the pulp necrosis varies significantly, also the success of the treatment varies significantly depending on the development stage of the tooth, obtaining better results when the apex is open more than $1 \mathrm{~mm}$.

Conclusions: The autotransplantion of theet have a very high rate of survival, this conclusion is supported by scientific literature after a lot of years of research. Failures such as root resorption, pulp necrosis or ankilosis have low rates, that is why this treatment is suitable and chosen by young people with dental agenesy or early loss of any tooth among other cases of difficult approach. 


\section{- Poster 36}

TITLE:- SUCCESS RATE OF DENTAL IMPLANTS IN PATIENTS WITH OSTEOPOROSIS. A SYSTEMATIC REVIEW

Córdoba Del Moral G, Manso Herencias A, Antúnez Antúnez C, Sevilla Hernández M, García Casal J, Del Canto Pingarrón $M$.

Master's degree in Oral Surgery, Implantology and Periodontics. University of Leon. Spain.

Introduction: Osteoporosis is considered a systemic bone disease, it characterized by a decrease in bone mass and degradation, causing an increase in medullary spaces and producing an increased risk of fractures. It is a very common disease, mainly in women over 50 years.

Objectives: Carry out a systematic bibliographic review of the affectation that osteoporosis can have in the integration of dental implants.

Material and Methods: The searches have been done in articles, and systematic reviews of the PUBMED and MEDLINE databases, using as key words osteoporosis, dental implants, osseointegration, bone density decrease, marginal bone loss. Post-2013 articles and references of relevant studies have been selected.

Results: Most of studies realised did not seem statistically significant differences in survival and osteointegration of dental implants between patients with osteoporosis and healthy patients. However, it has been shown that there is an increased risk of implant failure in bone type IV, wich is similar to that found in patients with osteoporosis.

Conclusions: Osteoporosis is not a contraindication for treatment with dental implants. The survival rate of the implants placed in patients with osteoporosis is similar to those placed in healthy patients, but the studies conclude that it is necessary to perform long-term follow-ups to see the evolution of the treatments

\section{- Poster 37}

\section{TITLE:- BENEFITS OF ALL-ON-FOUR THECNI- QUE ON GERIATRIC PATIENTS}

Costa Costas MV, Troncoso de la Cuesta A, Alvarez Peguero M, López Sacristán H, Domínguez Vigera J, del Canto Pingarrón M.

Master's Degree in Oral Surgery, Implantology and Periodontics from de University of León.

Purpose: The aim of the following systematic review is to establish the suitability of "All-on-Four" technique on geriatric patients. This method is based on the implanta- tion of both tilted $\left(30-45^{\circ}\right)$ and axial implants, combined with an immediate loading through provisional prothesis which will be replaced by a definitive prothesis after 3-4 months.

Material and Methods: Sixteen publications met all inclusion criteria on PubMed database, including systematic reviews and comparative studies with patient followup. Combined- technique treatments were not included since "All-on-Four" contribution to treatment success or failure cannot be established.

Results: All-on-Four technique is a valid treatment for both maxilar and mandibular atrophy, establishing an alternative to bone grafts o maxillary sinus lifts. Dental nerve damage is prevented and no significant difference was found on marginal bone-loss with immediate loading. Osseointegration is successful in more than $95 \%$ of cases. Conclusion: All-on-Four technique decreases morbidity enhancing functionality, aesthetics and patient satisfaction. More long-term studies are required.

Key words: All-on-Four, edentulism, edentulous patient, immediate load, complete arch, atrophic maxilla, atrophic mandible, tilted implants, axial implants, fixed implant-supported prosthesis, immediate function, bone loss, osseointegration, cantilever, patient satisfaction.

\section{- Poster 38}

\section{TITLE:- FACTORS RELATED TO DENTURE STOMATITIS IN THE GERIATRIC POPULATION}

Solana Ferrer CM, Fernández García P, Bazal Bonelli $S$, Hernández Ruiz de Azcárate F, Rodríguez Archilla A. Universidad de Granada (UGR).

Objectives: To assess the different factors related to denture stomatitis (DS) in the geriatric population.

Material and Methods: A literature search of studies on factors related to denture stomatitis in the geriatric population wasconducted in the following databases: PubMed (MEDLINE, Cochrane Library), Google Scholar and the Information and Documentation of Science Database in Spain (ÍnDICEs-CSIC) which includes the Spanish Medical Index (IME). 155 articles with full-text availability were found from 1965 to 2018. 143 articles were excluded for various reasons: absence of clinical data (n $=31)$, lack of a control group of denture wearers $(n=67)$ and studies with no usable data $(n=45)$. The data were processed with the RevMan 5.3 statistical programme (The Cochrane Collaboration, Oxford, UK). For dichotomous outcomes, the estimates of effects of an intervention were expressed as odds ratios (OR) using Haenszel Mantel (HM) method and, for continuous outcomes, the estimates of effects of an intervention were expressed as 
mean differences (MD) using the inverse variance (IV) method, both with $95 \%$ confidence intervals.

Results: 12 studies on factors related to DS in the geriatric population were included in this meta-analysis. Factors related to DS were: Candida detection (OR: 5.58); wearing denture to sleep (OR: 2.98); denture age over 10 years (OR: 2.47); denture trauma (OR: 2.01); high carbohydrate intake (OR: 1.83) and decrease of salivary $\mathrm{pH}$ (DM: -0.49).

Conclusions: Chronic Candida infection is the main factor related to DS in the geriatric patient.

\section{- Poster 39}

\section{TITLE:-DENTAL MANAGEMENT IN THE EL- DERLY PATIENT TREATED WITH ORAL ANTI- COAGULANTS}

López Bautista M, Sobrino Colorado LM, Zavala de Diego C, Solana Ferrer CM, Hernández Vallejo G, López-Pintor Muñoz RM.

Título Especialista Universitario en Medicina Oral, Universidad Complutense de Madrid.

Objectives: To protocolize the dental management of patients under treatment with oral anticoagulants.

Material and Methods: A PubMed search was carried out (MEDLINE, Cochrane Library), introducing the following words "Elderly patients AND oral anticoagulants"

Results: We found 226 full text articles. We excluded those articles published more than 5 years ago $(n=149)$, obtaining a total of 77 articles. Other articles were discarded after reading the titles and abstracts $(n=64)$, finally 13 articles were selected for this review.

Conclusions: People on treatment with anticoagulants increase, being more frequent in elderly patients. Anticoagulated patients should be treated the same as healthy patients, and the dentist should be informed about various local hemostatic measures. When it comes to treating this type of patients, there is always doubt about whether it is necessary to stop the medication. Several authors defend that it is better not to stop the anticoagulant treatment because the unnecessary interruption increases the risk of embolism. If interruption is needed, it will always be the doctor who suspends it. As for pharmacology, anesthesia with vasoconstrictor is preferable to reduce the risk of hemorrhage. Paracetamol is the drug of choice for analgesia, since aspirin and NSAIDs may increase the risk of bleeding. As for the "non-antagonists of the action of vitamin K", it is recommended to suspend them the morning of surgery and to take it back 6 hours after the intervention.

\section{- Poster 40}

TITLE:- DENTAL MANAGEMENT IN THE ELDERLY PATIENT TREATED WITH ORAL ANTICOAGULANTS

Sobrino Colorado LM, López Bautista M, Zavala de Diego C, Melero Alarcón C, Hernández Vallejo $G$, López-Pintor Muñoz RM.

Título Especialista Universitario en Medicina Oral, Universidad Complutense de Madrid.

Objectives: To protocolize the dental management of patients under treatment with oral anticoagulants.

Material and Methods: A PubMed search was carried out (MEDLINE, Cochrane Library), introducing the following words "Elderly patients AND oral anticoagulants". Results: We found 226 full text articles. We excluded those articles published more than 5 years ago $(n=149)$, obtaining a total of 77 articles. Other articles were discarded after reading the titles and abstracts $(n=64)$, finally 13 articles were selected for this review.

Conclusions: People on treatment with anticoagulants increase, being more frequent in elderly patients. Anticoagulated patients should be treated the same as healthy patients, and the dentist should be informed about various local hemostatic measures. When it comes to treating this type of patients, there is always doubt about whether it is necessary to stop the medication. Several authors defend that it is better not to stop the anticoagulant treatment because the unnecessary interruption increases the risk of embolism. If interruption is needed, it will always be the doctor who suspends it. As for pharmacology, anesthesia with vasoconstrictor is preferable to reduce the risk of hemorrhage. Paracetamol is the drug of choice for analgesia, since aspirin and NSAIDs may increase the risk of bleeding. As for the "non-antagonists of the action of vitamin K", it is recommended to suspend them the morning of surgery and to take it back 6 hours after the intervention.

\section{- Poster 41}

\section{TITLE:- IMMEDIATE LOADING ON MANDIBU- LAR OVERDENTURES FOR ELDERLY PATIENTS}

Gervás Barceló A, Mena Collado P, Reyes Tejero A, Núñez Márquez E, Matos Garrido N, Ortiz García I. Master of Implant Dentistry. Faculty of Dentistry. University of Seville.

Objectives: Overdentures arise as a good option to avoid, in the first instance, the use of conventional prostheses (which in many cases generate problems of retention, 
comfort, etc.). And they also arise to avoid more complex interventions in fixed rehabilitations with implants. Both are great advantages in their geriatric use.

The objective of this work is to carry out a bibliographic review of the use of this type of prosthesis in elderly patients and, in turn, of the results of its immediate loading with respect to the conventional one.

Material and Methods: an article search was conducted between 2000 and 2018 in Pubmed database

Results: The studies regarding the success of said treatment in elderly patients to whom mandibular implants are placed that exercise the function of retaining the overdenture immediately are good.

Conclusions: The immediate loading of the lower overdentures gives similar guarantees of success than their conventional loading as long as it is carried out following some protocols of surgery and the elaboration of the prosthesis.

\section{- Poster 42}

\section{TITLE:- PHANTOM TOOTH PAIN}

Gómez Mañas P, Baltasar Corral MV, Frutos Saucedo R, Rodríguez Martín A, Puente Gutiérrez C, López Sánchez $A$.

Expert in Oral Medicine. Rey Juan Carlos University.

Objectives: To know the hypothesis about the pathophysiology of the disorder, prevalence, diagnostic criteria and current lines of treatment.

Material and Methods: A bibliographic research has been done in Pubmed and Science Direct without limiting years of publication.

Results: Atypical odontalgia (AO), also called Phantom tooth pain, can be defined as a chronic pain located in a tooth or in the place of a tooth after an extraction, without clinical or radiographic pathology signs. Affecting 3-6\% of the population and in greater proportion to women, the symptoms described range from a strong and acute pain to a tingling sensation. Regarding to the mechanisms that cause OA, the pathophysiology of the syndrome is unclear. The most supported hypothesis is that it is a pain by deafferentation with neuropathic origin; however, its debut is associated in most cases with psychiatric disorders or with other pains of vascular origin. Currently, treatment with antidepressants is the one that have obtained the best results in patients affected with OA, followed by other drugs such as anticonvulsants and local therapies that are still being investigated.

Conclusions: The investigations carried out until today in relation to the physiopathology are insufficient to determine the mechanisms of the disease, as well as to establish protocols for the correct diagnosis and treatment.

\section{- Poster 43}

TITLE:- INFLUENCE OF DIABETES MELLITUS ON OSSEOINTEGRATION AND SURVIVAL OF DENTAL IMPLANTS. BIBLIOGRAPHIC REVIEW

\author{
Granger Marin E, Cabezas Mojón J, Diab A, Oliván \\ Molina S, Fernández Domínguez $M$. \\ Universidad CEU San Pablo.
}

Diabetes mellitus has usually been considered a contraindication when it comes to implant treatments, and it is becoming increasingly important to assess whether implant placement is viable in patients who suffer from this disease or who do not have good control of glucose levels, this may be a risk factor that can cause a failure in the treatment.

Objectives: The main objective is to determine the survival level of implants when they are inserted in diabetic patients.

Material and Methods: Different articles were found in databases of free access like PubMed, MEDLINE and Cochrane, using the search strategy with the connectors (dental implants OR oral implants) AND (diabetes OR diabetic) and the keywords: diabetes, dental implants, osseointegration and glycemic control.

Results: Articles reviewed affirm that the presence of diabetes has a direct influence on the osseointegration of dental implants, it has other problems associated with the mouth, however, if this diabetes is controlled there is no problem to carry them out.

Conclusions: Diabetes mellitus can affect the osseointegration, either due to the complications involved in the oral cavity, due to it's influence on bone remodeling or because it is a modifying factor in vascularization. However, good control of glucose with insulin therapy allows treatment to be carried out without major complications.

\section{- Poster 44}

\section{TITLE:- EFFECTIVENESS OF TERIPARATI- DE IN OSTEONECROSIS OF THE JAWS IN PA- TIENTS TREATED WITH BISPHOSPHONATES}

Hernández Zanotty G, Luque de Diego M, Longo A, Ortíz García I, España Lopez A, Velasco Ortega E. Master of Implant Dentistry. Faculty of Dentistry. University of Seville.

Objectives: To review the literature of the last five years to determine if teriparatide is really effective in osteonecrosis of the jaws in patients treated with bisphosphonates. 
Material and Methods: A paper review has been carried out in the database Pubmed between the years 2014 and 2019 using the words "teriparatide", "biphosphonatos", "osteonecrosis".

Results: The most important clinical effect of bisphosphonates is the inhibition of bone resorption by osteoclasts, which harms bone formation. ON first line of treatment is usually a passive conservative treatment, including antibacterial mouth rinse, oral antibiotics, and superficial debridement. Due to the anabolic action of teriparatide, it has been suggested as a beneficial treatment option in cases of improvement of bone remodeling, being very important in case of implant rehabilitation. It is currently the only drug to increase bone formation. There are studies that show that it is more effective when used before antiresorptive medications.

Conclusions: No scientific evidence has been found to claim that teriparatide is considered an effective adjuvant treatment for osteonecrosis of the jaws in patients treated with bisphosphonates.

\section{- Poster 45}

\section{TITLE:- ORAL MANIFESTATIONS DURING THE AGING PROCESS IN GERIATRIC PATIENTS}

Jimeno Rodríguez B, Cabezas Mojón J, Redondo Bellido F, Oliván Molina S, Álvarez Berenguer JA, Fernández Domínguez $M$.

Master in Oral Surgery and Implantology. University San Pablo CEU.

Aging increases the risk of deterioration and produces changes in the oral cavity that must be diagnosed and treated to improve life's quality.

Objectives: To transmit a greater knowledge in the odontogeriatric field about the repercussion of the natural processes of aging on the oral cavity of the geriatric patient. Material and Methods: Databases such as PubMed, Medline and Science Direct were used, using the following keywords: "oral changes", "geriatric dentistry".

Results: Due to the natural process of aging of the organism, and important number of elderly people presented oral manifestations in supporting tissues including atrophy of the papillae and hypertrophy of the tongue, attrition and erosion of the teeth, periodontal disease, atrophy of the oral mucosal epithelium, commissural cheilitis due to vitamin deficiency or loss of vertical dimension and reabsorption of the alveolar bone with thinning of the cortical. Some of these changes are natural process with a certain genetic, environmental or nutritional component and others are a consequence of medication of antihypertensive, anticholinergic, psychotropic and sedative, causing a reduction in the salivary function.
Conclusions: Numerous changes have been observed in the oral cavity of the geriatric patient, due to the aging process, which must be observed and meticulously diagnosed in order to propose a preventive and effective treatment.

\section{- Poster 46}

\section{TITLE:- THERAPEUTIC ATTITUDE TO THE TOOTH INCLUDED IN THE GERIATRIC PA- TIENT}

Jubera Pérez A, De Blas Alonso A, Roche Bellido A, Barrilero Martín C. Alobera Gracia MA, del Canto Pingarrón M.

Master's Degree in Oral Surgery, Implantology and Periodontics from de University of León.

Objectives: To determine the best treatment option against teeth included in geriatric patients taking into account the different factors that we could find, including pathologies, medication, poor oral opening, behavioral problems.

Material and Methods: A bibliographic review of scientific articles is made by consulting the Medline-Pubmed and The Cochrane Library databases of the last five years. The keywords used in the review were "oral surgery gerodontology", "tooth included", "therapeutic attitude geriatric extraction", using the operator "AND "

Results: Aging is a process that involves a series of anatomical and physiological changes that reduce the functional and physiological capacity of our body. The management of teeth included in this type of patients is of special importance. A thorough diagnosis must be made through clinical and radiological evaluation, as well as determining the possible associated complications and treatment options, individualizing each case. Three treatment options are evaluated for the included teeth: observation, orthodontic-surgical treatment and extraction of the same. In geriatric patients, traction is not considered and the other two therapeutic options will depend on the situation and circumstance of each patient, taking into account medication, pathologies and the need for action. Conclusions: The therapeutic attitude to the tooth included in gerodontological patients will depend on the risk situation that the patient presents due to pathologies and / or medication. We must put in a balance the risk / benefit of the treatment to be carried out. In this type of patients, the monitoring of the included tooth is considered the treatment of choice, as long as the situation allows it. 


\section{- Poster 47}

\section{TITLE:- IS OLD AGE A LIMITATION FOR THE DENTAL IMPLANT TREATMENT?}

Longo A, Perez Martinez, V, Rodríguez, Martin MM, Jiménez Guerra A, Monsalve Guil L, Velasco Ortega E. Master of Implant Dentistry. Faculty of Dentistry. University of Seville.

Objectives: Analyze as age can influence implants treatment prognosis in geriatric patient. Value if old age can represent a risk factor or a contraindication of treatment. Define what is upper age limit considered safe and predictable for the correct process of osteointegration and the success of oral rehabilitation treatment with dental implants. Material and Methods: A paper review has been carried out in the database between the years 1993 and 2018.

Results: Has been analyzed different groups of elderly patients treated with oral implants, and it's been showed that there is not any significant difference during the correct process od osteointegration.

Conclusions: Discarding any risk factors, usually associated to elderly patients, age does not represents a limitation in oral implant treatments. Oral implant treatment, when it is well diagnosed and well planned, it's predictable and safe in these patients.

\section{- Poster 48}

\section{TITLE:- 3D PRINTING AND FACIAL SCANNING IN ELDERLY PATIENTS}

Gautreau Nadal JL, Gautreau Nadal JM, Luque de Diego M, España López A, Moreno Muñoz J, Ortiz Garcia I. Master of Implant Dentistry. Faculty of Dentistry. University of Seville.

Objectives: The information we can obtain of soft and hard tissue with a facial scanner, blend with the data obtained from an intra or extraoral scan of the mouth, can let us plan and reproduce in a predictable outcome a aesthetic and functional rehabilitation for our patients in record time. The objective was to make a systematic review of this field.

Material and Methods: Systematic review in Pubmed database of papers in JCR journal during last 5 years.

Results: The improvemant we have in a timely, aesthetic and functional plane will be both beneficiary for the patient and the dentist. Systems like Bellus, AFT, Artec spider joined with dental planning softwares such as exocad or meshmixer and with 3D printer ( Nexdent, Anycubic, Moonray), either for inmediate loading or previous rehabilitations before the final prothesis with a digital waxup, that we will later translate into reality to avoid future mistakes, surprises to the patient.

Conclusions: The rehabilitation of elderly patients, in combination with a good protocol can lead to a normal or immediate fixed prothesis with high degree of predictability and accuracy in a low cost.

\section{- Poster 49}

\section{TITLE:- INCREASE KERATINIZED TISSUE IN MANDIBULAR EDENTULOUS GERIATRIC PA- TIENTS}

Lopez Nogales J, Malano Martinez A, Hernández Zanotty G, Nuñez Marquez E, Jiménez Guerra A, Matos Garrido N.

Máster de Implantología Oral. Facultad de Odontología. Universidad de Sevilla.

Objectives: Using tecniques such as vestibuloplasty, it can be possible to remove muscular insertions and the mucosa can be repositioned apically. With free gingival grafts or a collagen matrix xenograft, we can increase the keratinized tissue. As a result, a better quality tissue and a more stable area can de obtained.

Material and Methods: A bibliographic search in the pubmed database is carried out, with the key words: vestibuloplasty, mandible, overdenture,matriz, collagen, atrophy, keratinised gingiva, free mucosa graft. Related articles in the last 10 years were selected.

Results: The selected articles were compared in terms of keratinised tissue increase and a decrease in the vestibular bottom with, or not, free mucosa grafts or collagen matrix. Good result were obtained with all tecniques.

Conclusions: Apart from the limitations of this review, as a conclusion, it can be said that with all the keratinised tissue increase techniques, a better quality of tissue is obtained in the implants as well as stability and a longterm predictability.

\section{- Poster 50}

TITLE:- DENTAL ATTENTION PROTOCOL IN THE GERIATRIC PATIENT TREATED WITH NEW ORAL ANTICOAGULANTS

Lorenzo Carballal AC, Fernández-Nespral Loring V, Granger Marín E, Cabezas Mojón J, Oliván Molina S, Fernández Domínguez M.

Master in Oral Surgery and Implantology. University San Pablo CEU. Madrid. 
The new oral anticoagulants are an important alternative to vitamin $\mathrm{K}$ antagonists in the prevention and treatment of thromboembolisms and strokes.

Objectives: To establish an attention protocol for the clinical management of the geriatric patient treated with new oral anticoagulants.

Material and Methods: Independent bibliographic search strategies were conducted, using the MEDLINE and the Cochrane Plus Library databases, , with the following keywords: "anticoagulant", "dentistry", "oral surgery".

Results: According to several authors, it is determined that it is not necessary to suspend anticoagulant treatment in procedures with low risk of bleeding. In contrast, in view of the concern for excessive bleeding and/or the presence of renal pathology, according to other authors it is suggested to interrupt it at least $24 \mathrm{~h}$ before the procedure since dabigatran, rivaroxaban, apixaban and edoxaban have a short onset of action and predictable pharmacokinetics that reduce bleeding without increasing the risk of thromboembolic events. However, an agreement is reached on the need to perform local hemostatic measures to control postoperative bleeding.

Conclusions: Currently, the scientific evidence does not present a consensus that allows establishing a protocol of action regarding patients treated with new oral anticoagulants. However, it is important to evaluate the bleeding risk of each treatment, the presence of renal pathology, the availability of hemostatic measures and the need to query with the responsible doctor to determine the maintenance or cessation of the drug.

\section{- Poster 51}

TITLE:- SURGICAL AND PROSTHETIC RELATED FACTORS WITH PERI-IMPLANT BONE LOSS

Luque de Diego M, Hernández Zanotty G, Gervás Barceló A, Ortiz Garcia I, Nuñez Márquez E, Matos Garrido $N$.

Master of Implant Dentistry. Faculty of Dentistry. University of Seville.

Objectives: To asses differences in marginal bone loss in implants under three circumstances: when the implants are placed at crestal versus subcrestal level, when they are placed immediately or delayed and when they are rehabilitated with immediate loading.

Material and Methods: A review has been carried out in the database Pubmed between 2015 and 2019.

Results: Several studies reported that marginal bone loss in immediate implants is similar to that of delayed implants. Some researches have found similar bone loss in implants at a crestal and subcrestal level. Nevertheless, some authors agree to place the subcrestal implant to preserve the keratinized tissue: it may reduce the probability for the implant to become exposed in the future and thus avoid the risk of suffering from peri-implant pathologies. Finally, there are studies which reported that, although the overload of the prosthesis may lead to the loss of the implant, cases with favorable conditions to be rehabilitated by immediate loading presented stable levels of marginal bone.

Conclusions: Marginal bone loss seems to be similar in both immediate implant placement and delayed placement. The subcrestal position seems to be beneficial for maintaining the peri-implant bone over time. Apparently, the immediate loading of dental implants offers good results against bone loss.

\section{- Poster 52}

\section{TITLE:- VITAMIN D DEFICIENCY AS A RISK FACTOR FOR OSSEOINTEGRATION}

Malano Martínez A, Lopez Nogales J, Mena Collado P, Nuñez Marquez E, España López A, Velasco Ortega E. Master of Implant Dentistry. Faculty of Dentistry. University of Seville.

Objectives: In Spain, the deficiency of vitamin D in the population over 65 years reaches between $80 \%$ and $40 \%$ in people under 65 years. Osseointegration of dental implants could be negatively influenced by vitamin D deficiency. The aim of this study was to review the literature about the relationship between vitamin D deficiency and the osseointegration of dental implants.

Material and Methods: Literature review through the search of a simple keyword algorithm in indexed databases of articles published between 2009 and 2019.

Results: Seven experimental studies were found in animals, a retrospective study and a case report. Experimental studies indicate that the deficiency of the vitamin had a negative impact on the peri-implant cortical bone and when receiving supplementation, it had greater bone formation and/or bone-to-implant contact. Only one study reported no difference in micronutrient supplementation, including vitamin D3, in healthy rats. In the retrospective study, osseointegration was affected while decreasing serum vitamin D levels; the author found no statistically significant differences. The report of clinical cases directly relates vitamin D deficiency and osseointegration. Conclusions: Randomized clinical trials can be useful to find the correlation of vitamin D deficiency and osseointegration of dental implants. The supplementation with vitamin D in dental implants could have a beneficial effect. 


\section{- Poster 53}

TITLE:- SHORT IMPLANTS AS AN ALTERNATIVE TO SINUS LIFT IN GERIATRIC PATIENTS

Martín Vaquero A, Perez Saavedra P, Lopez Nogales J, Moreno Muñoz J, Matos Garrido N, Jiménez Guerra A. Master of Implant Dentistry. Faculty of Dentistry. University of Seville.

Objectives: Evaluate the treatment with short implants for an atrophic posterior maxilla in comparison with the standard implant associated with a sinus lift.

Material and Methods: Articles published between 2017 and 2019 were searched in the Medline (Pubmed), Scielo and ScienceDirect databases. Included keywords are "Short implants", "Short dental implants", "Sinus lift".

Results: Basing our study on the selected articles, short implants are, nowadays, the best alternative to conventional bone regeneration techniques, including sinus lift, due to fewer biological complications and similar survival and marginal bone loss rates. However, the risk of prosthodontic complications associated with this type of implant should be taken into account.

Conclusions: The need to reduce working times, economic costs and intraoperative morbidity together with the growing demand for implant-supported restorations in patients of an ever-increasing age range makes it necessary to add short implants among our implant rehabilitation options.

\section{- Poster 54}

TITLE:-OSTEOPOROSIS AS A RISK FACTOR FOR OSTEOINTEGRATED IMPLANTS. A SYSTEMATIC REVIEW

Melero Alarcón C, Cano Durán JA, Blanco RuizS, Pérez González F, Hernandez de Oliveira M, Buesa Barez JM. Máster de Cirugía Bucal e Implantología, Universidad Complutense, Madrid.

Objectives: Osteoporosis is a generalized disease of the skeleton characterized by a $25 \%$ decrease in bone mass. With the present systematic review, the relationship between osteoporosis and the failure of dental implants placed in patients suffering from this pathology is sought, as well as whether the therapies used for the treatment of osteoporosis can influence in some way the osseointegration of the implants.

Material and Methods: A search was performed in the PUBMED / MEDLINE and Cochrane database with the keywords ((Osteoporosis) OR Osteopenia) AND ((Dental implant) OR Osseointegration). The inclusion criteria were articles of greater scientific evidence found, in English made in humans without restriction in time.

Results: Of a total of 635 eligible studies, 16 were included to perform this systematic review. In the different studies, there are no conclusive studies with higher rates of failure or peri-implantitis, or a lower percentage of bone-implant contact in patients with osteoporosis.

Conclusions: Within the limitations of the present systematic review, it can be concluded that, although in some studies there has been an association between osteoporosis and the highest implant losses, the results are not significant, there being weak evidence for give the reason or refute the hypothesis that osteoporosis can have detrimental effects on the osseointegration of implants and healing.

\section{- Poster 55}

TITLE:- CLINICAL MANAGEMENT OF PATIENTS UNDER BISPHOSPHONATES TREATMENT WITH RISK OF OSTEONECROSIS OF THE JAW

Mena Collado P, Gervás Barceló A, Romero Alfageme M, Nuñez Márquez E, Gil González J, Rondón Romero $\boldsymbol{J L}$.

Master of Implant Dentistry. Faculty of Dentistry. University of Seville.

Objectives: Bisphosphonates are one of the drugs which cause most problems during dental treatment, so the general dentist, and even more specialists in implantology, must assess this possible risk.

Material and Methods: A paper review has been carried out in the database Pubmed and Medline between the years 2003 and 2019.

Results: Bisphosphonates administered intravenously or orally for a long period of time can cause osteonecrosis in the jaws. It is necessary know perfectly the drugs that belong to this group and the plan of treatment to follow when will attend a patient taking this type of medication, to avoid the possible development of maxillary osteonecrosis.

Conclusions: It is very important to make a good clinical history of the patient and to know perfectly the treatment that is being submitted, so that we can develop a good treatment plan to avoid the occurrence of maxillary osteonecrosis, and in the case of suffering it, be prepared to treat it effectively. 


\section{- Poster 56}

TITLE:- COMPUTER GUIDED SURGERY SOFTWARES USED IN THE PLANNING OF IMPLANT TREAT-MENT IN GERIATRIC EDENTULOUS PATIENTS

\author{
Oliveira NA, Matos Garrido N, Monsalve Guil L, More- \\ no Muñoz J, Nuñez Márquez E, Velasco Ortega E. \\ Master of Implant Dentistry. Faculty of Dentistry. University of \\ Seville.
}

Objectives: The aim of this study is to assess the publications related with acuraccy, clinical outcomes, limitations and complications of guided implant surgery in geriatric edentulous patients.

Material and Methods: It is perfomed a systematic review of related papers with guided surgery in older patients in Pubmed y Medline during last 10 years.

Results: The combine use of CBCT imaging with a computer software of guide surgery can planning the best location of implants in anatomical structures and the future prosthesis in geriatric edentulous patients. The accuracy of guided surgery is more high that conventional surgery. Planning achieve the fabrication of surgical templantes.

Conclusions: Guided surgery software achieve the surgical implant planning with a set of virtual system very important in the cases of severe resorption of maxilla/ mandible very frequent in edentulous older patients.

\section{- Poster 57}

\section{TITLE:- ONCOLOGICAL PATIENTS AND ORAL SURGERY: PREVENTING AND TREATING ORAL COMPLICATIONS}

Oponowicz L, Cabezas Mojón J, Burgos Montes M, Oliván Molina S, Fernández Domínguez M.

Master of Oral Surgery and Implantology. University San Pablo CEU, Madrid.

The odontologic treatment of oncologic patients may be one of the biggest challenges a dentist might confront at the dental practice. The knowledge on how to prevent and treat possible acute or chronic oral complications, like xerostomia or oral mucositis is essential since their prevalence is sometimes as high as $100 \%$ in post-irradiated patients. For the best prevention, a dental protocol should be followed, which is divided into three phases: pre, intra and post oncological care, and treatment. In addition, a multidisciplinary team is very important for better attention of this type of patients.

Objectives: Prevention and treatment of oncological patients undergoing oral surgery with possible compli- cations before and after the treatment. (chemotherapy/ radiotherapy).

Material and Methods: Data were obtained from PubMed, Cochrane, Lilacs, UpToDate. Between the year 2008-2018. The exclusion criteria were lower grade evidence analysis and papers not included in JCR, Journal Citation Reports. In total there had been 50 articles revised. Keywords: Oncologic-dentistry, pre and post dental treatment of oncological patients.

Results: Prevalence of xerostomia pre-radiotherapy $10 \%$, during therapy $81 \%$ and after 2 years $91 \%$. Osteoradionecrosis after radiotherapy was observed in $7.4 \%$ of cases.

Conclusions: Oncological therapies produce many acute and chronic oral complications. To avoid as many as possible, a dental protocol before, during and after the therapies should be followed for the best preventive care and treatment. Among the most common post-therapy, oral complications are xerostomia, oral mucositis and oral pain.

\section{- Poster 58}

TITLE:- THERAPEUTIC VIABILITY OF MINIIMPLANTS IN IMPLANT-RETAINED MANDIBULAR OVERDENTURES

Parra García S, Botellé del Hierro R, Gautreau Nadal $J$ L, Matos Garrido N, Nuñez Marquez, E, Moreno Mu$\tilde{\boldsymbol{n}} \boldsymbol{} \boldsymbol{z} \boldsymbol{E}$.

Master of Implant Dentistry. School of Dentistry. University of Seville.

Objectives: Today, mandibular overdentures with miniimplants can improve the prognosis of edentulous patients. The objective is to assess is an appropriate treatment option in severemadibular resorption in geriatric patients.

Material and Methods: A PubMed MedLine database search of studies based in humans was carried out with the keywords "mandibular overdenture" "mini implant". The time limitation was applied in the period between 2008-2019. The preference of the studies was focused on the trials, the systematic reviews and the meta-analysis.

Results: The placement of two mini implants on the interforaminal area in the edentulous mandible of the geriatric patient proves to be a reliable, low invasive, predictable and stable alternative over time. The patients refer an optimal quality of life. The investigations show how they sometimes show retentive values and perceived comfort similar to standard diameter implants. The existing bibliography recommends for a better prognosis and biomechanical behavior, as well as distribution of forces; 
the placement of 4 miniimplants in patients with severely reabsorbed edentulous mandible.

Conclusions: The mini implants are a feasible, predictable and not very traumatic alternative, which is why they are suitable for the retention of overdentures in elderly patients with severe mandibular atrophy.

\section{- Poster 59}

TITLE:- USE OF CONE BEAM COMPUTED TOMOGRAPHY IN IMPLANT TREATMENT OF OLDER PATIENTS

Pérez Errázuriz S, Balawi Balawi O, Gil González J, Jiménez Guerra A, Monsalve Guil L, Velasco Ortega E. Master of Implant Dentistry. Faculty of Dentistry. University of Seville.

Objectives: To identify, review, analyze and summarize the evidence available in the literature the benefits and limitations of $\mathrm{CBCT}$ in the treatment with dental implants in older patients.

Material and Methods: The search was performed in databases (Pubmed \& Medline) from January 2015 to March 2019.

Results: The literature described that the CBCT bring cross-sectional images with high precision and image quality for linear measurements on bone tissue. It should be noted that it should be used as a complementary tool that provides a benefit for the patient in terms of diagnosis or treatment plan. The importance of taking care a distance to the anatomical structures that occur in the oral cavity, to avoid complications during the surgical act.

Conclusions: The CBCT can be used in the pre-surgical, intraoperative and postsurgical stages of implant surgery. It is a technique that provides less radiation to the patient and delivers optimal image quality.

\section{- Poster 60}

\section{TITLE:- BONE EXPANSION TECHNIQUE FOR IMPLANT INSERTION IN ELDERLY PATIENTS}

Perez Martinez V, Rodriguez Martin M, Gautreau Nadal JM, Moreno Muñoz J, Ortiz Garcia I, Velasco Ortega E. Master of Implant Dentistry. School of Dentistry. University of Seville.

Objectives: In elderly patients there is usually a horizontal loss of the alveolar ridge, which requires complementary techniques for the placement of implants. The expansion is a technique that allows a gain in horizontal volume and the objetive is to know the characteristics of the technique applied in elderly patients.

Material and Methods: A systematic bibliographic review of the scientific literature has been carried out in the Pubmed database, using the following inclusion criteria: in humans, in English and in Spanish, written or published in the last 10 years, and the next key words, split crest; alveolar ridge aumentation; alveolar bone loss, osteotomy; piezosurgical procedure.

Results: 144 articles were obtained in Pubmed. After reviewing them by title and abstract, 18 articles were chosen for their relationship with the subjet. Bone expansion is a realiable and non-invasive technique that allows early bone gain with a rapid revascularization. This method was the most deefended by the authors.

Conclusions: Bone expansion is a predictable technique and with a lower postoperative incidence for the rehabilitation of elderly edentulous patients.

\section{- Poster 61}

\section{TITLE:- SINGLE IMPLANT AS RETENTION IN MANDIBULAR OVERDENTURES IN GERIATRIC PATIENTS}

Pérez Saavedra P, Martin Vaquero A, Reyes Tejero A, Moreno Muñoz J, Jiménez Guerra A, Núñez Marquez E. Master of Implant Dentistry. Faculty of Dentistry. University of Seville.

Objectives: To review in the literature the parameters of patient satisfaction and the masticatory effectiveness provided by the overdentures retained by an implant, two implants and conventional complete mandibular prostheses in totally edentulous patients.

Material and Methods: A search of articles in databases (PubMed and Scielo) with "overdenture implants" as keywords and "free full text", "five years" and "human" as filters, and publications consultations between 2014 and 2019 as well.

Results: From the articles provided by the search, 6 of them were selected as they are the most current and relevant for the study.

Conclusions: The placement of a single implant at the mandibular symphysis level is a valid treatment option to provide retention to mandibular overdentures in patients with total edentulism, by improving significantly the masticatory effectiveness and patient satisfaction, and reducing the economic cost and surgical complications especially in the case of a general deficit health, habitual characteristic in geriatric patients. 


\section{- Poster 62}

TITLE:- EFFICACY OF DENOSUMAB TREATMENT IN RECURRENT AND REFRACTORY GIANT CELL TUMORS IN THE JAWS

\author{
Ramos Quirós R, Akasuso Goitia ML, Duque Estévez \\ C., del Canto Pingarrón $M$, Baca Perez-Bryan $R$, \\ Alobera Gracia MA. \\ Master's degree in Oral Surgery, Implantology and Periodon- \\ tics. University of Leon. Spain.
}

Objectives: Determine the relevance of denosumab in the treatment of giant cell tumors (GCTs) of the jaws.

Material and Methods: A bibliographic search was carried out in Pubmed, Cochrane, Science Direct, Dialnet, Scielo and Ovid databases. Only valid results were achieved in Pubmed. Using the keywords "giant cell AND tumor" and "giant cell tumor AND denosumab" we obtained 48,034 results, 3 were finally valid.

Results: GCTs are aggressive lesions, rich in RANKL, and usually require combined treatment of enucleation with adjuvant therapies. Recently, Denosumab has been used effectively in long bone GCTs. However, there is less experience in the jaws, where its effect is still unknown. It is a monoclonal antibody that inhibits RANKL, approved for the treatment of non-resectable or refractory GCTs in adults and adolescents with skeletal maturity (requiring individualization of doses). Under this treatment, the lesion remains dimensionally stable, sclerotic and strongly calcified. No associated adverse reactions have been reported, and a radiological and pathological resolution was shown after one year of treatment. Bone turnover markers, calcium and vitamin D levels, dental images/biopsies and bone densitometry measured at the beginning of the study and in appropriate intervals provide clinical support to determine the duration of treatment.

Conclusions: Denosumab is an effective treatment for GCTs in the jaws. However, additional studies are required to confirm that, as well as to elucidate the quantitative measures in the monitoring of the clinical results and to know their negative effects, in order to be able to prevent them.

\section{- Poster 63}

TITLE:- TRANSZIGOMATIC IMPLANTS. SURGICAL TECHNIQUE AND COMPLICATIONS

Redondo Bellido F, Cabezas Mojón J, Diab N, Oliván Molina S, Fernández Domínguez M.

Master in Oral Surgery and Implantology. San Pablo CEU University. Madrid.
In a maxilla of an elderly patient, treatment with implants is not supposed to be a feasible solution. Since the discovery of transgenomatic implants by Bränemark and its intrasinusal technique, several authors tried to improve their placement procedure and prosthodontic results: sinus groove technique (Stella and Warner), extrasinusal technique (Miglioranca) and ZAGA concept (Aparicio).

Objectives: 1. Indicate the advantages of the new surgical techniques of the transzigomatic implants compared to the original technique. 2 . To study the incidence of sinusitis as a complication in the surgery of transzigomatic implants.

Material and Methods: A search was made in the PubMed, EBSCO, Dialnet and Google Academic databases, taking as an inclusion criterion the articles published after 2004 and in Spanish and English.

Results: The analysis of the data suggested that the transzigomatic implant presents a survival percentage of almost $100 \%$ in the medium and long term, independently of the technique used; However, new surgical techniques prevent the head of the implant from emerging towards the palatine, achieving less voluminous prostheses. Of the complications associated with these implants, sinusitis was the most significant, presenting from 0 to $27 \%$.

Conclusions: 1 . The new transzigomatic implant fixation techniques presented greater advantages at the prosthetic level compared to the original technique. 2 . The techniques that compromise the integrity of the maxillary sinus (intrasinusal and sinus slot) revealed a higher incidence of sinusitis than the extrasinusal technique.

\section{- Poster 64}

\section{TITLE:- IMMEDIATE IMPLANT LOADING OF MAXILLARY POSTEXTRACCION IMPLANTS IN ELDERLY PATIENTS}

Reyes Tejero A, Romero Alfageme M, Ureña Castro F, Matos Garrido N, Jiménez Guerra A, Velasco Ortega E. Master of Implant Dentistry. Faculty of Dentistry. University of Seville.

Objectives: Immediate implants in fresh sockets constitue a clinical protocol that reduce the timing of the treatment. The basis is the insertion of the implant in the same time of the extraction of the teeth without alternative treatment, that can be loaded with immediate prosthesis. The objective of this study is to show the indications of this surgical technique in geriatric patients.

Material and Methods: A paper review has been carried out in the database Pubmed and Medline between the years 2004 and 2019. 
Results: The first indication of the immediate implants in fresh sockets is a reduction of time and the treatment of teeth with irreversible pathologic condition. This technique avoid a second surgery of implant insertion, and finally to reduce partially the reabsorption of periimplant tissues

Conclusions: A comprehensive diagnostic evaluation of geriatric patients and a correct planning based on a suitable surgical and prosthetic protocol allows the achievement of an alternative for success in the treatment.

\section{- Poster 65}

\section{TITLE:- COMPARISON OF IMPLANT SUCCESS BETWEEN OLDER AND YOUNGER ADULT PA- TIENTS}

Riballo Herrera S, Parra García S, Luque de Diego M, España López A, Moreno Muñoz J, Ortiz García I. Master of Implant Dentistry. Faculty of Dentistry. University of Seville.

Objectives: Partial and total tooth loos is a frequent oral condition in older people. The treatm,ent with dental implants has changed the dental rehabilitation in these patients. The objective is to compare the success rates in old adults with young adult patients

Material and Methods: A search of articles was carried out in the Pubmed and Medline databases between 2000 and 2019.

Results: The success rates in the observed reviews indicate that there is a greater percentage of success in the implants placed in elderly patients than in the young adult patients, in overdentures and fixed bridges. Early implant losses were more frequent in younger patients compared to older patients.

Conclusions: It is demonstrated in reviews that old age is not an important risk factor for implant failures, since it presents a higher rate of success than young adult patients.

\section{- Poster 66}

TITLE:- OSTEONECROSIS OF JAWS RELATED WITH THE DENTAL IMPLANTS IN OLDER ADULTS TREATED WITH DENOSUMAB

Rodríguez Martín MM, Perez Martinez MV, Malano Martinez A, Moreno Muñoz J, España Lopez A, Velasco Ortega $E$.

Master of Implant Dentistry. Faculty of Dentistry. University of Seville.
Objectives: An implant treatment is frequently demanded nowadays by older patients. The denosumab is a common medicine which can be used by both, men and women. We want to know its relation with the osteonecrosis of the jaws.

Material and Methods: A bibliographic searching of scientific articles published between 2009 and 2019 was made in Pubmed and Medline.

Results: The denosumab is a monoclonal antibody which acts as ligando Rank's inhibitor. The relation of the denosumab with the osteonecrosis of the jaws is clear and moreover it takes place when an invassive dental intervention is produced, as for example if we aplly a dental implants treatment due to the fact that denosumab does not allow the uterus osseous joining. There are not researches which evaluate the medicine suppresion effectiveness before making and invassive dental intervention of the ONM's effect reduction.

Conclusions: Denosumab's comsumption can favour the osteonecrosis of the jaws in an invassive dental intervention but the pathology is not known exactly yet when the osteonecrosis has been induced by medicines. The AAOMS recomm

ends a multidisciplinary approach based on the prevention.

\section{- Poster 67}

\section{TITLE:- OSTEONECROSIS OF THE JAWS. SYS- TEMATIC REVIEW}

Rodríguez Rodríguez N, Sancho Esper RS, Paisal Sordo I, Jacobo Orea C, del Canto Pingarrón M, Alobera Gracia MA.

Master's Degree in Oral Surgery, Implantology and Periodontics from de University of León.

Objectives: Osteonecrosis of the jaws has been related to medication (MRONJ) being a serious adverse reaction of antiresorptive and antiangiogenic agents. The objective of this work is to familiarize the clinician with the current state of the problem, the possible causes and the different protocols of preventive action in patients at risk, before and during the administration of the related medications.

Material and Methods: Was performed a literature search of systematic reviews using the MEDLINE database through PubMed using as key words: "osteonecrosis of the jaw", "medication related osteonecrosis of the jaw", selecting the most relevant articles published between 2016 and 2018.

Results: Depending on the type of medication related to osteonecrosis of the jaws are antiresorptive or antiangio- 
genic drugs, according to the type of dose, duration of exposure, the onset of this adverse reaction may be more predisposing. Obtaining that the development of new medicines in the treatment of cancer, autoimmune and bone conditions has led to the reporting of more cases of MRONJ.

Conclusions: Dentists have a fundamental role in reducing the risk of MRONJ by application of a correct protocol of primary prevention before and after treatment, being crucial the knowledge of new medicines and their associated risks. The need for a standardized multidisciplinary approach, with a sustained dialogue among the specialists involved should always be adopted to improve the effectiveness of preventive strategies and improve the patient's quality of life.

\section{- Poster 68}

TITLE:- SOCKET SHIELD: TECHNIQUE IN THE PRESERVATION OF THE ALVEOLAR RIDGE AND GINGIVAL CONTOUR IN AESTHETIC AREAS

Romero Alfageme M, Reyes Tejero A, Martin Vaquero A, Matos Garrido N, Nuñez Marquez E, Velasco Ortega E.

Master of Implant Dentistry. Faculty of Dentistry. University of Seville.

Objectives: Socket Shield technique is an effective method of preserving the buccal bone and gingival profile table. This technique and all its variants have been called "partial extraction therapies."

Material and Methods: a search of articles was carried out in Pubmed, Medline and Scopus databases between 2010 and 2018.

Results: The main indication of this technique is the implant replacement in the anterior sector of the maxillary, of those teeth that are not restorable and this extraction is indicated, they must have root without being the periapical pathology a contraindication to apply this technique. Of all the cases studied, the incidence of complications / failures is very low, and satisfactory results were obtained in all of them.

Conclusions: The partial extraction therapies are effective to preserve the bone and gingival profile as a consequence of the preservation of the periodontal ligament associated to the radicular fragment that is retained in the alveolus that favors the blood supply of the hard lamina.

\section{- Poster 69}

\section{TITLE:- TREATMENT OF GERIATRIC EDEN- TULOUS PATIENTS WITH MANDIBULAR OVERDENTURES RETAINED BY TWO IM- PLANTS}

\author{
Rondón Romero JL, Gil González J, España López A, \\ Ortiz Garcia I, Monsalve Guil L, Velasco Ortega E. \\ Master of Implant Dentistry. Faculty of Dentistry. University of \\ Seville.
}

Objectives: Implant dentistry has changed the negative effects of convencional removable dentures in older edentulous patients. This study reports the assessment of treatment with overdentures in the mandible in edentulous older patients.

Material and Methods: 54 edentulous patients were treated with 108 Galimplant ${ }^{\circledR}$ implants for prosthodontic rehabilitation with overdentures in the mandible. Two implants were inserted in each patient. Implants were loaded after a healing free-loading period between 6 weeks with locator attaches Overdent ${ }^{\circledR}$. Clinical findings (implants and prosthodontics) were followed during at least 60 months.

Results: Clinical results indicate a survival and success rate of implants of $96.3 \%$ after a mean follow-up of 94,6 months. Four implants failed. Two implants was lost by mobidity and after two implants by peri-implantitis. 54 overdentures retained two implants were perfomed. Technical complications were related with changes of attaches reported in 20 implants (18.5\%). Mean marginal bone loss was $0.5 \mathrm{~mm}$.

Conclusions: Clinical results of this study indicate the success of treatment with mandibular overdentures retained with two implants in geriatric patients.

\section{- Poster 70}

\section{TITLE:- ORAL STATUS OF ELDERLY PATIENTS INTERNED DURING A LONG STAY IN A HOSPI- TAL OR GERIATRIC CENTER. A SYSTEMATIC REVIEW}

Ruiz Roca JA, Martínez Beneyto Y, Martín Fuentes D, Pecci Lloret M, Guerrero Gironés J, Linares Tovar EK. Gerodontología. Departamento de Dermatología, Estomatología, Radiología y Medicina Física. Facultad de Medicina. Universidad de Murcia.

Objectives: To conduct a systematic review in order to know the oral health status of elderly patients admitted to institutions or hospitalized for a long period of time. 
Material and Methods: A systematic review of the literature published in PubMed and Cochrane Library was carried out, with 12 combinations of keywords following the selection criteria that were established: clinical studies published in the last 5 years, in English and / or Spanish, with samples $\geq 30$ patients, performed in patients $>65$ years, admitted to any type of institution and/or hospital center during, at least, 7 days and in which the state of hard and/or soft tissues of the oral cavity were evaluated in some way. The selected articles were subjected to a complete analysis.

Results: The search strategy result in 1.014 articles, and selected 5 articles for our review. Regarding the oral situation of the participants of the different studies, we conclude that, only Gerritsen et al (2015) specify it, it is understood that also a great need for treatment.

With regard to oral care measures, Poisson et al (2014) does not reflect whether or not any type of oral hygiene protocol is followed.

Conclusions: the oral health of the patients $>65$ years old is worse than the rest population, to being in a situation of long hospital stay or institutionalized in some type of residence or center. It is necessary to study this issue and the development of protocols for the oral health care of these patients, as well as training programs for the personnel responsible for it.

\section{- Poster 71}

\section{TITLE:- ORAL ANTIAGREGANTS. PROTOCOLS}

Sánchez Sánchez L, Ciudad Cano M, Gil Bado C, del Canto Pingarrón M, Baca Pérez-Bryan R, Alobera Gracia MA.

Máster en Cirugía Bucal, Implantología y Periodoncia de la Universidad de León.

One of the main causes of mortality at present are cardiovascular diseases, so it is common to find patients under treatment with antiaggregant medication for this pathologies. Antiplatelet drugs increase the bleeding during and after oral surgery procedures and the risk increases with dual therapies. The suspension of antiplatelet therapy prior to dental treatment to avoid increased bleeding and complications is no longer indicated, since it implies a greater risk of discontinuing it than the risk of postoperative bleeding.

The current protocols recommend maintaining the patient's anticoagulant treatment, and performing local hemostatic measures (suturing the wound, compression with tranexamic acid impregnated gauze, hemostatic sponges ...) to control bleeding and complications.
Objectives: The aim of this literature review is to analize the most common antiagregants drugs (AAS, Clopidogrel, Prasugrel, Ticaprelor) to be able to establish a protocol to control of bleeding and postoperative complications.

Material and Methods: A literature search is done in pubmed with the keywords antiaggegants, extraction, surgery, dental.

Results: 31 paper are selected for the astract reading, from which they pass to the analysis phase 14 .

Conclusions: The use of antiplatelet therapy increases bleeding and the incidence of postoperative complications after oral surgery. The withdrawal of antiplatelet medication is not indicated due to an increased risk of cerebrovascular accident. Bleeding and post-surgical complications can be controlled with local hemostatic measures even in the case of dual antiplatelet therapy.

\section{- Poster 72}

\section{TITLE:- BONE REGENERATION WITH BETA- TRICALCIUM PHOSPHATE IN SINUS LIFT IN GERIATRIC PATIENTS WITH SEVERE ATRO- PHY OF THE POSTERIOR MAXILLA}

Sierra Baztán A, Jiménez Guerra A, Matos Garrido N, España López A, Monsalve Guil L, Velasco Ortega E. Master of Implant Dentistry. Faculty of Dentistry. University of Seville.

Objectives: In oral implantology in geriatric patients due to the great bone loss that usually occur in the posterior maxilla we must opt for regeneration techniques to increase the bone volume necessary for the insertion of the implants. Due to advances in the world of implantology, new regeneration materials have been incorporated, such as beta-tricalcium phosphate.

Material and Methods: A systematic review was carried out in the Pubmed and Medline databases, selecting articles from the last 5 years.

Results: It has been observed in different studies that after a period of 6 months the bone material obtained with the use of beta-tricalcium phosphate is very similar to that obtained with autologous bone. Beta-tricalcium phosphate is a temporary material used to help the new formation of bone but in a period of about 6-9 months is reabsorbed.

Conclusions: It has been proven that beta-tricalcium phosphate is an excellent material with osteoconductive property to be able to regenerate bone. 


\section{- Poster 73}

TITLE:- IMMEDIATE LOADING PROTOCOLS WITH INTRAORAL WELDING IN EDENTULOUS PATIENTS

\author{
Gautreau Nadal JM, Gautreau Nadal JL, Perez Saavedra \\ P, España López A, Moreno Muñoz J, Ortiz Garcia I. \\ Master of Implant Dentistry. Faculty of Dentistry. University \\ of Seville.
}

Objectives: So, the use of intraoral welding is going to be subjected to a method to ensure the success of the treatment of our patients with immediate loading where the primary stability of these implants may or may not be adequate to perform such immediate loading. the immediate loads in the provisionalization phase the prosthesis can be split and consequently lose implants which makes it difficult for us to have predictable and stable results.

Material and Methods: A search of articles in the Pubmed databases with the keywords was carried out. "Intraoral welding", " Failure of implants in the provisional phase "

Results: The functional load in Immediate implants generates enough controversy due to the failure in the early phase of osseointegration due to the fractures of our provisionals and unwanted movements due to the complete non-splinting of our implants, it is verified that using an intraoral welding and performing a splinting of all our pillars to perform our immediate load we achieve greater passivity and less rate of loss of our implants

Conclusions: It has been verified that the passivity and the range of implant survival in immediate loading is greater when we use intraoral welding, which is why we consider it an essential tool in our day-to-day life for the treatment mentioned above.

\section{- Poster 74}

\section{TITLE:- SJÖGREN SYNDROME. TREATMENT ALTERNATIVES}

Frutos Saucedo R, Gómez Mañas P, Baltasar Corral MV, Rodríguez Martín A, Migueláñez Medrán BC, López Sánchez A.

Expert in Oral Medicine. Rey Juan Carlos University.

Objectives: To know new alternatives for the treatment of the disease in order to have a better management of the patient at the dental clinic.

Material and Methods: A bibliographic review has been done in Pubmed and Cochraine Library databases. Keywords: Sjögren Syndrome and treatment.

Results: Sjogren's Syndrome is a chronic autoimmune systemic disorder that mainly affects the exocrine glands. It is produced by a leukocyte infiltration process that progressively destroys the glands, the main ones are the salivary and lacrimal. It can be primary origin if it appears isolated or secondary if it is accompanied by systemic diseases such as Rheumatoid Arthritis and Systemic Lupus Erythematosus. In dentistry the main problem we face is the hyposialia and its consequences like caries, mucosal dryness and fungal diseases. In addition , there are treatment alternatives such as local salivary stimulators, salivary substitutes, salivary vibrotactile stimulation and systemic drugs such as pilocarpine and cevilemine. Today, more treatment lines are being investigated, including tumor antineocrosis factors and monoclonal antibodies.

Conclusions: There is a lack of studies, that's why the treatments are based on professional observations. The treatment is based on improving the quality of patients life. At the moment there is no therapy with long-term demonstration.

\section{- Poster 75}

\section{TITLE:- ARTERIAL HYPERTENSION AND ORAL SURGERY. BIBLIOGRAPHIC RESEARCH}

\section{Tapia Canelas A, Félix López P, González Benavente E, Sevilla Hernández M, Garcia Casal J, Del Canto Pingarrón M. \\ Master's degree in Oral Surgery, Implantology and Periodon- tics. University of Leon. Spain.}

Arterial hypertension is a disease that affects a big amount of people all over the world. It is not given any importance to this desease because it produces no symptomatology, until a more serious cardiovascular disease appears, like heart attacks, mindvascular accidents, etc.

Objectives: A systematized bibliographic research will be made with the aim of getting to know the measures we must take for the surgery treatments, to prevent or to be able to control complications come from arterial hypertension.

Material and Methods: Bibliographic research in different data bases, in Spanish and English: Pubmed, Medline, Liliac of Cochrane. Key words: "hypertension" "cirugía bucal" " presión arterial" " high- bloodpressure" "oral surgery". From the 15 articles found, 13 bibliographic researches have been chosen, published in the last 5 years. All of them studied humans.

Discussion: Getting to know arterial hypertension is crucial for the odontologist due to the enormous quantity of patients suffering this patology. The patient gets engulfed in a huge stress, and it would be necessary to prevent and solve posible complications through ansiolitic 
pre-medication and by using the correct local anaesthetics.

Conclusions: We have observed an increasing of the tension levels in the people who get oral surgery. Because of that, a previous planification would be needed before the surgery act with the aim of reducing possible complications, especially with people who had high levels before.

\section{- Poster 76}

TITLE:- TECHNIQUES FOR IMPROVING THE POLYME-THYLMETHACRYLATE OF DENTAL PROSTHESIS USING NANOPARTICLES

Ureña Castro F, Riballo Herrera S, Botellé del Hierro R, España López, Moreno Muñoz J, Jiménez, Guerra A. Master of Implant Dentistry. Faculty of Dentistry. University of Seville.

Objectives: With the increase in the geriatric population, Oral Implantology acquires a fundamental role in terms of providing techniques and procedures that deliver the highest quality of life and health to this population. The integral improvement of PMMA (polymethylmethacrylate) by nanoparticles offers innumerable advantages to facilitate the maintenance of oral health of patients with resinous-based dentures.

Material and Methods: A bibliographic search was made in the PubMed database and EBSCO Academic Search Complete, from 2005 to 2019.

Results: The incorporation of nanoparticles like $\mathrm{TiO} 2$ or $\mathrm{Ag} \mathrm{TiO} 2$ to PMMA, proved to increase the resistance to deterioration over time, decreases its porosity, also offers antimicrobial properties and reduces the adhesion of Cándida Albicans.

Conclusions: The implementation of nanoparticles for the improvement of PMMA, offers a better quality over time to the treatment with acrylic prostheses to elderly patients with dental absence.

\section{- Poster 77}

\section{TITLE:- FIBROUS DYSPLASIA}

Velasco Moliz JA, Alonso Rubido P, Vila Barros S, de Elio Oliveros J, Alobera Gracia MA, del Canto Pingarrón M.

Master's Degree in Oral Surgery, Implantology and Periodontics from de University of León.

Abstract: Fibrous dysplasia (FD) is a rare bone disease caused by postzygotic mutations in the GNAS gene, which causes the replacement of normal bone by fibrous tissue and abnormal bone: monostotic (an affected bone), polyostotic (several bones) or in the context of the Sd. of McCune-Albright (in combination with hyperfunctional endocrinopathies and hyperpigmented skin lesions). The most frequent location is the craniofacial, causing facial deformity, bone pain and dental anomalies. The treatment has a multidisciplinary approach (doctor-surgeon-dentist). Objectives: To evaluate the main characteristics, diagnosis and treatment of the FD through a systematic review. Material and Methods: The PubMed.org database has been used; the key words used in the search were [maxillary fibrous dysplasia]. All the clinical cases that spoke of FD in which there was a histopathological confirmation were accepted. We also excluded all those epidemiological articles, since the objective of this bibliographic review was the main characteristics of the FD, its diagnosis and its treatment.

Results: Given that MacDonald-Jankowski carried out a systematic bibliographic review about FD in 2009, the search focused on any related article after the date, also accepting said revision.

Conclusions: The patient affected by FD must be treated by a multidisciplinary group. The first clinical manifestations can be carried out by the dentist, so the knowledge of this disease and above all a correct diagnosis is basic. It is also imperative to know the endocrinopathies that accompany the disease when correctly planning the treatment plan (growth hormone).

\section{- Poster 78}

\section{TITLE:- NEW ORAL ANTICOAGULANTS. STA- TE OF THE ART AND PROTOCOLS FOR USE IN ORAL SURGERY AND IMPLANTOLOGY}

Vidal Silván D, Arranz Fernández MC, Fernández Díaz P, Jacobo Orea C, del Canto M, Alobera Gracia MA. Master's Degree in Oral Surgery, Implantology and Periodontics from the University of León.

Objectives: To describe the characteristics of the new oral anticoagulants and review their suspension and replacement protocols in oral surgery and implantology.

Material and Methods: Classic bibliographic review by searching the PubMed Medline and The Cochrane Library databases, searching for articles published in the last 10 years in English and Spanish. The keywords "direct oral anticoagulants", "novel anticoagulants", "oral surgery", "dentistry" and the operator "AND" have been used. 39 references since 2012 have been retrieved.

Results: In recent years, these drugs have been introduced among the patterns of prevention and treatment of 
thromboembolic events for their safety and efficacy.

With regard interventions in oral surgery, the associated hemorrhagic events can be managed in most cases without suspension of the drug, applying local hemostatic measures. It will be suspended in more complex surgeries, patients with low creatinine clearance or with concomitant hemorrhagic pathology, between 24 and 48 hours before the intervention, based on the average life of these, and resuming when a stable clot has formed, usually 4 to 6 hours after the intervention, always having an interconsultation with the specialist.

Conclusions: The assessment of thromboembolic and hemorrhagic risk must be essential for the suspension of the anticoagulant drugNew oral anticoagulants have been proven to be safe and effective drugs, without presenting as many bleeding complications as previous generations.

\section{- Poster 79}

\section{TITLE:- CHANGES IN BONE TISSUE THAT OC- CUR IN AGING AND ITS INFLUENCE ON IM- PLANT PLACEMENT}

De la Rosa García A, Izquierdo Orts R, Cascos Sánchez R, Baca González L, San Hipólito Marín L, Cáceres Madroño E.

Master in Oral Surgery and Implantology, Department of Dental Clinical Specialties, Complutense University of Madrid.

Bone tissue is dynamic, in constant formation and resorption, maintaining its structural integrity. Ideally, this process is balanced, however, if unbalanced, it will produce pathology in any of its forms, excessive formation or osteopetrosis; or excessive resorption, producing osteoporosis or osteopenia. In addition, aging involves a series of changes within the bone tissue that we must consider in treatments involving dental implants.

Objectives: to describe the changes that occur in the bone with physiological and pathological aging and its importance in the placement of dental implants.

Material and Methods: An electronic search on PubMed, Medline and EMBASE databases was performed, with the following keywords: "changes in bone" AND "aging"; "Dental implants" AND "osteoporosis"; "Bone tissue".

Results: Of all the changes produced in the bone due to aging, the increase in bone destruction or osteoporosis is the most frequent bone disease.

Conclusions: Osteoporosis is the most frequent disease and implant placement in these patients does not show a significant risk compared to patients with healthy bone.

\section{- Poster 80}

TITLE:- COMPREHENSIVE GERODONTOLOGY CARE. STUDY ON THE MOST FREQUENT REASONS FOR CONSULTATION OF THE ELDERLY IN THE DENTAL CLINIC

\author{
Medina Cebrián B, Jover Cerveró A, Sáez Prado B, \\ Haya Fernández $M^{a} C$, Cabo Pastor $M$. \\ Universidad Cardenal Herrera CEU de Valencia.
}

The global demographic trends are showing a significant rise of the elderly population. This evidence presents a great challenge to our society both at social and health level.

Objectives: Perform a study about the most frequent reasons for consultation of the elderly people at the University Clinic. Find the percentage of patients who had toxic habits and allergies. To analyze if there is a positive relationship between the presence of systemic diseases and the medication consumed. Determine what was the treatment received by this group of patients.

Material and Methods: Computerized and manual review of all the clinical histories of the elderly patients that attended the University clinic between the months of September and December of 2018. The registered variables were: gender, age, toxic habits, allergies, pathologies, medication, reason for consultation and treatment. Results: The sample size was 150 patients. The most common reason for consultation was the prosthesis $54 \%$, followed by the caries $47,3 \%$ and periodontal pathologies $32 \%$.

Conclusions: The most common reason for consultation was the prosthesis, followed by the caries and periodontal pathologies. The female gender was more frequent. The average age was 71,2 years old. One third of the patients presented toxic habits and most of them suffered a systemic disease. The most frequent treatment was the prosthesis. 